\title{
APPLICATION OF THE PRECAUTIONARY PRINCIPLE DURING CONSENTING PROCESSES IN NEW ZEALAND: ADDRESSING PAST ERRORS, OBTAINING A NORMATIVE FIX AND DEVELOPING A STRUCTURED AND OPERATIONALISED APPROACH
}

BY

\author{
DALE PETER SCOTT \\ SUPERVISOR: CATHERINE IORNS
}

\begin{abstract}
A thesis
submitted to the Victoria University of Wellington

in fulfilment of the requirements for the degree of

Master of Laws
\end{abstract}

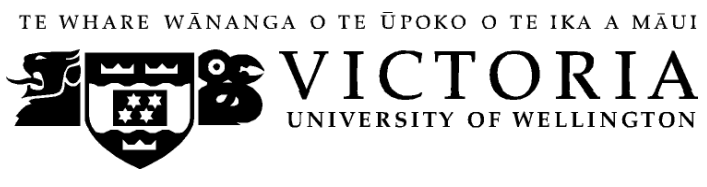

2016 


\section{Abstract}

The precautionary principle is increasingly being adopted as a legal risk management tool in international environmental law and regulation, especially in the marine context. In fact, over the last 35 years it has been included, often as a central feature, in the vast majority of international law instruments relating to protection and management of the environment. This rise to prominence is largely driven by widespread recognition that the ability of environmental law to successfully avert long term and significant harm is very much contingent on the successful implementation and application of the precautionary principle (specifically, the decision-making and planning measures it advocates).

Owing to the above, it is unsurprising that like many other countries New Zealand has incorporated the precautionary principle expressly and implicitly into domestic law and policy over the last 25 years. The most recent and arguably most notable instance of the incorporation of the precautionary principle in New Zealand law is in the Exclusive Economic Zone and Continental Shelf (Environmental Effects) Act 2012 ("EEZ Act"). Indeed, for reasons explained in this paper, the success of the EEZ Act will in large part depend on the successful application of the precautionary principle contained in the Act.

Unfortunately, New Zealand's incorporation and application of the precautionary principle to date has been problematic, with confusion and a variety of approaches taken to its core concepts, and arguably outright misapplication of it. For this reason, this paper seeks to take comprehensive stock of the precautionary principle, first to identify what is the likely cause of such confusion and misapplication, and second, to provide a foundational understanding to assist policy makers and the courts with the task of operationalising and applying it during legislative consenting processes. In doing so, this paper focuses on its operation in the marine setting, with a view to assisting with its interpretation and application under the EEZ Act. It argues that in order to secure consistent and proper application of the precautionary principle, significant work needs to be done to clarify definitional ambiguities embedded within the principle. It then argues that further work needs to be done to properly operationalise the New Zealand formulations of the 
precautionary principle (i.e. unpack the substantive content of the principle and pin down what such content requires of decision-makers in practice) so they can be consistently and correctly applied under New Zealand's environmental risk management regimes. 


\section{Table of Contents}

Abstract....... 2

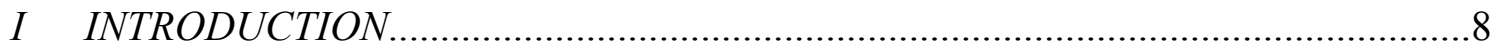

A The precautionary principle .......................................................................... 9

B Significant new role for precaution in New Zealand environmental regulation.11

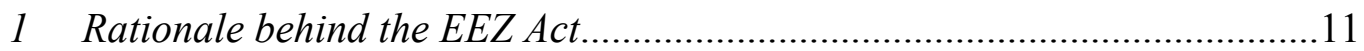

2 The central role of the precautionary principle.......................................13

C Fundamental lack of guidance on how to apply the precautionary principle.... 15

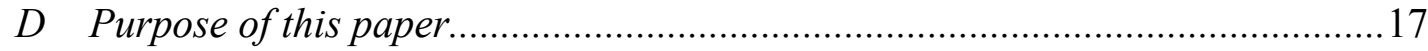

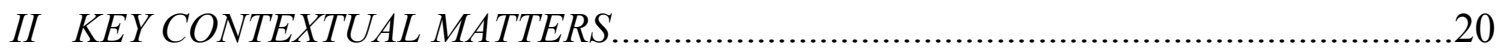

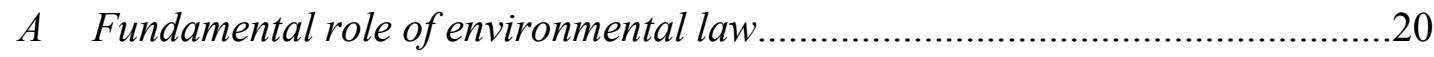

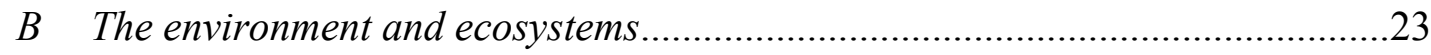

$1 \quad$ Ecosystems: Their life sustaining capacity...........................................27

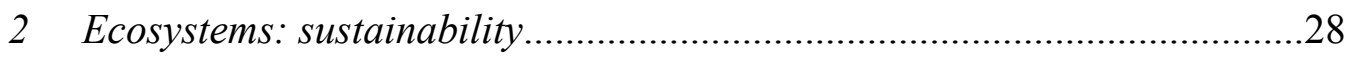

3 The relationship between science and environmental law.........................30

III THE TRADITIONAL APPROACH: PREDECESSOR TO PRECAUTION...............34

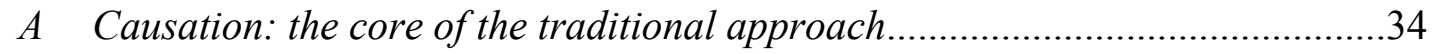

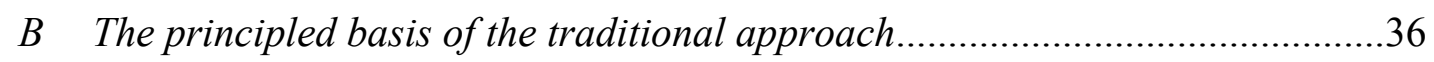

C The hallmarks of the traditional approach....................................................41

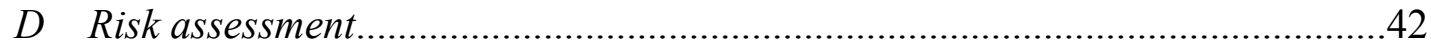

$1 \quad$ Purpose and function of risk assessment ............................................42

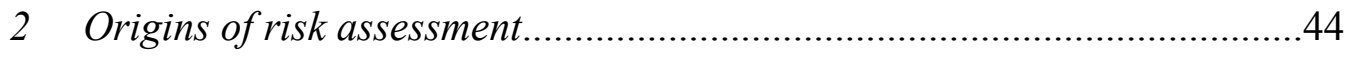


A The seminal realisation.................................................................................47

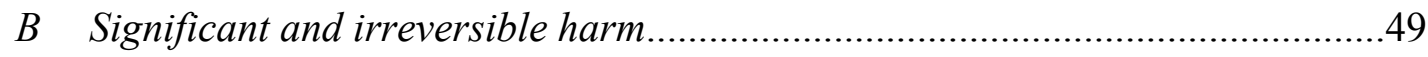

1 Gravity of anthropogenic harm ..............................................................50

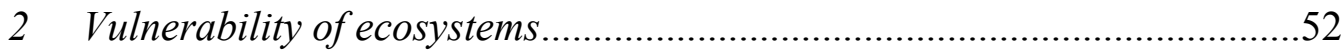

$3 \quad$ Susceptibility to non-linear changes..........................................................59

C Scientific uncertainty and limited ability to predict ecological impacts.............61

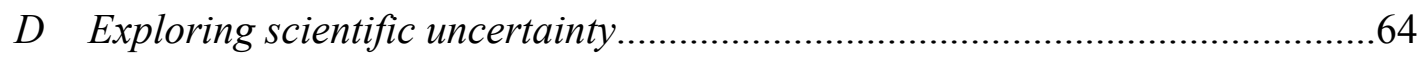

1 The scientific process, its limitations, inherent uncertainty, and lack of suitability to environmental decision-making.............................................65

2 Implications of statistical uncertainty .......................................................67

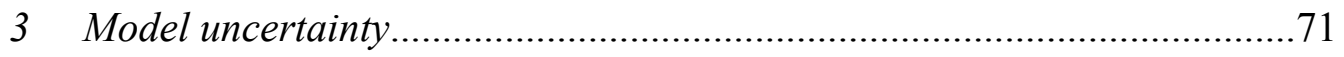

4 Ecological complexity as a source of uncertainty ………………...............73

$5 \quad$ Practical implications of scientific uncertainty ...........................................78

$V \quad$ INTRODUCING THE PRECAUTIONARY PRINCIPLE ………............................

A Introducing the precautionary principle.............................................................81

1 Common purpose and conceptual core......................................................82

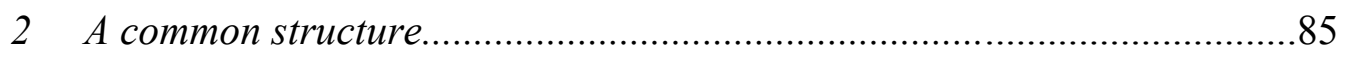

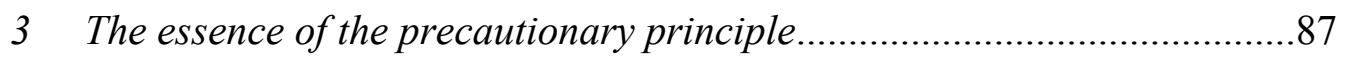

B Going beyond the conceptual core................................................................... 89

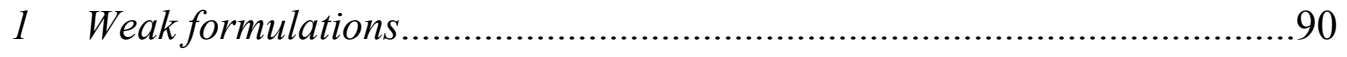

2 Strong formulations.............................................................................. 91

C German origins of the precautionary principle ................................................92

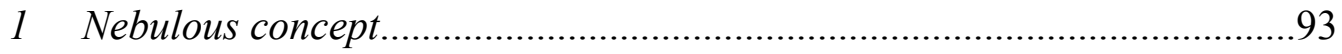


2 Beyond the duty to avoid harm..............................................................94

D The precautionary principle in international law ........................................98

$1 \quad$ Widespread adoption of the precautionary principle ..................................103

2 Status of the precautionary principle in international law........................ 109

E Relationship with other environmental norms ............................................. 113

$1 \quad$ Sustainable development .................................................................... 114

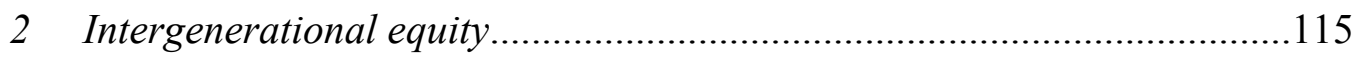

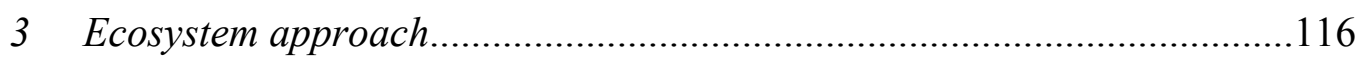

VI IMPLEMENTING THE PRECAUTIONARY PRINCIPLE ...................................120

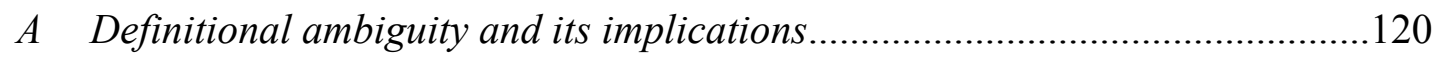

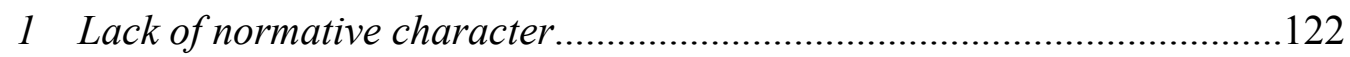

2 Relevance to New Zealand environmental law.....................................124

3 Legislative recognition of the link with sustainable development.............132

$4 \quad$ New Zealand's use of the precautionary principle ..................................133

B Initial steps towards an operational definition .......................................... 138

C Operationalising the harm dimension.......................................................139

1 Gravity of harm: imposing a harm threshold........................................140

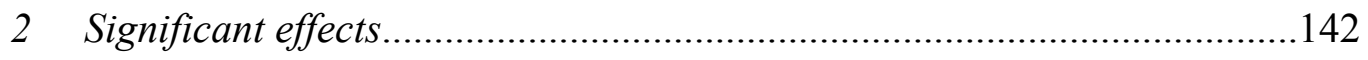

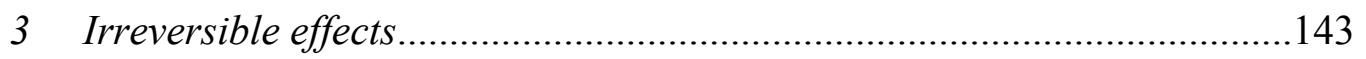

4 Objective criteria for decision-makers................................................145

D Operationalising the certainty dimension................................................... 146

$1 \quad$ General operation of the certainty threshold ..........................................146

2 Deriving an alternative threshold ..................................................... 149

3 Deriving an alternative New Zealand threshold....................................152 


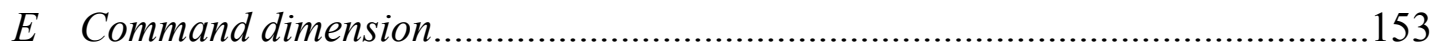

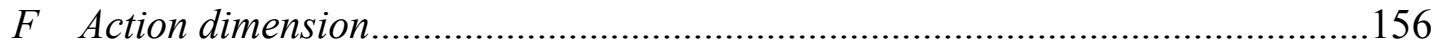

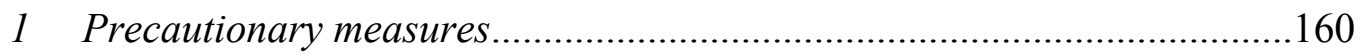

2 Effectiveness as a general consideration..............................................161

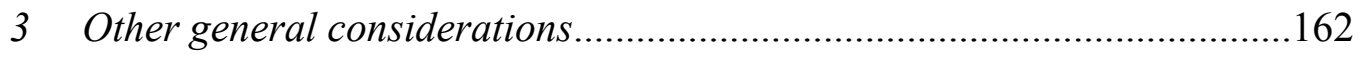

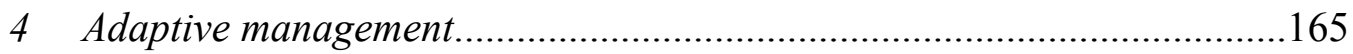

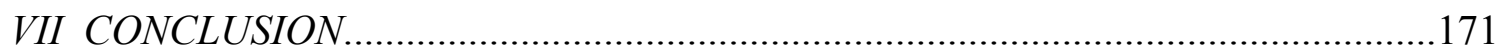

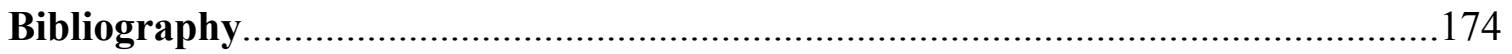




\section{Introduction}

"Few things are certain in life - except, of course, death and taxes. If certainty were a requirement for action, we would never do anything. How well we do in life depends in large measure on how successfully we cope with uncertainties" Benjamin Franklin ${ }^{1}$

That care and foresight are required in the face of an uncertain future is an abiding and universal notion: " "[w]e check our driving mirrors before overtaking; we use condoms to avoid HIV infections; we fasten seatbelts to avoid injury in [motor] accidents". 3 This practice, better known as erring on the side of caution, ${ }^{4}$ is represented in numerous maxims such as; "an ounce of prevention is worth a pound of cure", "a stich in time saves nine", and "better be safe than sorry". ${ }^{5}$ Common to each of these exemplars is the combination of a threat, and uncertainty (i.e. as to the nature of the threat and likelihood of it materialising) which, if present, operate as conditions that trigger a need to exercise caution when conducting an activity. ${ }^{6}$ As Trouwborst notes:

Although the degree of likelihood of the feared danger materialising in the absence of preventative measures varies with each instance, this materialisation remains

\footnotetext{
${ }^{1}$ Daniel Bodansky “The Precautionary Principle in US Environmental Law” in T O'Riordan, and J Cameron (eds) Interpreting the Precautionary Principle (Cameron May, London, 1994) 203 at 203.

2 James Cameron and Juli Abouchar "The Status of the Precautionary Principle in International Law" in David Freestone and Ellen Hey (eds) The Precautionary Principle and International Law: The Challenge of Implementation (Kluwer International, Hague, 1996) 29 at 29. David Vanderzwaag "The Precautionary Principle and Marine Environmental Protection: Slippery Shores, Rough Seas, and Rising Normative Tides" (2002) 33 Ocean Development \& International Law 165 at 166. Arie Trouwborst Evolution and Status of the Precautionary Principle in International Law (Kluwer Law International, The Hague, 2002) at 7. Tim O'Riordan "The Politics of the Precautionary Principle" in Ronnie Harding and Elizabeth Fisher Perspectives on the Precautionary Principle (The Federation Press, Sydney, 1999) 283 at 283.

${ }^{3}$ Earl RC "Common-Sense and the Precautionary Principle: an Environmentalist's Perspective" (1992) 24 MPB182 at 182.

${ }^{4}$ Bodansky, above $\mathrm{n}$ 1, at 203.

${ }^{5}$ David VanderZwaag "The Precautionary Principle in Environmental Law and Policy: Elusive Rhetoric and First Embraces” (1999) 8 JELP 355 at 358. David Vanderzwaag, above n 2, at 167. Arie Trouwborst, above n 2, at 7 .

${ }^{6}$ Arie Trouwborst, above $\mathrm{n} 2$, at 7.
} 
uncertain in all three [examples] - there may or may not be a car passing at the moment of an overtaking manoeuvre, a bed partner may or may not carry the HIVvirus, and an accident may or may not occur. Still in all these cases precautionary measures are widely considered appropriate.

\section{A The precautionary principle}

Over the last 35 plus years, this common-sense notion has crystallised into a legal principle, and arguably a legal norm, known as the precautionary principle. ${ }^{7}$ In the most general sense, it operates as a legal risk management tool initially developed at international law primarily in the marine context. ${ }^{8}$

The core definition of the precautionary principle reflects it common sense origins. In particular it provides: ${ }^{9}$ where there is a threat of environmental harm, in order adequately to protect the environment, decision-makers must take protective measures in advance of the establishment of scientific certainty as to, or, indeed, proof of causation between, the relevant activity and the potential environmental harm. ${ }^{10}$

The precautionary principle has been incorporated into "an overwhelming majority" of modern international instruments and domestic law legislative regimes relating to the

\footnotetext{
${ }^{7}$ Gary E Marchant "From General Policy to Legal Rule: Aspirations and Limitations of the Precautionary Principle" (2003) 111(14) Environmental Health Perspectives 1799 at 1799. See also James Cameron and Juli Abouchar, above n 2; Arie Trouwborst, above n 2.

${ }^{8}$ Ronnie Harding and Elizabeth Fisher "Introducing the Precautionary Principle" in Ronnie Harding and Elizabeth Fisher, above n 2, at 2; and David Vanderzwaag, above n 2, at 165-188, as cited in Catherine J Iorns Magallanes "The Precautionary Principle in the New Zealand Fisheries Act: Challenges in the New Zealand Court of Appeal" (paper presented to Australasian Law Teachers Association, Melbourne, July 2006) at 7, available at http://papers.ssrn.com/sol3/papers.cfm?abstract_id=2079837.

${ }^{9}$ Philippe Sands Principles of International Environmental Law (2nd ed, Cambridge University Press, New York, 2003) at 268-279; Arie Trouwborst, above n 2, at 245. David Freestone and Ellen Hey "Origins and Development of the Precautionary Principle" in David Freestone and Ellen Hey (eds), above n 2, at 13. John S Applegate "The Taming of the Precautionary Principle” (2002) 27 Wm \& Mary Envtl L \& Pol'y Rev 13 at 14 .

${ }^{10}$ David Freestone and Ellen Hey, above n 9, at 13. Arie Trouwborst, above n 2, at 245.
} 
environment since its introduction. ${ }^{11}$ In doing so, it has become a fundamental norm of international environmental law - so much so it is now widely believe that it occupies a central place in any realistic strategy for sustainable development and in ensuring that the environment is adequately protected from the effects of human activities. ${ }^{12}$

New Zealand has been a vocal advocate for the precautionary principle's inclusion as a central, if not fundamental feature, in a multitude of pivotal international law instruments. In doing so, New Zealand has played a significant and active role in facilitating the principle attaining its prominent status at international law. ${ }^{13}$ For this reason, it is unsurprising that, to date, New Zealand's legislature has elected to import the precautionary principle into domestic law by either expressly or implicitly incorporating versions of it into several pieces of environmental legislation. ${ }^{14}$ Furthermore, the Executive has also incorporated the precautionary principle into certain legally binding tertiary instruments and domestic environmental policy documents, which inform the exercise of statutory decision-making powers under domestic environmental legislation. ${ }^{15}$

\footnotetext{
${ }^{11}$ Alan Boyle and David Freestone, International Law and Sustainable Development: Past Achievements and Future Challenges (Oxford University Press, Oxford, 1999) at 138. Simon Marr The Precautionary Principle in the Law of the Sea: Modern Decision Making in International Law (Martinus Nijhoff Publishers, New York, 2003) at 13.

${ }^{12}$ David Freestone "International Fisheries Law Since Rio: The Continued Rise of the Precautionary Principle" in Alan Boyle and David Freestone (eds) International Law and Sustainable Development: Past Achievements and Future Challenges (Oxford University Press, Oxford, 2001) 134 at 134.

${ }^{13}$ Iorns, above $\mathrm{n} 8$. See also Linda Cameron "Environmental Risk Management in New Zealand - Is There Scope to Apply A More Generic Framework?” (New Zealand Treasury Policy Perspectives Paper 06/06, July 2006) at 15.

${ }^{14}$ See Chapter VI which discusses its incorporation into domestic law.

${ }^{15}$ Iorns, above n 8. Alexander Gillespie "Precautionary New Zealand" (2011) 24 NZULR 3 364. Greg Severinsen "Letting our Standards Slip? Precaution and the Standard of Proof under the Resource Management Act 1991" (2014) 18 NZJEL 173. Joan Forret "Scientific Evidence and Environmental Litigation in New Zealand" (1998) 2 NZJEL 39 at 51; McIntyre v Christchurch City Council [1996] 2 ELRNZ 84 at 99. Derek Nolan "The Legal Standards of Proof to be Applied to Coastal Projects and Predictions of Coastal Behaviour, and the role of the Precautionary Principle" in Pacific Coasts and Ports '97: Proceedings of the 13th Australasian Coastal and Ocean Engineering Conference and the 6th Australasian Port and Harbour Conference; Volume 1. Christchurch, NZ: Centre for Advanced Engineering, University of Canterbury, 1997
} 


\section{B Significant new role for precaution in New Zealand environmental regulation}

The most recent and arguably most notable instance of the New Zealand legislature incorporating the precautionary principle into domestic legislation is the Exclusive Economic Zone and Continental Shelf (Environmental Effects) Act 2012 ("EEZ Act"). This Act came into force on 28 June 2013. In doing so, it put in place New Zealand's first legislative framework for regulating and managing the environmental effects of certain activities conducted in New Zealand's exclusive economic zone ("EEZ") and continental shelf areas. ${ }^{16}$ Putting into perspective the monumental size of the EEZ Act's environmental management responsibilities, the geographical area that the Act presides over (e.g. is responsible for protecting and ensuring is used or managed in a sustainable fashion), is 20 times the size of New Zealand's land area. Specifically, it includes 400 million hectares of exclusive economic zone marine space and 170 million hectares of extended continental shelf area, which spans from the subtropics to the Sub-Antarctic.

\section{Rationale behind the EEZ Act}

The primary reason behind Parliament's move to regulate use of this marine space was the expected rise in opportunities (brought about by advances in technology), for people to undertake a variety of novel industrial activities such as "seabed mining, petroleum activities, energy generation, carbon capture and storage, and marine farming". ${ }^{17}$ Specifically, the prospect of having to field an increasing number of applications to perform such complex, technological and often large-scale activities, turned the Government's mind to the absence of a coordinated statutory process for assessing and managing the associated environmental effects, to ensure they do not "cause environmental harm, affect

\footnotetext{
${ }^{16}$ Ministry for the Environment "Managing our Oceans: A Discussion Document on the Regulations Proposed under the Exclusive Economic Zone and Continental Shelf (Environmental Effects) Bill" (May 2012) ME 1090 at vii and ix; Cabinet Paper "Proposal for Exclusive Economic Zone Environmental Effects Legislation" (May 2011) Cab 07-C-0751http://www.mfe.govt.nz/more/cabinet-papers-and-related-materialsearch/cabinet-papers/proposal-exclusive-economic-zone; Donald Anton and Rakhyun Kim "The Application of the Precautionary and Adaptive Management Approaches in the Seabed Mining Context: Trans-Tasman Resources Ltd Marine Consent Decision under New Zealand's Exclusive Economic Zone and Continental Shelf (Environmental Effects) Act 2012" (2015) 30(1) IJRL 175 at 175.

${ }^{17}$ Ministry for the Environment above n 16, at vii and ix. Cabinet Paper 2011 above n 16 at 2.
} 
marine life, habitats and biodiversity". ${ }^{18}$ As such, Parliament enacted the EEZ Act to plug certain regulatory gaps, which: ${ }^{19}$

...were acknowledged to include the lack of comprehensive and consistent environmental assessment for: activities affecting seafloor habitats and biodiversity; effects associated with new and existing offshore installations and structures; managing cumulative effects of such activities; and activities/proposals which extend across both territorial waters and the EEZ

Drawing heavily on the Resource Management Act 1991, the EEZ Act seeks to create an analogous but distinct framework for managing the EEZ space. In doing so, it classifies activities as either permitted, discretionary or prohibited, ${ }^{20}$ and a marine consent is required before one can perform discretionary activities.

As will be discussed in Chapters II and VI, the purpose of the EEZ Act is to promote sustainable management, and through doing so, "[c]ontinue or enable the implementation of New Zealand's obligations under various international conventions relating to the marine environment". ${ }^{21}$ In addressing the purpose section of the Act (then Bill) the then Minister for the Environment Amy Adams noted: ${ }^{22}$

The proposed purpose clause will use the concept of sustainable management and include the same environmental foundation as the purpose of the RMA...Because the proposed wording is similar to the purpose of the RMA, it should benefit from more than 20 years of the RMA case law that clarifies the meaning and implementation of sustainable management.

As will be demonstrated below, reliance on the 20 years of case law, so far as it relates to application of the precautionary principle, is arguably problematic and likely to result in a

\footnotetext{
${ }_{18}$ Ministry for the Environment above n 16. Chris Simmons "The RMA at Sea?" (2012) NZLJ 385 at 385.

${ }^{19}$ Simmons, above $\mathrm{n} 18$, at 385; (8 August 2012) 683 NZPD 4779.

${ }^{20}$ EEZ Act, ss 20 and 35-37.

${ }^{21}$ Sections 10 and 11 .

22 (8 August 2012) 683 NZPD 4779, at 4780.
} 
flawed approach to applying the principle being carried over to the EEZ Act.

\section{The central role of the precautionary principle}

The EEZ Act likely represents Parliament's most incisive effort to embed the precautionary principle into environmental decision-making. ${ }^{23}$ As is discussed later, this is demonstrated through:

(1) the inclusion of the precautionary principle twice in the operative decision-making provisions of the Act; first at s 31 , where it is to be applied when considering whether to permit, make discretionary or prohibit an activity; and second, at s 61 where it is to be applied by decision-makers when considering whether to grant a marine consent;

(2) the fact that the formulations of the precautionary principle found in ss 31 and 61 likely represent the strongest versions of the precautionary principle, in terms of environmental protection, which Parliament has incorporated into New Zealand legislation to date; and

(3) the fact that compared to other environmental legislation, the EEZ Act treats proper application of the precautionary principle as being especially vital to whether or not the Act's decision-making process is capable of producing decisions that will achieve sustainable management objectives in the Act's purpose. ${ }^{24}$

As Chapters IV and V will explain, because "uncertainty" and "harm" come together in considerable abundance when conducting industrial activities in the marine space, the strong emphasis that the EEZ Act places on the precautionary principle is warranted and is in line with common practice at international law.

\footnotetext{
${ }^{23}$ See discussion of the EEZ Act's incorporation of the precautionary principle in Chapter VI.

${ }^{24}$ See s 10 of the EEZ Act which, in the most explicit terms found in legislation to date, expressly states: "[i]n order to achieve the purpose, decision-makers must - apply the information principles" (that is, the Act's version of the precautionary principle), "...to the development of regulations and the consideration of applications for marine consent. Also refer to further discussion on this point at Chapter VI.
} 
In addressing such inherent uncertainty, Cabined noted in its "Proposal for Exclusive Economic Zone environmental effects legislation" that: ${ }^{25}$

[t]he EEZ is an environment about which relatively little is known, and the decision-making framework for the legislation needs to acknowledge those uncertainties. The Fisheries Act deals with this issue by using information principles to guide decision-makers.

Regarding harm in this context, the EEZ Act swiftly followed the Gulf of Mexico Deepwater Horizon and Rena disasters. These incidents put in sharp relief the potential magnitude of harm, which activities the EEZ Act seeks to regulate can render on receiving ecosystems. The above therefore likely explains:

(1) Parliament's indication in s 10(3)(b) of the $\mathrm{Act}^{26}$ that the Act's success or failure hinges on the successful operation of the precautionary principle; and

(2) the decision to incorporate into the EEZ Act what the latter chapters will demonstrate is the strongest precautionary principle formulation, and which also is arguably the first to possess true normative character.

Based on the above, when managing potentially invasive activities in the marine space under the EEZ Act, proper application of the precautionary principle is arguably more critical to achieving the requisite environmental protection goals of the EEZ Act, than is the case under terrestrial environmental management regimes. ${ }^{27}$

\footnotetext{
${ }^{25}$ Cabinet Paper, above n 16, at 5.

${ }^{26}$ Specifically, ss $10(3)$ (b) provides that "in order to achieve the purpose [of the Act], decision makers must...apply the information principles to the development of regulations and the consideration of applications for marine consent".

${ }^{27}$ Marguerite Quin "The Fisheries Act 1996: Context, Purpose, and Principles" (1999) 8 AULR 503. Also see Chapter II discussion on the unique nature of the marine space.
} 


\section{Fundamental lack of guidance on how to apply the precautionary principle}

With the above in mind, it is worth emphasising that policy makers modelled the EEZ Act on the RMA. Furthermore, as will be discussed in chapter IV, the drafting of its formulation of precautionary principle in ss 31 and 61 is based on the equivalent provisions in the Fisheries Act. Thus, in the course of determining how to apply the principle under the EEZ Act, decision-makers and the courts will inevitably resort to the body of case law regarding the precautionary principle's application under such pre-existing legislation for guidance. ${ }^{28}$ The majority of such case law relates to the precautionary principle's application under the Resource Management Act 1991. However, the courts have also considered its application on numerous occasions under the Fisheries Act 1996 and the Hazardous Substances and New Organisms Act 1996. Furthermore, since its recent enactment decision-makers have applied the precautionary principle under the EEZ Act when considering marine consent applications. ${ }^{29}$

In spite of its considerable exposure to judicial scrutiny, the precautionary principle, and in particular how it ought to operate in practice, appears to have remained an elusive concept for New Zealand's Courts, and decision-makers of first instance alike. As Severinsen notes: ${ }^{30}$

...the courts have been prepared to read in precaution in a variety of ways in the consenting context. This has been done largely on a case-by-case basis, and has resulted in a range of inconsistent judicial approaches. (emphasis added)

Rive echoes the above sentiment. In discussing the circumstances in which the precautionary principle might appropriately be applied he observes the matter is far from settled "with different divisions of the Environment Court adopting various views as to the

\footnotetext{
${ }^{28}$ See discussion in Chapter VI, which discusses how two of the first decision under the EEZ Act (in particular the Trans-Tasman Resources Ltd Marine Consent Decision, and Chatham Rock Phosphate Limited Decision) have taken this approach.

${ }^{29}$ Gillespie, above n 15 .

${ }^{30}$ Severinsen above $\mathrm{n} 15$, at 173 . This view is supported by Cameron, above $\mathrm{n} 13$, at 15 .
} 
relevance of the precautionary principle". ${ }^{31}$ In addition to such confusion, Iorns identifies what is likely outright misapplication of the precautionary principle, by arguing that in applying the precautionary principle under the Fisheries Act 1996, "precaution is effectively being used contrary to its intended purpose". ${ }^{32}$

As explained above, the success of the EEZ Act will in large part turn on the successful application of the ss 31 and 61 versions of the precautionary principle. As such, the apparent inability to consistently and correctly apply the precautionary principle in the various consent decisions and case law that will likely guide its application under the EEZ Act going forward is alarming. As chapter VI of this paper discusses, even more alarming is the fact that this inconsistent and incorrect application is arguably the product of a flawed approach to incorporating the principle into New Zealand law. In particular, chapter VI asserts that the root cause of this flawed approach is a failure to recognise and confront the fact that the international law versions of the precautionary principle that New Zealand's formulations are modelled on are:

(1) intentionally vague high-level definitions, which house various unresolved legal issues that the negotiating states could not agree on; and

(2) do not represent or capture the full substantive legal content of the precautionary principle, but rather represent short-hand summaries of what the precautionary principle entails.

As such, like their international equivalents, New Zealand formulations are "situated at a meta-level", and for this reason, "require explication and operationalisation" in order to be suitable for application by decision-makers and the courts as a legal decision-making tool. ${ }^{33}$ In examining this, Chapter VI explains how New Zealand has not "operationalised" the precautionary principle. As a result, decision-makers and courts appear to have never taken

\footnotetext{
${ }^{31}$ Vernon Rive "Environmental Assessment" in Derek Nolan (ed) Environmental and Resource Management Law ( $4^{\text {th }}$ ed, Lexis Nexis, Wellington, 2011) chapter 18 at 1186-1188.

${ }^{32}$ Iorns, above $\mathrm{n} 8$, at 5 .

${ }^{33}$ See discussion in Chapter VI and footnote 392.
} 
pause to consider what the full substantive content of the precautionary principle entails and in turn how this content shapes how the principle should be applied.

\section{$D \quad$ Purpose of this paper}

In order to demonstrate how New Zealand decision-makers and courts have likely misunderstood and misapplied the precautionary principle, and in turn address this and the subsequent problems that this gives rise to, this paper seeks to take comprehensive stock of the precautionary principle. Specifically, it does so with a view to building a foundational understanding of the precautionary principle, which is capable of assisting policy makers and the courts with the task of operationalising the precautionary principle in New Zealand.

While this exercise is of importance to the precautionary principles application under all of the legislative regimes that it features in, due to its significance under the EEZ Act, this paper will focus this exercise on its operation in the marine setting. Given the likelihood that New Zealand decision-makers and courts are not properly acquainted with what the precautionary principle entails, in "taking stock" this paper goes back to first principles, and from this foundational level, seeks to build a practical understanding of the concept with those who must apply it in practice as the audience in mind.

On the above basis, Chapter II starts by examining the core contextual elements that assist one with attaining the level of understanding required for the proper application of the precautionary principle when exercising administrative decision-making power. Given that confusion over the precautionary principle often arises from a failure to distinguish it from the predecessor "traditional approach" that it replaces, Chapter III conducts an indepth analysis of this predecessor approach. Specifically, this exercise is useful because it:

(1) provides context that is essential to properly appreciating the mischief the precautionary principle seeks to address; 
(2) operates as a useful litmus test for ascertaining when decision-makers or the courts have, despite their best efforts to apply the precautionary principle, reverted back to a traditional approach; and

(3) informs the task of operationalizing the precautionary principle.

Chapter IV subsequently considers in detail the various scientific insights which: (a) led to the realisation that the traditional legal approach to environmental regulation is unable to adequately protect the environmental and prevent harm; and (b) provided the impetus for the emergence and adoption of the precautionary principle. This chapter does this on the basis that:

(1) such a detailed working knowledge of these issues helps with understanding the specific task given to the precautionary principle, something that decision-makers surely need to be cognisant of when wielding the principle as a tool for overcoming such issues; and

(2) due to the lack of certainty as to the precautionary principle's normative content and parameters, and the absence of proper guidance as to how it ought to be operationalised, a detailed appreciation of the mischief that underpins the principle's existence arguably serves as a useful compass that can guide decision-makers.

In response to the failure to go beyond the meta-level definitions of the precautionary principle when applying it in New Zealand, Chapter V discusses the emergence and development of the precautionary principle in depth in order to:

(1) identify its conceptual core, common purpose, structure, and key components on the basis that these are matters decision-makers must have a settled understanding of in order to properly apply the precautionary principle and do so in a consistent manner;

(2) identify the fact that the precautionary principle is a much broader concept than what is currently understood, and in fact entails a "territory" of substantive meaning;

(3) elucidate what the substantive content found within the "territory" of substantive meaning identified at (2) above includes; and 
(4) demonstrate that there are multiple formulations of the precautionary principle that vary in terms of the strength of environmental protection they afford.

Finally, in drawing upon the above analysis, chapter VI explains in detail the fundamental issues associated with the way in which various versions of the precautionary principle are incorporated into New Zealand legislation, and how this has likely given rise to the application difficulties experienced to date. Finally, in response to such difficulties, drawing on the preceding analysis, this chapter attempts to elucidate the broader legal content of the New Zealand precautionary principle formulations and identify issues that will need to be resolved in the course of operationalising them. 


\section{Key Contextual Matters}

There are three core contextual elements that greatly assist one with attaining the level of informed understanding required to apply the precautionary principle properly in the course of exercising administrative decision-making power. These include:

(1) the fundamental role of environmental law;

(2) what the environment and ecosystems are and what they entail; and

(3) the relationship between science and environmental law.

Logic dictates that awareness of these three elements leads to a better appreciation of the precautionary principle's proper place within the wider environmental law landscape. On this basis, consideration of these matters is an essential prerequisite to understanding how the precautionary principle should operate in practice.

\section{A Fundamental role of environmental law}

It has long been acknowledged that the human activities we conduct often carry a risk of having adverse impacts on the ecosystems that make up the receiving environment. Environmental law emerged in response to this acknowledgement and thus is aimed at addressing and managing adverse anthropogenic impacts. ${ }^{34}$

At its most basic, environmental law is a "body of law concerned with protecting the environment and human health from the risks arising from [human] industrial activity". ${ }^{35}$ Palmer's summary below aptly captures the essence of environmental law: ${ }^{36}$

...the purposes and objectives of legislation and the subject-matter of litigation

\footnotetext{
${ }^{34}$ Hon Justice Cooke "The Concept of Environmental Law - The New Zealand Law - An Overview” [1975] NZLJ 631. Hanling Wang, "Ecosystem Management and its Application to Large Marine Ecosystems: Science, Law, and Politics” (2004) 35 Ocean Dev \& Int'l L 41 at 43.

${ }^{35}$ Elizabeth Fisher "Is the Precautionary Principle Justiciable?" (2001) 13(3) Journal of Environmental Law 315 at 317.

${ }^{36}$ Kenneth Palmer "Introduction to Environmental Law" in Derek Nolan, above n 31, at 8.
} 
generally classified as "environmental" have as their central focus the interaction of human societies, individuals within those societies, with both the physical (abiotic) and organic (biotic) surroundings. Environmental law...[concerns] the use, management and protection of the physical and biological elements of the biosphere and the effects of human interactions within and between these physical and biological elements.

Throughout its crystallisation into a distinct legal discipline, environmental law has become states' primary means of safeguarding the environment from deleterious manmade impacts. Such protection remains the integral purpose of environmental law.

At a national level, the environmental law framework comprises national policies and strategies, legislation, and administrative structures, which seek to coordinate and regulate human activities with a view to achieving internationally agreed fundamental norms, such as sustainable development, intergenerational equity and "integrated resource practice" (otherwise known as the ecosystem approach). ${ }^{37}$ In general terms sustainable development means "development which meets the needs of the present without compromising the ability of future generations to meet their own needs". ${ }^{38}$ In line with international practice, New Zealand environmental legislation has adopted the overarching goal of "sustainable management", which embraces the above core essence of sustainable development, as the overarching goal it seeks to achieve. ${ }^{39}$

The recently enacted EEZ Act is illustrative of the above. Parliament enacted this Act to "set up a legislative framework to regulate and manage the environmental effects of activities in the EEZ and on the continental shelf, which were not previously managed". 40

\footnotetext{
${ }^{37}$ At 8 .

${ }^{38}$ World Commission on Environment and Development Our Common Future: From One Earth to One World (The Bruntland Report) 1987.

${ }^{39}$ Klaus Bosselmann "The Concept of Sustainable Development" in Klaus Bosselmann, David Grinlinton and Prue Taylor (eds) Environmental Law for a Sustainable Society (2 ${ }^{\text {nd }}$ ed, NZCEL, Auckland, 2002) at 95. ${ }^{40}$ Rakhyun Kim \& Donald Anton "The Application of the Precautionary and Adaptive Management Approaches in the Seabed Mining Context: Trans-Tasman Resources Ltd Marine Consent Decision under New Zealand's Exclusive Economic Zone and Continental Shelf (Environmental Effects) Act 2012" (2015) 30 IJRL 175 at 176.
} 
In terms of the EEZ Act's objectives, section 10 provides (emphasis added): ${ }^{41}$

(1) The purpose of this Act is to promote the sustainable management of the natural resources of the exclusive economic zone and the continental shelf.

(2) In this Act, sustainable management means managing the use, development, and protection of natural resources in a way, or at a rate, that enables people to provide for their economic well-being while-

(a) sustaining the potential of natural resources (excluding minerals) to meet the reasonably foreseeable needs of future generations; and

(b) safeguarding the life-supporting capacity of the environment; and

(c) avoiding, remedying, or mitigating any adverse effects of activities on the environment.

(3) In order to achieve the purpose, decision-makers must-

(a) take into account decision-making criteria specified in relation to particular decisions; and

(b) apply the information principles to the development of regulations and the consideration of applications for marine consent.

Although subject to slight variances, this purpose is modelled on the Resource Management Act 1991 section 5 purpose, which provides (emphasis added):

(1) The purpose of this Act is to promote the sustainable management of natural and physical resources.

(2) In this Act, sustainable management means managing the use, development, and protection of natural and physical resources in a way, or at a rate, which enables people and communities to provide for their social, economic, and cultural well-being and for their health and safety while-

(a) sustaining the potential of natural and physical resources (excluding minerals) to meet the reasonably foreseeable needs of future generations; and

\footnotetext{
${ }^{41}$ Exclusive Economic Zone and Continental Shelf (Environmental Effects) Act 2012 (hereafter referred to as the "EEZ Act"), s 10.
} 
(b) safeguarding the life-supporting capacity of air, water, soil, and ecosystems; and

(c) avoiding, remedying, or mitigating any adverse effects of activities on the environment.

Each of the above Acts lead with an overriding purpose of promoting sustainable management flanked by a series of sub-purposes that are either a natural corollary of, or prerequisite to, achieving sustainable management. ${ }^{42}$ For example: the principle of intergenerational equity is reflected in s 10(2)(a) of the EEZ Act and 5(2)(a) of the RMA; the ecosystem approach is reflected in s 10(2)(b) of the EEZ Act and s 5(2)(b) of the RMA, and the precautionary principle is reflected in s 10(3)(b) of the EEZ Act.

\title{
B The environment and ecosystems
}

Understanding the parameters of environmental law logically flows from the definition of "environment" and "ecosystems". While the term "environment" does not enjoy a generally accepted legal definition or usage as a term of art, the following definition is representative of most (emphasis added): ${ }^{43}$

\begin{abstract}
"Environment" means "...the circumstance, objects, or conditions by which one is surrounded...the complex of physical, chemical, and biotic factors (such as climate, soil and living things) that act upon an organism or an ecological community and ultimately determine its form and survival...the aggregate of social and cultural conditions that influence life of an individual or community"
\end{abstract}

The term 'environment' is also typically defined in relevant international agreements. In spite of this however, it is readily accepted that as a legal term, 'environment' includes all life forms, habitats, areas of the earth, ecosystems and organisms, as well as all land, marine and atmospheric resources. ${ }^{44}$

\footnotetext{
${ }^{42}$ Bosselmann, above n 39, at 107. Palmer above n 36, at 14-15 and 26-30.

${ }^{43}$ Alexandre Kiss and Dinah Shelton International Environmental Law ( $3^{\text {rd }}$ ed, Transnational Publishers, New York, 2004) at 2. Philippe Sands, above n 9, at 16.

${ }^{44}$ Bruce Pardy Environmental Law: A Guide to Concepts (Butterworths, Toronto, 1996) at 99.
} 
New Zealand environmental legislative regimes however, often provide a definition of 'environment'. For example, section 4 of the EEZ Act provides (emphasis added):

environment means the natural environment, including ecosystems and their constituent parts and all natural resources, of-

(a) New Zealand:

(b) the exclusive economic zone:

(c) the continental shelf:

(d) the waters beyond the exclusive economic zone and above and beyond the continental shelf

Similarly, section 2 of the RMA provides (emphasis added):

environment includes-

(a) ecosystems and their constituent parts, including people and communities; and

(b) all natural and physical resources; and

(c) amenity values; and

(d) the social, economic, aesthetic, and cultural conditions which affect the matters stated in paragraphs (a) to (c) or which are affected by those matters

Based on the different articulations of the term 'environment' found in common literature and innumerable legal instruments, it is clear that this term is intended to cover the totality of the different forms of life within a particular delimited region.

The term 'ecosystem' often appears in the various legal definitions of 'environment'. In a non-legal sense, scientists, policy and lawmakers alike often treat ecosystems as being synonymous with environment. Legal instruments however, often do not treat the term 'ecosystem' as being synonymous with 'environment'. Rather, the ecosystem concept regularly appears at the core of the definition of environment. For example, the EEZ Act and RMA definitions of 'environment' both record 'ecosystems' (and their constituent parts) as a central element to the overall concept. 
International and domestic legal instruments typically do not fully define the term 'Ecosystem'. While, the term 'ecosystem' is sometimes loosely identified within the definition of environment, ${ }^{45}$ its full substantive definition typically lies beyond that included in legislation and other legal instruments. The Oxford dictionary for example, defines ecosystem as: "a unit of ecology... which includes the plants and animals occurring together plus that part of their environment over which they have influence". 46 Although articulated in a multitude of ways, the basic connotations around 'ecosystems' remain unchanged. ${ }^{47}$ Multiple institutions and commentators have agreed that the key features of ecosystems can be summarised in the following five points: ${ }^{48}$

(1) An ecosystem exists in a space with boundaries that may or may not be explicitly delineated. Ecosystems are distinguishable from each other based on their biophysical attributes and their locations. (2) An ecosystem includes both living organisms and their abiotic environment, including pools of organic and inorganic materials. (3) The organisms interact with each other, and interact with the physical environment through fluxes of energy, organic and inorganic materials amongst the pools. These fluxes are mediated and functionally controlled by species' behaviour and environmental forces. (4) An ecosystem is dynamic. Its structure and function change with time. (5) An ecosystem exhibits emergent properties that are characteristic of its type and that are invariant within the domain of existence.

\footnotetext{
${ }^{45}$ Specifically the "environment" definitions in both the EEZ Act and RMA refer to "ecosystems and their constituent parts" although the RMA does further elaborate on the definition by subsequently noting ecosystems also "[include] people and communities".

${ }^{46}$ Sands, above n 9, at 15. Pardy, above n 44, at 87 (footnotes omitted). R Schlaepfer Ecosystem-Based Management of Natural Resources: A Step towards Sustainable Development (IUFRO, Occasional Paper No. 6, 1997) at [2.3]. Bruce Hatcher and Roger Bradbury Marine Ecosystem Management: Is the whole greater than the sum of the parts?" in Donald Rothwell and David VanderZwaag (eds) Towards Principled Oceans Governance: Australian and Canadian approaches and challenges (Routledge, New York, 2006) 205 at 206 to 209 .

${ }^{47}$ Hatcher and Bradbury above $\mathrm{n}$ 46, at 207.

${ }^{48}$ G Likens An Ecosystem Approach: Its Use and Abuse (Ecology Institute, Oldendorf, 1992) at 10; RV O'Neill and others A Hierarchical Concept of Ecosystems (Princeton University Press, New Jersey, 1986) at 68-69. Wang, above n 34, at 43. Pardy above n 44, at 87 (footnotes omitted).
} 
Maintenance of ecosystem health and integrity refers to an ecosystem that retains its structure, activity (also referred to as 'function'), and resilience over time; in other words, whether it is sustainable. ${ }^{49}$

As is discussed in chapter IV, the complex nature and function of the ecosystem is at the heart of the precautionary principle, and the bulk of issues faced when applying it. Thus, a basic appreciation of what ecosystems entail informs one's understanding of the precautionary principle and how it ought to be applied. As will become apparent, understanding the meaning and relevance of ecosystems is also integral to appreciating the proper place of the precautionary principle in environmental law. More importantly, as chapter IV demonstrates, the a priori assumptions underpinning the precautionary principle stem from the complex and interconnected nature of ecosystems captured in the definition set out below.

In order to provide context to later discussion regarding the precautionary principle's prominence in the marine setting, it is worth noting that two key attributes distinguish marine ecosystems from other categories of ecological organisation (e.g. such as terrestrial ecosystems): ${ }^{50}$

First marine ecosystems explicitly include the interactions among organisms and the viscous, energetic environment they inhabit (i.e. the processes at the biophysical interface). The fluid medium of the ocean connects marine populations, communities, habitats and pools of biochemical far more intimately that their terrestrial counterparts. Second, marine ecosystems implicitly exhibit some form of integrity reflected in emergent properties (i.e. the whole is greater than the sum of the parts...) and organisational or thermodynamic closure (i.e. internal transformations exceed trans boundary fluxes).

\footnotetext{
$\overline{49}$ Oceans and the Law of the Sea: Report of the Secretary General GA Res 69(a) A/61/63, (2006) at [135].

${ }^{50}$ J Steele "The Ocean Landscape" (1989) 3 Landscape Ecology 185 at 185 to 192. S Woodley, J Kay and G Francis (eds) Ecological Integrity and the Management of Ecosystems (University of Waterloo Press, Waterloo, 1993). Hatcher and Bradbury above n 46, at 207. Oceans and the Law of the Sea, above n 49, preamble.
} 
As chapter IV demonstrates, such interconnectivity and interdependency makes the marine space (relative to terrestrial ecosystems) considerably more vulnerable to the adverse effects of human activities. As Chapters IV and V demonstrate, it is these characteristics, which are responsible for the precautionary principle's particularly swift emergence in international law (especially in the ocean management setting).

\title{
1 Ecosystems: Their life sustaining capacity
}

Simply put, ecosystems are life-supporting systems. They are essential to the survival and welfare of human beings and all other life forms. ${ }^{51}$ In particular, "marine ecosystems, which cover more than 70 per cent of the globe and support an abundant and diverse web of life, are extremely valuable for the health and development of our planet". ${ }^{2}$ At international law it is almost universally accepted that "[e]cosystems should be managed for their intrinsic values and for the tangible or intangible benefits for humans...". 53 As Kiss notes: ${ }^{54}$

\begin{abstract}
Environmental law springs form the understanding that the environment determines the form and survival of each organism and community thus national, regional and international efforts must be taken to ensure the continued viability of the planet and the sustainability of its myriad of species...
\end{abstract}

In terms of anthropogenic benefits, humankind derives benefit from ecosystems by way of

\footnotetext{
${ }^{51}$ Alan Boyle and David Freestone "Introduction" and David Freestone "International Fisheries Law Since Rio: The Continued Rise of the precautionary Principle" in Alan Boyle and David Freestone (eds), above n 12, at 1. David Farrier "Factoring Biodiversity Conservation into Decision-Making Processes: The Role of the Precautionary Principle" and David James "Economic Concepts and the Precautionary Principle and Implementation of Safe Minimum Standards" in Ronnie Harding and Elizabeth Fisher Perspectives on the Precautionary Principle, above n 2, at 155. Klaus Bosselmann "Environmental Law for Sustainability" in Benjamin J Richardson and Stepan Wood (eds) Environmental Law for Sustainability (Hart Publishing, Oxford, 2006) 129 at 145 and 146.

${ }^{52}$ Oceans and the Law of the Sea: Report of the Secretary General, above n 49, at [115].

${ }^{53}$ Decision V/6 by the Conference of the Parties to the Convention on Biological Diversity at its fifth meeting (COP), Nairobi, 15-26 May 2000, UNEP/COP/5/23.

${ }^{54} \mathrm{Kiss}$ and Shelton above $\mathrm{n} 43$, at 2.
} 
their: ${ }^{55}$

(1) provision of life-sustaining and life-enhancing resources (for example, through the harvesting of living marine resources);

(2) provision of ecological processes which regulate and sustain biospheric processes (such as the ozone layer, climate systems, carbon cycle and water cycle) within the "relatively narrow range of parameters [required] to sustain life"; 56 and

(3) inputs into culture, aesthetics and spiritual practices.

Ecosystems are life-support systems for all organisms regardless of their worth to human society. ${ }^{57}$ Today it is generally recognised that all life-forms have intrinsic value and should be "recognised, protected and conserved simply because they exist". ${ }^{58}$ It is this very dedication to protecting all life forms on the basis of their mere existence, which signifies the necessity to protect ecosystems - they are a sine qua non for the sustainability of life.

\section{Ecosystems: sustainability}

In spite of the numerous international and domestic definitions, the Convention on Biological Diversity aptly captures the main thrust of sustainable use. It provides: ${ }^{59}$

\footnotetext{
${ }_{55}$ Boyle and Freestone, above n 12, at 1; Oceans and the Law of the Sea: Report of the Secretary General, above $\mathrm{n} 49$, at [135]; Rusong Wang and others "Understanding Eco-Complexity: Social-Economic-Natural Complex Ecosystem approach" (2011) 8 Ecological Complexity 15 at 17.

${ }^{56}$ Boyle and Freestone, above n 12, at 1.

${ }^{57}$ Rosie Cooney "From Promise to Practicalities: The Precautionary Principle in Biodiversity Conservation and Sustainable Use" in Rosie Cooney \& Barney Dickson Biodiversity and the Precautionary Principle: Risks and Uncertainty in Conservation and Sustainable Use (Earthscan, London. 2005) 3 at 3. Convention on Biological Diversity 1760 UNTS 79, 142 (opened for signature 5 June 1992, entered into force 29 December 1993), preamble. Decision V/6 by the Conference of the Parties to the Convention on Biological Diversity at its fifth meeting, above $\mathrm{n} 53$. Decision VII/11 of the Conference of the Parties to the Convention on Biological Diversity at its seventh meeting, Kuala Lumpur, 20 February 2004 UNEP/COP. Kenneth Palmer above $n$ 31, at 6 (references omitted).

${ }^{58}$ Decision V/6 by the Conference of the Parties to the Convention on Biological Diversity at its fifth meeting, above n 53. Decision VII/11 COP above n 57. Palmer, above n 36, at 6 (references omitted).

${ }^{59}$ Convention on Biological Diversity 1760 UNTS 79, 142 (opened for signature 5 June 1992, entered into force 29 December 1993), art 2.
} 
"Sustainable use" means the use of components of biological diversity in a way and at a rate that does not lead to the long-term decline of biological diversity, thereby maintaining its potential to meet the needs and aspirations of present and future generations.

Essentially, sustainability entails ensuring "the proper functioning of natural systems",60 and that "essential processes shall not be impaired", while contemporaneously facilitating efficient utilisation of ecosystems; "but not in such a way as to endanger the integrity of those other ecosystems or species with which they coexist". ${ }^{61}$ Thus, as a matter of logic, understanding the multitude of ecological linkages, interactions, and their implications (e.g. manner, gravity and extent to which human-induced harm communicates through an ecosystems), is an essential prerequisite to ascertaining whether an activity will compromise the "proper functioning", "essential processes" and overall integrity of a receiving ecosystem. In this regard, without such knowledge, decision-makers are:

(1) blind to an ecosystem's capacity to accommodate human demands (that is, whether a proposed activity will unduly compromise ecosystem structure or function); and

(2) in turn are unable to ascertain the conservation / use balance capable of achieving sustainable use. ${ }^{62}$

As will become apparent in Chapter IV and V, it is the virtual impossibility of fully appreciating and understanding the ecosystem functions and processes that are in play within a given receiving environment, is ultimately responsible for the emergence of the precautionary principle and its close ties with sustainable development (or in the case of New Zealand, 'sustainable management').

\footnotetext{
${ }^{60}$ World Charter for Nature 1982 General Assembly Resolution 37/7, Report of the United Nations Conference on Environment and Development, Rio de Janeiro, 3-14 June 1992 (United Nations publication, Sales No. E.93.I.8 and corrigenda) at [1].

${ }^{61}$ At [4]. Decision VII/11 COP above n 57, at [6(a)].

${ }^{62}$ Oceans and the Law of the Sea: Report of the Secretary General, above n 49, at [115].
} 


\section{The relationship between science and environmental law}

As noted earlier in this Chapter, environmental law exists to regulate human activities and respond to environmental problems they may generate, particularly those that threaten quality of life for human society. ${ }^{63}$

Fundamental to legal decision-making, the appropriate outcome that should be reached upon the application of the relevant legal principles turns on the facts of any particular case. In the environmental law setting, science is largely the means employed to identify and explain the relevant facts. As one author notes, environmental law "is perhaps uniquely dependant on science for the determination of the existence and scope of problems and appropriate... responses to them". ${ }^{64}$ As such, it goes without question that science is the only discipline capable of studying environmental issues. This is why science is referred to as "...the linchpin around which environmental law is organised". ${ }^{65}$ As von Moltke observes: ${ }^{66}$

Without science we know little or nothing about the threats to the environment which require our attention...Science makes the environment speak. Without science, trees have no standing...

...toxics go unknown, ecosystems degrade unrecognized and species are lost without our knowing. Scientists are deeply implicated in the process of environmental policy formation.

In particular, science is the only discipline with the means to identify, analyse, understand and predict:

\footnotetext{
${ }^{63}$ Dinah Shelton "The Impact of Scientific Uncertainty on Environmental Law and Policy in the United States" in David Freestone and Ellen Hey (eds), above n 9, at 210.

${ }^{64}$ At 210.

${ }^{65}$ Nicolas de Saadeleer "The Principles of Prevention and Precaution in International Law: Two Heads of the Same Coin?" in Malgosia Fitzmaurice, David Ong and Panos Mekouris (eds) Research Handbook on International Environmental Law (Edward Elgar, Cheltenham, 2010) at 185.

${ }^{66}$ Konrad Von Moltke "The Relationship Between Policy, Science, Technology, Economics and Law in the Implementation of the Precautionary Principle" in David Freestone and Ellen Hey (eds), above n 2, at 98.
} 
(1) ecosystem structures, processes and the plethora of complex and inextricable, but often unseen, connections between ecosystems; ${ }^{67}$ and

(2) the environmental impact of often technological human activities on an ecosystem's structures, processes, and interactions with other ecosystems.

As an illustration of this, Shelton's comment is noteworthy: ${ }^{68}$

New technologies and the consequences of them pose complex technical issues that require scientific "translations" for lay persons charged with fact finding or [decision-]making.

Further, de Saadler states that science is "...much more in evidence in environment law than in other branches of the law..." because: ${ }^{69}$

First, scientists detect, identify and set out the ecological problems to which the law must respond. Second, environmental crises are increasingly perceived through scientific descriptions of our physical world. Last but not least, science is often called upon to play a decisive role in judicial procedures.

Thus, environmental decision-makers rely on science for the basic information regarding:

(1) a "particular factual claim" that a harm or threat which is caused by or relates to a given human activity exists (for example, whether dust plumes generated by seafloor mining interfere with marine life) ${ }^{70}$ and

(2) what environmental measures that are capable of mitigating the alleged threat, exist and should be implemented.

\footnotetext{
${ }^{67}$ Daniel Bodansky, Jutta Brunnee and Ellen Hey "Mapping the Field" in Daniel Bodansky, Jutta Brunnee and Ellen Hey (eds) The Oxford Handbook of International Environmental Law (Oxford University Press, Oxford, 2007) at 7.

${ }^{68}$ Dinah Shelton, above $\mathrm{n} 63$.

${ }^{69}$ Nicolas de Saadeleer, above n 65, at 185-186.

${ }^{70}$ Dinah Shelton, above $\mathrm{n} 63$.
} 
As de Saadler goes on to note: ${ }^{71}$

Scientists thus play a decisive role in the conception and implementation of environmental law; all the regulations adopted in this field, without exception, are based on their calculations, computations or affirmations. In fact, no area of public policy is comparably dependent on science.

Scientists are deeply implicated in the processes of environmental [decisionmaking]. Without them it cannot occur. No other area of [decision-making], not even public health...is comparatively dependant on science. ${ }^{72}$

Environmental decision-makers are therefore uniquely dependent on science to furnish them with knowledge, and in particular the relevant facts, critical to making informed and effective decisions, be it at the policy level, or at operational level (e.g. when deciding whether to grant a consent, and if so what conditions ought to be imposed). In explaining the relationship between environmental law and science, Shelton notes: ${ }^{73}$

...law thus comes into contact with science when scientific experts present conclusions based on reasoning and analysis concerning the extent to which there are environmental problems and the appropriate means of remedying them...

Therefore, in light of the above we can say that unlike most other legal areas, environmental law necessarily rests on, is informed by, and depends on good science. In order to achieve its fundamental purpose of protecting human, animal and plant life by curbing the effects human activities can have on ecosystems, it must be directed by comprehensive and accurate scientific findings. This applies at a macro-level, where policies are transformed into legal principles, as well as at a micro-level, where, for example, an ecosystem is assessed in the context of a given resource consent. One could

\footnotetext{
${ }^{71}$ Nicolas de Saadeleer, above n 65, at 185.

${ }^{72}$ Konrad Von Moltke, above n 66, at 98.

${ }^{73}$ Dinah Shelton, above n 63.
} 
even go as far as saying there cannot be environmental law, in any meaningful and practical sense, without the effective and proper application of science. 


\section{The traditional approach: predecessor to precaution}

As Chapter IV will discuss in detail, the precautionary principle arose in response to the failure of its predecessor, typically referred to as the 'preventative principle' or 'traditional approach'. As outlined in the Chapter I, a detailed examination of the traditional approach forms an integral part of this papers' approach of going back to first principles in order to rebuild from scratch an understanding of where the precautionary principle comes from, what it is meant to achieve, and in turn how it operates. Specifically, examination of the traditional approach in detail is useful because:

(1) it is essential to appreciating the mischief the precautionary principle seeks to address and thus operates as a useful high level guide for decision-makers when applying the precautionary principle

(2) it operates as a useful litmus test for ascertaining when decision-makers or the courts have, despite the best of intentions to apply the precautionary principle, reverted back to a traditional approach; and

(3) as will become apparent in Chapter VI, the insights it provides help inform how one should go about operationalising the precautionary principle.

\section{A Causation: the core of the traditional approach}

Causation, which is an essential ingredient in law, entails proving a cause-and-effect relationship between a person's conduct and a resulting harm. ${ }^{74}$ As Iorns illustrates in tort, for example, a person is not liable for the loss or damage unless the plaintiff has proven a causal link between that person's actions and the loss the plaintiff suffered. It is a basic rule, therefore, that the law does not intervene and impose liability for harm, loss or damage until causation has been proved.

\footnotetext{
${ }_{74}$ Catherine J Iorns Magallanes, above n 8, at 5. James E Hickey and Vern R Walker "Refining the Precautionary Principle in International Environmental Law" (1995) 14 Va Envtl LJ 423 at 426-429. Philippe Sands, above n 9, at 268.
} 
Causation is also an established constituent of environmental law. In the consenting context for example, prior to the introduction of the precautionary principle opponents to a proposed activity carried the burden of presenting sufficient proof of causation between a proposed activity and an asserted environment effect, before a decision maker was able to take action to prevent such harm occurring (e.g. by restricting or refusing the activity). ${ }^{75}$ In this regard, as two lead authors note: ${ }^{76}$

The public has typically carried the burden of proving that a particular activity or substance is dangerous, while those undertaking potentially dangerous activities and the products of those activities are considered innocent until proven guilty. Chemicals, dangerous practices, and companies often seem to have more rights than citizens and the environment.

Under this traditional approach, the need to prove causation also restrained the ability of regulators' to validly exercise any discretionary powers that authorised them to restrict or prohibit human activities in order to protect the environment. The imposition of this burden stemed from the entrenched legal position that administrative decision-making is: ${ }^{77}$

...based on the precept that the only valid action is that based on facts. This concept has its source in the Rule of Law... The Rule of law dictates that governments are non-arbitrary and principled in their decision-making...[consequently]...unless

\footnotetext{
75 James Cameron and Will Wade-Gery Addressing Uncertainty: Law, Policy and the Development of the Precautionary Principle (CSERG, Working Paper GEC 92-43, 1992) at 18. Elizabeth Fisher "The Precautionary Principle as a Legal Standard for Public Decision-making: The Role of Judicial and Merits Review in Ensuring Reasoned Deliberation" in Ronnie Harding and Elizabeth Fisher, above n 2, at 90. Nicolas de Sadeleer, Environmental Principles: From Political Slogans to Legal Rules (Oxford University Press, Oxford, 2002) at 211-213. James E Hickey and Vern R Walker, above n 74, at 426. Charmian Barton "The Status of the Precautionary Principle in Australia: Its Emergence in Legislation and as a Common Law Doctrine" (1998) 22 Harv Envtl L Rev 509 at 510. Richard Hildreth, Casey Jarman and Margaret Langlas "Roles for a Precautionary Approach in Marine Management" (2005) 19 Ocean YB 33 at 34. Ronnie Harding and Elizabeth Fisher, above n 8, at 2-3. Arie Trouwborst Precautionary Rights and Duties of States (Martinus Nijhoff Publishers, Leiden, 2006) at 193.

${ }^{76}$ Joe Tickner and Carolyn Raffensperger The Precautionary Principle in Action: A Handbook $\left(1^{\text {st }}\right.$ ed, Science and Environmental Health Network, Massachusetts, 1999) at 1.

${ }^{77}$ Elizabeth Fisher, above n 75, at 90.
} 
there is a substratum of objective evidence for the reasons and policies acted upon, discretionary powers are liable to a charge of arbitrariness". These "principles of fundamental justice" are to be observed where government action entails potential interference with "life, liberty and security of the person".

The need to prove causation thus, led to " $[\mathrm{t}]$ he requirement that proof of harm must be shown before regulatory action occurs". As one author notes: ${ }^{78}$

\begin{abstract}
the main feature of this model...is that action to protect the environment is solely justified when conclusive evidence shows that an activity will cause (substantial) damage in the absence of preventative and abatement measure.
\end{abstract}

In sum, the rule of law mandates that regulatory intervention is legal if, and only if, a causative link can be demonstrated between an action that has environmental effects and the relevant environmental harm.

\title{
$B$ The principled basis of the traditional approach
}

Essentially the basis of the traditional approach is the view that in order to afford ecosystems and human interests in them sufficient protection, only predictable harm needs to be regulated. This flawed view rested on the following broad presumptions:

(1) science can accurately foretell and determine the nature, extent and likelihood of harm an activity may cause (namely, "threats"); and

(2) once this is determined, there is sufficient time to take preventative action before significant harm occurs. ${ }^{79}$

\footnotetext{
${ }_{78}$ Arie Trouwborst, above n 2, at 11. Geoffrey Palmer Environment: The International Challenge (Victoria University Press, Wellington, 1995) at 70. Dinah Shelton, above n 63, at 218.

${ }^{79}$ Ellen Hey "The Precautionary Concept in Environmental Policy and Law: Institutionalizing Caution" (1992) 4 Geo Int'1 Envtl L Rev 303. Charmian Barton, above n 75, at 510 to 511. Arie Trouwborst, above $n$ 2, at 11. Geoffrey Palmer, above n 78, at 70. Owen McIntyre and Thomas Mosedale "The Precautionary Principle as a Norm of Customary International Law" (1997) 9 JEL 221 at 221. Stephen Dovers and John Handmer "Ignorance, Sustainability, and the Precautionary Principle: Towards an Analytical Framework" in Ronnie Harding and Elizabeth Fisher, above n 2, at 168. Michael M'Gonigle and others "Taking Uncertainty
} 
Most cite the above presumptions as being the principal rationale or basis underpinning the traditional approach. However, as this chapter will demonstrate, these presumptions are in fact the product of a more detailed suite of assumptions, which taken together, represent a more comprehensive and accurate explanation of the logic behind this approach. As this chapter will also demonstrate, the fundamentally flawed nature of these assumptions are what is responsible for: (a) the failure of the traditional approach; and (b) the subsequent emergence and adoption of the precautionary principle.

While not typically described as such, collectively, more specific flawed assumptions that underpin the traditional approach essentially comprise the mischief that the precautionary principle seeks to address. On this basis, this paper asserts that in order to appreciate the precautionary principle, both in principle, and at an operational level, one must first understand the specific reasons behind the failure of the traditional approach.

In terms of policy background, the traditional approach is based on a "permissive regulation" paradigm, whereby environmental laws operate from the starting point that an activity should permitted unless proven otherwise. ${ }^{80}$ Belief in the validity of this overarching approach to environmental management was itself is based on the theory known as "assimilative capacity" ${ }^{81}$ In short, assimilative capacity is a theory which provides that certain levels of "discharges into, or activities in, a receiving environment are permitted" on the basis of the central assumption "that the environment has an enduring capacity to assimilate" a prescribed level of such pollutants, or impacts from activities, without suffering any harm as a result. In other words, up to a "specified limit which purportedly reflects "safe" levels", the impact of such activities will not harm the receiving

Seriously: From Permissive Regulation to Preventative Design in Environmental Decision Making" (1994) 32(1) Osgoode Hall Law Journal 99 at 129.

${ }^{80}$ RC Earll "Common Sense and the Precautionary Principle - An Environmentalists Perspective" (1992) 24(4) Marine Pollution Bulletin 182.

${ }^{81}$ Note that for simplicity however, most literature provides that the traditional approach is based on assimilative capacity. Michael M'Gonigle and others, above n 79. Owen McIntyre and Thomas Mosedale, above n 79, at 221. Arie Trouwborst, above n 2, at 18. 
environment. ${ }^{82}$ In sum, assimilative capacity assumes science will, primarily through predictive modelling: $:^{83}$

(1) provide decision-makers with the information and means necessary to prevent humans from encroaching upon the carrying or assimilative capacity of ecosystems and environmental media; ${ }^{84}$ and

(2) allow regulators to permit activities (such as the release of substances) "...within and up to the limits of that capacity”.

As most institutions and academics agree, however, this is a paradigm in crisis. Specifically, as M'Gonigle et al note: ${ }^{85}$

...the problems associated with the paradigm are evident in the common but illconsidered and incorrect assumptions about how the environment assimilates waste, how scientific research is done, how reliable the results of such research are, and how regulatory agencies operate.

Assimilated capacity, and in turn the traditional approach to environmental regulations, is rooted in "strict observance of the scientific method", ${ }^{86}$ and is premised on the a priori assumptions, set out below which Chapter IV will demonstrate, are unequivocally flawed. ${ }^{87}$

\footnotetext{
${ }^{82}$ K Stairs and P Taylor "Non-Governmental Organisation and the Legal Protection of Oceans: A Case Study" in A Hurrell and B Kingsbury (eds) The International Politics of Environment (Clarendon Press, Oxford, 1992) at 132. JF Whitehouse "Will the Precautionary Principle Environmental Decision Making and Impact-Assessment" in Ronnie Harding and Elizabeth Fisher, above n 2, at 59. Owen McIntyre and Thomas Mosedale, above n 79, at 222; Charmain Barton, above n 75, at 512.

${ }^{83}$ Arie Trouwborst, above $\mathrm{n} 2$, at 18 .

${ }^{84}$ Ellen Hey, above n 79, at 307 and 308. Owen McIntyre and Thomas Mosedale, above n 79, at 229-133. Charmian Barton, above $\mathrm{n} 75$, at 511 .

${ }^{85}$ M'Gonigle and others, above $\mathrm{n} 79$, at 129.

${ }^{86}$ Laurence David Mee "Scientific Methods and the Precautionary Principle" in David Freestone and Ellen Hey (eds), above n 2, at 109.

${ }^{87}$ Ellen Hey, above n 79, at 307 and 308. Arie Trouwborst, above n 2, at 18. Owen McIntyre and Thomas Mosedale, above n 79, at 221. Charmian Barton, above n 75, at 510-511. Nicolas de Saadeleer, above n 65, at 184. M'Gonigle and others, above n 79, at 129-130.
} 
(a) Assumption that ecosystems readily assimilate human impacts

As indicated above, the core assumption underpinning the traditional approach is the view that each ecosystem possesses an enduring but finite capacity to accommodate a certain level of a given kind of human impact, without that impact giving rise to significant or long-term adverse effects on the receiving ecosystem. Commentators typically refer to such tolerance to human impacts as an ecosystem's 'carrying' or 'assimilative' capacity, which, as noted above, determines the allowable limits on human interference. Its proponents also assumed that if the assimilative capacity is overwhelmed, ecosystems could handle some measure of harm. ${ }^{88}$

\section{(b) Assumption of scientific knowledge}

The second-most important assumption behind the traditional approach is the assumption that carrying capacity "...can be quantified, apportioned for a certain activity, and utilised", 89 and that science is equipped with the tools and ability to achieve this. From a regulator's perspective: ${ }^{90}$

...underlying the assumption of assimilative capacity is a corresponding assumption that we are, in some way, basing our regulations and allowable limits on firm scientific knowledge.

Specifically, this is the assumption that science is capable of resolving any uncertainty as to the effects an activity will have on the environment, by accurately determining:

(1) the likely ecological impact of an activity (that is, the ecological threat it presents) ${ }^{91}$

\footnotetext{
$\overline{88}$ Raffensberger and Tickner "Introduction: to Foresee and Forestall" in Carolyn Raffensberger and Joel Tickner (eds) Protecting Public Health and the Environment: Implementing the Precautionary Principle (Island Press, Washington DC, 1999) at 2.

${ }^{89}$ V Pravdic "Environmental Capacity - Is a New Scientific Concept Acceptable as a Strategy to Combat Marine Pollution?” (1985) 16 Marine Pollution Bull 295 as cited in Charmian Barton, above n 75, at 511.

${ }^{90}$ M'Gonigle and others, above n 79, at 129. Charmian Barton, above n 75, at 511.

${ }^{91}$ Raffensberger and Tickner, above n 88, at 1-2. Ronnie Harding and Elizabeth Fisher, above n 8, at 3.
} 
(2) an ecosystem's carrying capacity for a given impact or confluence of impacts; $;^{92}$ and (3) the measures needed to prevent or mitigate it.

In this respect one author aptly notes that assimilative capacity is based on the belief that humans can fully understand the ecological impacts "of their activities and establish levels of insult at which the environment...[can] rebound from harm...". ${ }^{93}$

(c) Operational assumptions

Assimilative capacity is premised on operational assumption, which can be categorised as both technological and regulatory. It is assumed from a technological or science perspective that science is capable of providing the requisite technological solutions to mitigate those threats, once it has identified or predicted them.

\section{(d) Temporal assumption}

The temporal assumption essentially provides that, by the point in time at which science has identified $:^{94}$

(1) a given threat (that is, an instance where an ecosystem's carrying capacity will likely be overwhelmed by a given activity resulting in significant detrimental effects); and (2) the corresponding means of addressing such a threat,

there will be sufficient time to act (e.g. take steps to limit or prevent the harm generated by the offending activity), before an ecosystem's carrying capacity is overwhelmed and in turn given rise to significant and/or long-term detrimental effects.

\footnotetext{
${ }^{92}$ M'Gonigle and others, above $\mathrm{n} 79$, at 129.

${ }^{93}$ Raffensperger and Tickner, above $\mathrm{n} 88$, at 1 .

${ }^{94}$ Charmian Barton, above n 75, at 511. Malcolm MacGarvin "Precaution, Science and the Sins of Hubris" in T O'Riordan and J Cameron (eds), above $\mathrm{n} \mathrm{1,} \mathrm{at} 74$.
} 


\section{(e) Economic assumption}

It is subsequently assumed that, in light of the above, acting after science identifies an ecological harm and solution, rather than before, will ensure that financial resources are not wasted (i.e. expended on avoiding or mitigating human impacts that can in any case be assimilated), but rather are efficiently allocated. This is because, in such circumstances (for example, where human impacts are likely to be assimilated, or the harm identified prior to its occurring) "...it is difficult to justify high initial expenditures for uncertain future environmental gains". As Hey further notes: ${ }^{95}$

the assimilative capacity concept emphasises... reliance on short-term economic considerations, while emphasising the unreliability of long-term economic considerations and the uncertainties involved in determining the present value of future economic degradation.

\section{The hallmarks of the traditional approach}

In light of the above, once can say that the traditional approach is characterised by the following three concepts that stem from the requirement to prove causation:

(1) Until proven harmful a human activity may continue or proceed ${ }^{96}$ in other words, environmental action necessarily follows scientific proof. ${ }^{97}$

(2) The approach to be favoured is the one that is only concerned with preventing, and therefore only capable of implementing measures that prevent foreseeable and predictable harm. ${ }^{98}$

\footnotetext{
${ }^{95}$ Ellen Hey, above n 79, at 308. See also Charmian Barton, above n 75, at 511.

96 James Cameron and Will Wade-Gery, above n 75, at 18. Arie Trouwborst, above n 75, at 196.

${ }^{97}$ Nicolas de Sadeleer, above n 75, at 53.

${ }^{98}$ Arie Trouwborst, above n 2, at 18. Ronnie Harding and Elizabeth Fisher, above n 8, at 2
} 
(3) Because it relies on science to determine the existence, nature and scope of the harm caused by human activities, the approach must fundamentally be "science-based", and as such, factual inquiries into causation are also intrinsically questions of science. ${ }^{99}$

\section{Risk assessment}

Operating under the assumptions detailed above, environmental management frameworks have evolved into decision-making structures based around risk assessment tools such as environmental impact assessments ("EIAs"). ${ }^{100}$ These risk assessment tools have:

(1) become the principal method of resolving scientific uncertainties regarding the effects an activity may have on the receiving environment; ${ }^{101}$ and

(2) because of that, become embedded into environmental decision-making frameworks (such as legislative environmental frameworks), as the vehicles by which causation is established and, in turn, regulatory action is justified and legitimised legally. ${ }^{102}$

\section{Purpose and function of risk assessment}

Such risk assessment based frameworks seek to reduce the scientific uncertainty associated with a given decision (e.g. to allow or not allow an activity). In this regard, they attempt to bridge the gap between science and environmental law in a procedural manner that is transparent to (i.e. can be assessed by) all parties including the public in the case of notified consent applications. ${ }^{103}$ These processes respond to the need to ensure accountable

\footnotetext{
99 As one author notes; "the search for causes is the essence of science" L King Medical Thinking: $A$ Historical Preface (Princeton University Press, Princeton, 1982) at 191 as cited in Dinah Shelton, above n 63 , at 219.

${ }^{100}$ Ronnie Harding and Elizabeth Fisher, above n 8, at 2. Raffensberger and Tickner, above n 88, at 2. Charmian Barton, above n 75, at 511.

${ }^{101}$ Konrad Von Moltke, above n 66, at 99.

102 Joe Tickner and Carolyn Raffensperger, above n 76, at 13-14.

${ }^{103}$ Konrad Von Moltke, above n 66, at 100-101.
} 
administrative decision-making, and in doing so provide for independent review of decisions, which: ${ }^{104}$

...in turn creates a burdensome requirement to document each step of a decisionmaking process and to find a specific justification for each critical decision. Absent such documentation and justification, the expectation is that some interested party will be able to successfully challenge the outcome, either in a court of law [and/]or through a legislative process.

Depending on the particular decision-making framework involved, the EIA process can involve decision-makers, applicants and the public relying on science accurately to discharge the task of: ${ }^{105}$

(1) hazard identification, whereby experts seek to determine whether an activity may cause a given ecological harm (this is often referred to as "risk");

(2) risk characterisation, whereby experts also attempt to ascertain the magnitude and distribution of the ecological risk;

(3) identifying and comparing alternatives, whereby "costs, technical and administrative feasibility, and distributive consequences of alternative" strategies to control risk are evaluated;

(4) chosing an appropriate management strategy, whereby, based on the information obtained at assessments (1) to (3) above, an acceptable level of risk (generated by the activity) is identified, and the appropriate means of maintaining the level of risk below accepted levels is chosen; and

(5) (if part of the chosen management strategy) implementation, review and adjustment of control strategy, whereby implementation of the strategy is monitored to assess its effectiveness, and change is made if performance is not satisfactory.

\footnotetext{
${ }^{104}$ Konrad Von Moltke, above n 66, at 100.

${ }^{105}$ Gavan McDonell "Risk Management, Reality and the Precautionary Principle: Coping with Decisions" in Ronnie Harding and Elizabeth Fisher, above n 2, at 190. Konrad Von Moltke, above n 66, at 101.
} 
Each aspect of the EIA process depends entirely on that which science can accurately observe measure and quantify. ${ }^{106}$ The traditional approach thus places virtually all of the decision-making emphasis on the role of science in modelling and predicting harm.

It is important to note that, as such, assessments are premised on, and operate within, the assimilative capacity model, their primary focus is not on the prevention of harm. As Tickner and Raffensperger provide: ${ }^{107}$

Risk assessment is used to manage and reduce risks, not prevent them...It asks how much pollution is safe or acceptable; which problems are we willing to live with; how should limited resources be directed?

Again, the premise of this approach is the assumption that receiving ecosystems can tolerate certain levels of detrimental impact, and, as such, it is legitimate to allow such harm to occur.

\section{Origins of risk assessment}

As McDonell notes, understanding the origins of these tools aids one's appreciation of the shortcomings if the EIA and similar assessments that have become the mainstream form of risk assessment in the environmental context. Risk assessment was “...originally developed for mechanical problems such as bridge construction ...., ${ }^{108}$ or, as one author notes:

Risk assessment, as a scientifically disciplined way of analysing risk and safety problems was originally developed for relatively well-structured mechanical problems, such as chemical and nuclear plants, aircraft and aerospace technologies. In such systems, the technical processes and parameters are well defined, and the

\footnotetext{
${ }^{106}$ Konrad Von Moltke, above n 66, at 101.

${ }^{107}$ Joe Tickner and Carolyn Raffensperger, above n 76, at 13-14.

${ }^{108}$ Raffensberger and Tickner, above n 88, at 2. See also Gavan McDonell, above n 105, at 190-192.
} 
reliability of separate components is testable or amenable to actuarial in-service analysis. Indeed, so controlled are the parameters

The application of that which came to be known as 'scientific risk assessment' has been significantly expanded to fields as scientifically and technologically varied as epidemiology, biology and general environmental studies. ${ }^{109}$ Academics attribute this shift to the increased demand on science to model and predict harm in extremely complex ecological and human systems. ${ }^{110}$ Essentially, the belief that risk assessment methods (such as EIAs) were fit for purpose in environmental law appears to be, at the operational level, an extension of the belief in the pre-eminence of scientific knowledge, which itself underpins the assumption of assimilative capacity. As such, it was initially though such risk assessment approaches were capable of effectively predicting environmental outcomes. However, this paper asserts that in reality the substantial complexity of ecosystems makes this task too substantial, complex and onerous for risk assessment to handle.

${ }^{109}$ Gavan McDonell, above n 105, at 190-192.

${ }^{110}$ Joe Tickner and Carolyn Raffensperger, above n 76, at 13-14. 


\section{Failure of the traditional approach}

By the early 1980s it was clear that "there were substantial adverse impacts associated with unlimited [industrial] growth". ${ }^{111}$ In spite of widespread global efforts to implement traditional-approach-based environmental management regimes (i.e. via risk management frameworks that employ impact assessments as the primary means of assessing risk), ecosystems were increasingly subject to significant anthropological harm. ${ }^{112}$ Significantly, over time this harm continued to become progressively more pervasive, destructive and global in nature.

Due to the above realisation, it became apparent that environmental regulation efforts that employed the traditional approach lacked the ability to manage the impacts of increasingly technological human activities effectively, so much so they often failed to prevent many instances environmental harm ${ }^{113}$ and forestall ever-increasing instances of mass environmental degradation. ${ }^{114}$ In response to this failure, the scientific community began to call into question the assumptions underpinning the traditional approach, including, most prominently, the assumption of assimilative capacity. ${ }^{115}$ By the mid-1980s this culminated in a series of scientific insights, which:

(1) established that the assumptions underpinning the traditional approach are either fundamentally flawed or largely incorrect; and

(2) in turn, provided the impetus for the precautionary principle and its widespread adoption by states, as a replacement for the traditional approach.

In describing these scientific insights, Trouwborst provides the following useful

\footnotetext{
${ }^{111}$ Raffensberger and Tickner, above $\mathrm{n} 88$, at 2.

112 Ronnie Harding and Elizabeth Fisher, above n 8, at 2.

113 Ronnie Harding and Elizabeth Fisher, above n 8, at 2. Carolyn Raffensperger and Ted Schettler "Precaution: Belief, Regulatory System, and Overarching Principle" (2000) 6 Int J Occup Environ Health 266 at 266.

${ }^{114}$ Malcolm MacGarvin, above n 94, at 69; Ronnie Harding and Elizabeth Fisher, above n 8, at 2.

${ }^{115}$ Ronnie Harding and Elizabeth Fisher, above n 8, at 2. Carolyn Raffensperger and Ted Schettler, above $n$ 113 , at 266 .
} 
summary: ${ }^{116}$

...the rationale of the precautionary principle - or precautionary approach, as it is often referred to - is a dual one. That is to say, two scientific insights account for the adoption by States of the precautionary principle. Plainly stated, the first is the realisation that in many cases the environmental harm caused by human activities is graver than previously thought and can be difficult, if not impossible, to undo. Due to the vulnerability of the environment, anthropogenic impacts are often of a long-term and sometimes irreversible nature. The second insight making up the rationale of the precautionary principle concerns the uncertainty about, and limited predictability of, the gravity and probability of environmental impacts, which is due in a significant measure to the complexity and variability of natural systems and processes.

\section{A The seminal realisation}

These scientific insights grew into the realisation that contrary to what assimilative capacity asserts, by the time that clear scientific proof of a causal link between an activity and ecological harm is available to decision-makers (i.e. policy and consenting decisionmakers), it is often too late to remedy or reverse the adverse effects associated with the activity in question. ${ }^{117}$ As von Moltke further explains, this is because: ${ }^{118}$

...often [environmental] threats are the result of complex processes with origins not identifiable by the human senses, more often than not the result of science and technological change themselves. By the time these changes become palpable to the human senses significant sometimes irreversible changes have taken place. Keystone species disappear from an eco-system long after micro-organisms have suffered the effects of human interventions unseen...Persistent chemicals enter the food chain long before contamination causes visible changes in the behaviour of

\footnotetext{
${ }^{116}$ Arie Trouwborst "Prevention, Precaution, Logic and Law: The Relationship between the Precautionary Principle and the Preventative Principle in International Law and Associated Questions" (2009) 2 Erasmus Law Review 105 at 107.

${ }^{117}$ Arie Trouwborst, above n 75, at 195. Dinah Shelton, above n 63, at 226.

${ }^{118}$ Konrad Von Moltke, above n 66, at 97-98.,
} 
and reproductive performance of birds and mammals. Large-scale environmental change may escape direct human observation entirely. Stratospheric ozone depletion is not something that can be smelled, felt, heard or seen. Global warming is so difficult to prove conclusively because of its very complexity. Even acid rain is not an intuitively obvious phenomenon."

The same realisation happened at an operational level, in that the scientific insights also led to the realisation amongst states, and subsequently domestic regulators, that under a traditional approach, significant or irreversible ecological changes will have already taken place $^{119}$ by the time: ${ }^{120}$

(1) the anthropogenic ecological harm associated with a given activity becomes "palpable to the human senses";

(2) science is afforded sufficient opportunity to investigate, isolate and establish a causal relationship between the activity and subsequent ecological harm to the extent required by rigorous standards of proof; ${ }^{121}$ and

(3) proof of causation marshals policy and regulatory decision-makers to implement the requisite protective, preventative or mitigation measures needed to abate or curb the effects of the identified resulting harm.

This is because until a causal link is proven the offending activity is typically left to continue, absent any preventative or mitigating measures being put in place to prevent the resulting harm, thereby allowing otherwise avoidable ecological damage to occur. ${ }^{122}$

\footnotetext{
${ }^{119}$ Konrad Von Moltke, above n 66, at 97-98. Charmian Barton, above n 75, at 510-511. Sumudu Arapattu, Emerging Principles of International Law (Transnational Publishers, New York, 2006) at 206, Philippe Sands, above $\mathrm{n}$ 9, at 203-204.

${ }^{120}$ Dinah Shelton, above n 63, at 226. Arie Trouwborst, above n 75, at 195. Catherine J Iorns Magallanes, above $\mathrm{n} 8$, at 5 .

${ }^{121}$ As Tickner and Raffensperger note: "traditional research science attempts to gather nearly complete and perfectly supportive information before claiming a cause-and-effect relationship": Joe Tickner and Carolyn Raffensperger, above $\mathrm{n} 76$, at 5 .

${ }^{122}$ Arie Trouwborst, above n 75, at 195. Dinah Shelton, above n 63, at 226. David Freestone and Ellen Hey, above $\mathrm{n} 9$, at 12 .
} 
The above explanation is sufficient to acquaint one with a high level understanding as to why the traditional approach failed and subsequently the precautionary principle subsequently emerged (i.e. as an overlay to existing risk assessment regimes). However, this high-level summary fails to account for and explain the specific mechanics that sit behind its emergence. This paper asserts that there are two key reasons why a detailed working knowledge of such mechanics is critical to the application of the precautionary principle in New Zealand. First, it asserts that such detail is instructive to appreciating the specific task given to the precautionary principle. Therefore, this is something that decision-makers need to be cognisant of when wielding the principle as a tool for overcoming such issues (e.g. without a proper understanding of the uncertainty a decisionmaker faces, they will be unable to ascertain for example, whether such uncertainty can be overcome by adaptive management, or whether it is incurable).

Second, as is discussed in detail in Chapter VI, this paper also asserts that the following factors plague the application of the precautionary principle. First, a lack of certainty as to the principle's normative content and boundaries undermines its application. Second, a dearth of proper guidance as to how the precautionary principle should be operationalised (i.e. further elucidated to the extent necessary to equip decision-makers with the requisite guidance and normative character and certainty required to enable proper and consistent application in practice) also hinders this. As such, this paper asserts that a detailed examination of the specific mischiefs that gave rise to and underpin the precautionary principle, arguably serve as a useful compass for navigating the ambiguity that surrounds the principle, and in turn, will assist with resolving such issues.

\section{B Significant and irreversible harm}

The principal insight to arise at this time was the realisation that ecosystems are considerably more vulnerable than initially thought. In turn, the global community subsequently acknowledged that human-induced harm is: ${ }^{123}$

\footnotetext{
${ }^{123}$ Konrad Von Moltke, above n 66, at 97-98. Arie Trouwborst, above n 116, at 107. Timothy O'Riordan and James Cameron "The History and Contemporary Significance of the Precautionary Principle" in Timothy O'Riordan and James Cameron (eds), above n 1, at 12. Philippe Sands, above n 9, at 3. Ronnie Harding and
} 
(1) often much graver than previously thought;

(2) often difficult, if not impossible, to undo; and

(3) above all else, often long-term and sometimes irreversible in nature.

This overarching ecosystem vulnerability insight was the product of (i.e. premised on) a suite of realisations, which, although often glanced over by most academic discussion on the precautionary principle, are central to its rationale, and thus are particularly informative to understanding the mischief the principle seeks to address.

\section{Gravity of anthropogenic harm}

Such acknowledgements and insights led scientists to become aware of the true gravity and pervasiveness of damage that is actually inflicted on species and ecosystems because of human activities. Significantly, it became apparent that human society had acquired the capacity to alter the environment in unprecedented ways on an unprecedented scale, and that this capacity would likely continue to increase over time. ${ }^{124}$

In particular, science was now being used to establish that, over time; the ecological effects generated by increasingly large-scale technological industrial activities had and were continuing to become progressively more invasive, pervasive and severe in nature. ${ }^{125}$ In addition, rapid and exponential population growth, coupled with globalisation, had operated to increase the frequency and prevalence of those activities that generate such increased harms. As two leading commentators note: ${ }^{126}$

Elizabeth Fisher, above n 8, at 2. Alan Boyle and David Freestone (eds), above n 12, at 1. Durwood Zaelke, Donald Kaniaru and Eva Kruzikova (eds) Making Law Work: Environmental Compliance and Sustainable Development Volume 1 (Cameron May, London, 2005) at 32.

${ }^{124}$ Ted Schettler and Carolyn Raffensperger "Why is a Precautionary Approach Needed" in Marco Martuzzi and Joel Tickner (eds) The Precautionary Principle: Protecting Public Health, the Environment and the Future of our Children (World Health Organisation Europe, ISBN 928901098 3, 2004) at 63.

${ }^{125}$ Alan Boyle and David Freestone (eds), above n 12, at 1. International Encyclopaedia of Laws (reissue, 1998) Volume 1 Environmental Law at [International 10]. Philippe Sands, above n 9, at 3. Dinah Shelton, above $\mathrm{n} 63$, at 228 .

126 Ted Schettler and Carolyn Raffensperger, above n 124, at 63. 
...humans have increasingly dominated the earth's ecosystems in unprecedented ways...the scale of change has expanded rapidly and dramatically...population growth and human activities such as resource extraction, manufacturing, transport, agriculture and fishing have escalated these changes and contributed to serious, widespread and often avoidable harm to humans, wildlife, and ecosystems...

As author de Saadler further notes, such technological activities have created "postindustrial risks", that the traditional approach of environmental management now has to mitigate. Specifically: ${ }^{127}$

...the twentieth century has taken us fully into a risk civilisation. Scientific development gives rise to so many new risks...The globalisation of the economy and the rise of new technologies characteristic of post-industrialised society have caused a new generation of risks to emerge (CFCs, POPs, BSE, greenhouse gases, hormone-disrupting chemicals, electromagnetic fields etc).

It is important to note that this scientific realisation arose concurrently with the political-economic acknowledgement that attempts to repair ecosystems after harm has already occurred will typically be substantially more expensive than the cost of prevention in the first place. ${ }^{128}$

The above realisations countered the view under assimilative capacity that anthropogenic harm is usually readily assimilated and where it was not, the receiving ecosystems would accommodate the resulting harm without resulting in severe and permanent adverse outcomes.

${ }^{127}$ Nicolas de Sadeleer, above n 75 , at 150-153.

${ }^{128}$ Nicolas de Sadeleer, above n 75, at 16. Alexandre Kiss and Dinah Shelton, above n 43, at 204. 


\section{Vulnerability of ecosystems}

As discussed above, contrary to the traditional contention that ecosystems are robust entities with a substantial capacity to assimilate anthropogenic impacts (particularly the more severe technological industrial activities described above), science established that ecosystems are typically much more vulnerable than first anticipated. This section seeks to discuss this vulnerability in more depth.

Flowing from the scientific community's acknowledgement of how vulnerable ecosystems in fact are, it is now recognised that anthropogenic impacts often inflict harm more readily and more acutely than first thought. ${ }^{129}$ In fact, the more science uncovered the complexities of ecosystems, the more apparent it became that ecosystems are particularly sensitive to seemingly modest insults, ${ }^{130}$ and that such vulnerability likely stems from several key ecosystem characteristics.

The first characteristic is that ecosystem health and integrity overall is contingent on ecosystem structure and function ${ }^{131}$ remaining within the "narrow range of parameters" 132 required to secure the production of the essential ecosystem services which are critical to maintaining an ecosystem's ability to sustain life. ${ }^{133}$ As Decision VII/11 of the Conference of the Parties to the Convention on Biological Diversity notes: ${ }^{134}$

Ecosystems must be managed within the limits of their functioning...Just as there are limits to the demands (production, off-take, assimilation, detoxification) that can be made on ecosystems, so too there are limits to the amount of disturbance that ecosystems can tolerate, depending on the magnitude, intensity, frequency and

\footnotetext{
${ }^{129}$ Nicolas de Sadeleer, above n 75, at 14-19. James E Hickey and Vern R Walker, above n 74, at 423. Alexandre Kiss and Dinah Shelton, above n 43, at 204. Nicolas de Sadeleer, above n 65, at 182.

${ }^{130}$ Konrad Von Moltke, above n 66, at 99.

${ }^{131}$ See the discussion of ecosystems in Chapter II.

${ }^{132}$ Allan Boyle and David Freestone "Introduction" in Alan Boyle and David Freestone (eds), above n 12, at 1. Ted Schettler and Carolyn Raffensperger, above n 124, at 64.

${ }^{133}$ Allan Boyle and David Freestone, above n 132, at 64.

${ }^{134}$ Secretariat of the Convention on Biological Diversity The Ecosystem Approach (CBD Guidelines, Montreal, 2004) at 18.
} 
kind of disturbance...

Vulnerability therefore exists because it is much easier than first thought for human activities to eclipse an ecosystem's capacity to assimilate impacts, and in turn, cause significant and irreparable harm.

The second ecosystem characteristic revelation was that contrary to the traditional view that harm generated by unassimilated impacts can always be made good ex post facto, ecosystems in fact can and do suffer deleterious and irreparable changes to their integrity as a result of human activities. For example, where human activities induce a deviation from the parameters of variance tolerated by receiving ecosystems, this can trigger "ecosystem shifts" which are likely impossible to correct. ${ }^{135}$ As the Conference of the Parties to the Convention on Biological Diversity noted in the context of exceeding such parameters: ${ }^{136}$

If these limits are exceeded, an ecosystem undergoes substantial change in composition, structure and functioning, usually with a loss of biodiversity and resulting lower productivity and capacity to process wastes and contaminants.

Schettler and Raffensperger further explain: ${ }^{137}$

[w] hen change is sufficient to cause a system to cross a threshold, it operates within a new dynamic equilibrium that has its own stability and does not change...These new interactions become the norm...from which there is not turning back... When systems exist near a threshold, small perturbations at a critical point may be sufficient to cause a shift to a new dynamic equilibrium or more chaotic activity...

\footnotetext{
$\overline{{ }^{135} \text { H Osterblom and others "Making the Ecosystem Approach Operational - Can Regime Shifts in Ecological }}$ and Governance Systems Facilitate the Transition?” (2010) 34 Marine Policy 1290 at 1293.

${ }^{136}$ Decision V/6 by the Conference of the Parties to the Convention on Biological Diversity at its fifth meeting, above $n 53$.

${ }^{137}$ Ted Schettler and Carolyn Raffensperger, above n 124, at 64, 67 and 84.
} 
Such shifts can come about when human activities subject an ecosystem to one or multiple anthropogenic stressors, and often lead to the re-organised ecosystems capacity to confer life-supporting and enhancing ecosystem services being severely compromised. ${ }^{138}$

The third characteristic is that ecosystems are highly connected systems. Specifically, they are replete with complex inter-connections, intra-connections and co-dependencies that exist between their innumerable component parts. ${ }^{139}$ Furthermore, their continued functioning and resilience hinges on the health of the dynamic relationship between such components. The following relationships illustrate this characteristic: ${ }^{140}$

(1) The relationship within species groups and between various organisms. This includes biological dependencies (where the survival or wellbeing of one kind of organism is contingent on the survival and wellbeing of another), ${ }^{141}$ as well as biological interactions (for example, where chemicals and energy are transferred between trophic levels via food chain or web interactions). ${ }^{142}$

138 PM Vitousek and LR Walker "Biological Invasion by Myrica Faya in Hawaii: Plant Demography, Nitrogen Fixation, Ecosystem Effects" (1989) 59 Ecol Mon at 247 to 265. J Terborgh and others "Ecological Meltdown in Predator Free Forest Fragments" (2001) 94(2) Science 1923 at 1923-1926. Thomas Elmqvist and others "Response Diversity, Ecosystem Change, and Resilience" (2003) 9(1) Frontiers in Ecology and the Environment 488 at 489. H Osterblom, above n 135, at 1293.

139 Division for Ocean Affairs and the Law of the Sea United Nations Ecosystem Approaches and Oceans E.07.V.4 (2007) at 77. Secretariat of the Convention on Biological Diversity, above n 134, at 12. Decision $\mathrm{V} / 6$ by the Conference of the Parties to the Convention on Biological Diversity at its fifth meeting, above $n$ 53, Principle 3.

${ }^{140}$ Decision VII/11 of the Conference of the Parties to the Convention on Biological Diversity at its seventh meeting, Kuala Lumpur, 20 February 2004 UNEP/COP, principle 6. Secretariat of the Convention on Biological Diversity, above n 134, at 6.

141 JA Estes and others "Killer Whales Predation on Sea Otters Linking Oceanic and Nearshore Ecosystems" (1998) 282 Science 473-476; KT Frank and others "Trophic cascades in a formerly cod dominated ecosystem" (2005) 308 Science 1621-3; Myers RA et al "Cascading effects of the loss of apex predatory sharks from a coastal ocean" (2007) 315 Science 1846-1850, as cited in Larry Crowder and Elliott Norse "Essential ecological insights for marine ecosystem-based management and marine spatial planning" (2008) 32 Marine Policy 772 at 774-776. Karl-Hermann Kock and others "Fisheries in the Southern Ocean: An Ecosystem Approach" (2007) 362 PhiL Trans' R' Soc' B 2333 at 2333-2349. Ted Schettler and Carolyn Raffensperger, above n 124, at 64.

142 For example: "Removing top predators...can have effects that cascade down the food web... These cascades can link factors not linked in the minds of most..." (i.e. "an increase in abundance of killer whales 
(2) The relationship between organisms and their abiotic environment, as well as the physical and chemical interactions within the environment. This includes ecological process, such as biogeochemistry cycles, where organisms participate in the uptake, transfer, transformation and storage of chemical substances that are of fundamental importance to life-sustaining biological processes. ${ }^{143}$

(3) The relationship between abiotic components and ecosystem processes. ${ }^{144}$

It is through such dependencies and connections that these ecosystem components interact as a functional unit, whereby these component parts support, facilitate and regulate each

in the North Pacific could drive declines in threatened kelp rockfishes-when Orca increase, they reduce the abundance of sea otters, releasing herbivorous sea urchins from predation. Abundant urchins can then overgraze giant kelp, reducing habitat for juvenile rockfish"). Larry Crowder and Elliott Norse, above n 141, at 774-776.

${ }^{143}$ Ted Schettler and Carolyn Raffensperger, above n 124, at 64. Larry Crowder and Elliott Norse, above n 141, at 772, 775-778. DU Hooper and others "Effects of biodiversity on ecosystem functioning: a consensus of current knowledge" (2005) 75 Ecological Monographs 3 at 3-5 as cited in Cagan Sekercioglu "Ecosystem functions and services" in Navjot Sodhi and Paul Ehtlich Conservation Biology for All (Oxford University Press, Oxford, 2010) 45 at 45 and 53. R Wang "Understanding eco-complexity: Social-Economic-Natural Complex Ecosystem approach" (2011) 8 Ecological Complexity 15 at 21. Secretariat of the Convention on Biological Diversity, above n 134, at 32. SM Ferreira, and DR Towns "An ecosystem approach to maximise conservation of indigenous biological assets of New Zealand" (paper presented to the Department of Conservation, Auckland, 2001). A Hector and others "Conservation implications of the link between biodiversity and ecosystem functioning" (2001) 129 Oecologia 624 at 624-628, as cited in Anne-Marie Smit Adaptive monitoring: an overview (Department of Conservation, DOC Science Internal Series 138, 2003) at 13. Jon Day "The need and practice of monitoring, evaluating and adapting marine planning and management - lessons from the Great Barrier Reef' (2008) 32 Marine Policy 823 at 824. Tim O’Riordan, James Cameron and Andrew Jordan "The Evolution of the Precautionary Principle" in Tim O'Riordan, James Cameron and Andrew Jordan (eds) Reinterpreting the Precautionary Principle (Cameron May, London, 2001) 9 at 19. Malcolm McGarvin "Science, Precaution, Facts and Values" Principle in Tim O'Riordan, James Cameron and Andrew Jordan (eds) Reinterpreting the Precautionary Principle (Cameron May, London, 2001) 35 at 38. Erik Jaap Molenaar "Ecosystem-Based Fisheries Management, Commercial Fisheries, Marine Mammals and the 2001 Reykjavik Declaration in the Context of International Law" (2002) 17 Int'1 J Marine and Coastal L 561 at 572.

${ }^{144}$ Division for Ocean Affairs and the Law of the Sea United Nations Ecosystem Approaches and Oceans E.07.V.4 (2007) at 77. Nordic Council of Ministers Workshop on the Ecosystem Approach to the Management and Protection of the North Sea Oslo (Nordic Council, Norway, June 1998) at 41. G Likens, above n 48, at 10. RV O'Neill and others, above n 48, at 68-69. BG Hatcher "Coral Reef Ecosystems: How Much Greater Is the Whole than the Sum of the Parts?" (1997) 16 Coral Reefs S83 as cited in Hanling Wang, above n 34, at 43. Oceans and the Law of the Sea: Report of the Secretary General, above n 49, at [113]. 
other's existence. ${ }^{145}$ This is particularly the case for marine ecosystems, where such interactions persist in unparalleled abundance (e.g. by comparison to terrestrial ecosystems). ${ }^{146}$

The fourth characteristic is that individual ecosystems themselves are not closed systems, but rather, are open systems with ambiguous boundaries and common characteristics. ${ }^{147}$ Importantly, through shared ecosystem processes and overlapping structures ecosystems are inextricably linked with other ecosystems that surround them. ${ }^{148}$ For example, in the marine context: ${ }^{149}$

...the active movement of species provides a link between ecosystems by the transport of energy predation pressure, competition pressure and genetic variation...water masses containing different levels of salinity, temperature and oxygen...different levels of nutrients, toxins and living planktonic organisms....are transported between open sea and coastal areas...

\footnotetext{
$\overline{{ }^{145} \text { For example, ecosystem components regulate one and other via "negative feedback loops" whereby one }}$ or more components can act to stabilise the system by pushing pack against change to preserve the system in a status quo. International Risk Governance Council "Preparing for Future Catastrophes: Governance principles for slow-developing risks that may have potentially catastrophic consequences" (Lausanne, 2013) at 10. Decision V/6 by the Conference of the Parties to the Convention on Biological Diversity at its fifth meeting, above n 53, at 36. Hatcher and Bradbury above n 46, at 207 and 208. Strategy for Managing the Environmental Effects of Fishing: New Zealand Ministry of Fisheries at iv. http://www.fish.govt.nz/NR/rdonlyres/B7A02B28-7F2D-4419-BD81-903686124DD5/0/smeefpapa2.pdf.

146 "First marine ecosystems explicitly include the interactions among organisms and the viscous, energetic environment then inhabit...The fluid medium of the ocean connects marine populations, communities, habitats and pools of biochemical far more intimately that their terrestrial counterparts. Second, marine ecosystems implicitly exhibit some form of integrity reflected in emergent properties (i.e. the whole is greater than the sum of the parts...) and organisational or thermodynamic closure (i.e. internal transformations exceed trans boundary fluxes). J Steele, above n 50, at 185-192. S Woodley, J Kay and G Francis (eds), above n 50. BG Hatcher "Coral reef ecosystems: How much greater is the whole than the sum of the parts?" (1997) 16 Coral Reefs 77 to 91 as cited in Hatcher and Bradbury above n 46, at 207. Oceans and the Law of the Sea, above $\mathrm{n} 49$, preamble.

${ }^{147}$ Secretariat of the Convention on Biological Diversity, above n 134, at 12. Decision V/6 by the Conference of the Parties to the Convention on Biological Diversity at its fifth meeting, above $\mathrm{n} 53$, principle 3.

${ }^{148} \mathrm{H}$ Osterblom, above n 135, at 1293.

${ }^{149} \mathrm{H}$ Osterblom, above n 135, at 1293.
} 
As one author notes, in essence "...the entire planet is a vast network of integrated ecosystems". 150

Such connectivity and dependency leaves ecosystems highly vulnerable to the impacts caused by human interference. For example, the fact ecosystems operate as a functional unit makes their respective components vulnerable. This is because such connectivity makes the health and integrity of the ecosystem as a whole (or large parts or systems within it) highly contingent on the continued health and viability of the various dynamic relationships that exist between the various ecosystem components. ${ }^{151}$

Therefore, vulnerability arises because of the "open structure and connectedness of ecosystems [because it] ensures that effects on ecosystem functioning are seldom confined to the point of impact or only to one system". This is because such connections and dependencies often operate as vectors for harm, which communicate the detrimental impact of an activity beyond ecosystem components, which are directly or initially impacted - e.g. which are within the immediate location (i.e. receiving environment) that the activity is conducted in. ${ }^{152}$ For example:

(1) an initial ecological impact can trigger "knock-on" or "cascading effects", which "feed through" such connections causing changes to various linked ecosystems components, and in doing so, can culminate in significant harm to ecosystem structure and function over time; ${ }^{153}$

\footnotetext{
${ }^{150}$ Cagan Sekercioglu, above n 143, at 45.

${ }^{151}$ Decision VII/11 of the Conference of the Parties to the Convention on Biological Diversity at its seventh meeting, Kuala Lumpur, 20 February 2004 UNEP/COP principle 6. Secretariat of the Convention on Biological Diversity, above n 134, at 6 .

${ }^{152}$ Philippe Sands, above n 9, at 3. See also Alexandre Kiss and Dinah Shelton, above $n$ 43, at ix: who note the physical reality that the "biosphere [is] composed of interdependent elements that do not recognise political boundaries". Tim O'Riordan, James Cameron and Andrew Jordan, above n 143, at 19. Malcolm McGarvin, above n 143, at 38 .

$153 \mathrm{~J}$ Ebbesson Compatibility of international and national environmental law $\left(6^{\text {th }}\right.$ ed, Kluwer Law International, London, 1996) at 8. M'Gonigle and others, above n 79, at 110. David Vanderzwaag, above $n$ 2, at 171 and 182. WC Kerfoot "Cascading effects and indirect pathways" in WC Kerfoot and A Sih (eds) Predation: direct and indirect impacts on aquatic communities (University Press of New England, Hanover,
} 
(2) through biological dependencies, ${ }^{154}$ human-induced "...change in the abundance of one species [can produce] a relatively large impact on the mortality, growth or recruitment of another species..."; and

(3) since "the planet's climate, ecosystems, and creatures are tightly linked" by biogeochemical cycles, human-induced "changes in one component can have drastic effects on another..." (e.g. because interfering with one component can drastically affect the distribution of such substances). ${ }^{155}$

Cognisance of the true mobility of anthropogenic impacts between environmental mediums is critical to effective environmental management. This is because such awareness best ensures that decision-makers:

(a) readily acknowledge that human activities have the capacity to create regional and sometimes global harm or threats of harm (as exemplified by impacts such as global warming, ocean acidification, and loss of biodiversity); and

(b) in turn take steps to account for the potential high mobility or far reaching nature of such harms.

Such awareness is growing. For example, states increasingly acknowledge this aspect of ecosystem vulnerability through their recognition that "global environmental stresses and strains" are often generated by activities conducted within domestic boarders, and that this

1987) 57 at 57-70. PA Larkin "Concepts and issues in marine ecosystem management" (1996) 6 Reviews in Fish Biology and Fisheries 139 at 140, 151. Cagan Sekercioglu, above n 143, at 52-53 and 63. Division for Ocean Affairs and the Law of the Sea United Nations Ecosystem Approaches and Oceans E.07.V.4 (2007) at 15. Erik Jaap Molenaar, above n 143, at 584. Larry Crowder and Elliott Norse, above n 141, at 775. Daniel Pauly "Fishing Down Marine Food Webs" (1998) 279 Science 860 - 863 as cited in L. Juda, "Rio Plus Ten: The Evolution of International Marine Fisheries Governance" (2002) 33 Ocean Development and International Law 109 at 141.

${ }^{154}$ Estes, above $\mathrm{n} \mathrm{141}$, at 473-476; Frank and others, above n 141, at 1621-1623; Myers and others "Cascading effects of the loss of apex predatory sharks from a coastal ocean" (2007) 315 Science 1846-50, as cited in Larry Crowder and Elliott Norse, above n 141, at 774-776. Karl-Hermann Kock and others, above n 141, at 2333-2349. Ted Schettler and Carolyn Raffensperger, above n 124, at 64.

${ }^{155}$ Larry Crowder and Elliott Norse, above n 141, at 775. 
has significant implications for the way in which such human impacts are managed. ${ }^{156}$ As von Moltke notes, due to this ecological reality: ${ }^{157}$

...countries are not alone in managing the environment. No country is sovereign when it comes the environment. Indeed only historical accident has left national governments in charge of managing resources which are locally based and globally linked.

\section{Susceptibility to non-linear changes}

Finally, it emerged that human impacts can cause non-linear changes to ecosystems, and these changes can sometimes be "abrupt...large in magnitude and difficult, expensive, or impossible to reverse". ${ }^{158}$ Initially, it became clear that ecosystem functions and processes often operate in a non-linear fashion, whereby small changes to one ecosystem component would produce sudden and disproportionally large changes in another. ${ }^{159}$ Consequently, small human-induced changes to ecosystem components that form part of such a non-linear process could produce sudden and disproportionate harmful changes to another part of that process.

\footnotetext{
${ }^{156}$ Timothy O'Riordan and James Cameron, above n 123, at 12.

${ }^{157}$ Konrad Von Moltke, above n 66, at 107.

${ }^{158}$ Ted Schettler and Carolyn Raffensperger, above n 124, at 64. A Kumar Duralappah and others Ecosystems and Human Wellbeing: Diversity Synthesis: A Millennium Ecosystem Assessment Report (Washington, DC, 2005) at 11.

159 Jamie Benidickson et al "Practicing Precaution and Adaptive Management: Legal, Institutional and Procedural Dimensions of Scientific Uncertainty" Final Report Submitted to SSHRC and Law Commission of Canada (University of Ottowa, June 2005) at 20. Ted Schettler and Carolyn Raffensperger, above n 124, at 68. James Lovelock "Taking Care" in Timothy O'Riordan and James Cameron (eds) Interpreting the Precautionary Principle (Cameron May, London, 1994) at 114. Jeroen van der Sluijs and Wim Turkenburg "Climate change and the precautionary principle" in Elizabeth Fisher, Judith Jones and Rene von Schomberg (eds) Implementing the Precautionary Principle: Perspectives and Prospects (Edward Elgar, Cheltenham, 2006) 245 at 248, 257 and 265. Decision VII/11 of the Conference of the Parties to the Convention on Biological Diversity at its seventh meeting, Kuala Lumpur, 20 February 2004 UNEP/COP principle 6 Rationale. Secretariat of the Convention on Biological Diversity, above n 134, at 6. Douglas Clyde Wilson The Paradoxes of Transparency: Science and the Ecosystem Approach to Fisheries Management in Europe (Amsterdam University Press, Amsterdam, 2009) at 170. Christopher Stone "Is there a Precautionary Principle?" (2001) 31 ELR 10790 at 10795.
} 
In addition, it became apparent that harm could come about suddenly and violently when an ecological 'threshold' (i.e. point at which a given human impact can no longer be assimilated) is met. ${ }^{160}$ This phenomenon is known as 'cumulative effects', and can occur when, for example, negative feedback loops, buffering capacities, and like mechanisms that make ecosystems resilient to limited quantities of change, are overwhelmed. ${ }^{161}$ As one author notes: ${ }^{162}$

When systems exist near a threshold, small perturbations at a critical point may be sufficient to cause a shift to a new dynamic equilibrium or more chaotic activity...

This may subsequently trigger an "ecosystem shift", whereby the affected system post "shift", continues to operate, however the ecological structure, function and various interactions within and between each, are irreversibly "reorganised" in a new "stable", but typically less dynamic (i.e. robust and productive) equilibrium. ${ }^{163}$ Speaking in the context of ecological re-organisation, one author notes that "[t]his is true of both individual populations that have complex behaviour, and of whole ecosystems" (i.e. can apply to ecosystems as a whole or individual species alone). ${ }^{164}$

Under the principle of assimilative capacity, the belief in a regulator's ability to prevent harm is largely premised on the assumption that harm manifests itself in a gradual and linear fashion. Thus, because of this, assimilative capacity asserts that regulators and others will have sufficient time to prove causation and subsequently intervene (i.e. by stopping the offending activity or taking steps to mitigate the harm) before any significant

\footnotetext{
$\overline{160}$ "The problems are often non-linear, so that a little more pollution may produce a profound change, like the last step before falling off a cliff" Durwood Zaelke, Matthew Stilwell and Oran Young "Compliance, Rule of Law and Good Governance: What Reason Demands: Making Law Work For Sustainable Development" in Durwood Zaelke, Donald Kaniaru and Eva Kruzikova (eds), above n 123, at 37. M'Gonigle and others, above n 79, at 110 (see footnote 26).

${ }^{161}$ Such as "response diversity" see footnote 138 above. R Wang, above n 143, at 21. Secretariat of the Convention on Biological Diversity, above n 134, at 32.

${ }^{162}$ Ted Schettler and Carolyn Raffensperger, above n 124, at 64, 67 and 84.

${ }^{163}$ Ted Schettler and Carolyn Raffensperger, above n 124, at 69. H Osterblom, above n 135, at 1292. Larry Crowder and Elliott Norse, above n 141, at 776.

${ }^{164}$ Larry Crowder and Elliott Norse, above n 141, at 776.
} 
or irreversible harm results. However, as demonstrated above, due to the non-linear manner in which harm can arise, significant yet avoidable harm can often occurs long before there is any meaningful opportunity to identify its cause and take steps to avoid or mitigate it.

\section{Scientific uncertainty and limited ability to predict ecological impacts}

The second insight to come out of the failure of the traditional approach, and rise of the precautionary principle, was the realisation that environmental science is inherently uncertain and, in particular, has a limited ability to detect, predict, understand and prove the nature, gravity and probability of ecological impacts caused by human activities. Put another way, science has a very limited ability to predict and prove cause-and-effect relationships. ${ }^{165}$

Commentators assert that such scientific uncertainty, and limited predictive ability of science (a factor that distinct from uncertainty but which is a key contributor to it), is largely due to the complexity and variability of natural systems and processes (e.g. as such complexity frustrates most efforts to fully understand ecosystems and accurately predict the impact of human interference on them). ${ }^{166}$ It is indeed true that: ${ }^{167}$

[e]cosystems are inherently complex. They are not easily reducible to a simple model or scientific theory and typically neither their components nor processes, nor the interrelationships between these are well understood. Consequently uncertainty is the norm in environmental management...

As de Saadler also notes: ${ }^{168}$

\footnotetext{
${ }^{165}$ Ronnie Harding and Elizabeth Fisher, above $\mathrm{n} 8$, at 2.

${ }^{166}$ Arie Trouwborst, above n 116, at 116 to 117 . Ted Schettler and Carolyn Raffensperger, above n 124, at 68.

${ }^{167}$ Elizabeth Fisher and Ronnie Harding "Uncertainty, risk and precaution: exploring the links" in Ronnie Harding and Elizabeth Fisher, above n 2, at 163.

${ }^{168}$ Nicolas de Sadeleer, above n 75, at 18.
} 
... as scientists discover new facts about how ecosystems operate, they find it increasingly difficult to precisely evaluate the scope of [harm]... science cannot deliver certainty... To some extent the more science learns, the more it understands the limits of its knowledge...The entire foundation of the 'assimilative capacity' approach, which rests upon a blind confidence in science, is thus crumbling under the pressure of uncertainty.

This led to almost universal recognition (especially amongst the scientific community) that science is frequently unable to provide decision-makers with the information and means necessary to avoid them encroaching on the capacity of ecosystems to assimilate human impacts. ${ }^{169}$ This is demonstrated by the fact that: ${ }^{170}$

[m]any industrial activities and by-products have followed a pattern of an initial judgement of safety, followed by uncertainty and circumstantial evidence of harm, acrimonious debate, and finally hard evidence of detrimental effects.

Accordingly, for the above reasons (particularly when taken together with the insights regarding the potential magnitude of anthropogenic harm discussed above), environmental management regimes that require proof of causation before taking steps to avoid or mitigate harm will often fail to protect the environment. As Schettler and Raffensperger note, the uncertainty of environmental science means that: ${ }^{171}$

...human activities often have effects that are difficult to predict or even to recognize until damage is done...by the time a fact or causal relationship has been established by rigorous standards of proof, considerable avoidable damage may have already occurred.

In particular, it became apparent that scientific uncertainty renders decision-makers blind

\footnotetext{
${ }^{169}$ Charmian Barton, above n 75, at 510-511. Ronnie Harding and Elizabeth Fisher, above n 8, at 2. M'Gonigle and others, above n 79, at 108.

${ }^{170}$ M'Gonigle and others, above n 79, at 101.

${ }^{171}$ Ted Schettler and Carolyn Raffensperger, above n 124, at 70.
} 
to whether (if consented to or allowed to continue), an activity would: ${ }^{172}$

(1) compromise the structure, proper functioning, and essential processes necessary to maintain the resilience and overall integrity of the effected ecosystem over time; ${ }^{173}$ and

(2) unduly impact any existing competing human uses of the affected ecosystem.

As such, science, and in particular the science-led risk assessment process employed in most (traditional approach based) environmental decision-making frameworks, is unable to determine with sufficient accuracy, the use and protection balance required to ensure that consenting decisions secure sustainable development outcomes.

This insight, more so than the recognition of the irreversibility of ecological harm, is the primary impetus behind the formation of precautionary principle. As Tickner and Kriebel note: ${ }^{174}$

Put simply, the need for precaution arises because of uncertainty. If all potential hazards could be quantitatively assessed with minimal error, then it would be relatively easy to base...decisions on quantative risk assessments, and little else.

Scientific uncertainty, therefore, is, "by definition, at the core of the precautionary principle". ${ }^{175}$ Although not typically described in so many words, fundamentally, the problems caused by scientific uncertainty makes up the core mischief that the precautionary principle seeks to address.

\footnotetext{
${ }^{172}$ Malcolm MacGarvin, above $\mathrm{n} 94$, at 74.

${ }^{173}$ Oceans and the law of the Sea: Report of the Secretary General, above n 49, at [135].

${ }^{174}$ Joel Tickner and David Kriebel "The role of science and precaution in environmental and public health policy" in Elizabeth Fisher, Judith Jones and Rene von Schomberg (eds), above n 159, at 43.

${ }^{175}$ Ronnie Harding and Elizabeth Fisher, above n 8, at 9. Arie Trouwborst, above n 116, at 116. Simon Marr, above $\mathrm{n} 11$, at 9 and 24 .
} 


\section{$D \quad$ Exploring scientific uncertainty}

Given that scientific uncertainty is "the basic ingredient of the precautionary principle", close analysis of the nature of this uncertainty is critical to understanding: its substantive meaning; and, how to apply it in practice (i.e. to ensure proper giving of effect to its purpose). ${ }^{176}$ Indeed, as Trouwborst notes, a meaningful discussion about the precautionary principle cannot occur without such context. ${ }^{177}$ On this basis a strong argument can be made that where decision-makers' fail correctly to apply the precautionary principle and as a result regress into or gravitate back towards more traditional approach based decision-making, this is often because scientific uncertainty and its implications "remain largely unappreciated". ${ }^{178}$ For this reason, the remainder of this chapter explores scientific uncertainty and its implications in detail.

While commentators typically assert that the uncertainty of environmental science is entirely due to the complex and variable nature of ecosystems, ${ }^{179}$ in reality, the concept of scientific uncertainty is far more multi-faceted. ${ }^{180}$ Fundamentally, scientific uncertainty is a product of the scientific method itself. ${ }^{181}$ Ecological complexity is a major contributor to the uncertainty that pervades environmental science. However, the very nature of the scientific method itself also frequently limits the ability of science to effectively and accurately predict and address ecological harm. As the European Commission states in its

\footnotetext{
${ }^{176}$ Elizabeth Fisher and Ronnie Harding, above n 167, at 164.

${ }^{177}$ Arie Trouwborst, above $\mathrm{n} 75$, at 71.

${ }^{178}$ Malcolm MacGarvin "The precautionary principle, science and policy” in Ronnie Harding and Elizabeth Fisher, above n 2, at 226.

${ }^{179}$ Arie Trouwborst, above n 116, at 116 to 117.

${ }^{180}$ Ronnie Harding and Elizabeth Fisher, above n 8, at 9. Elizabeth Fisher and Ronnie Harding, above n 167, at 164. Ted Schettler and Carolyn Raffensperger, above n 124, at 68. Steve Maguire and Cynthia Hardy "The Emergence of New Global Institutions: A Discursive Perspective" (2006) 27(1) Organisational Studies 7 at 17. European Commission Communication from the Commission on the Precautionary Principle, $\operatorname{COM}(2000) 1$ final: 2000 Brussels at 25.

${ }^{181}$ Douglas Clyde Wilson, above n 159, at 39-40. Morgan, GM \& Henrion, M Uncertainty. A guide to dealing with uncertainty in quantitative risk and policy analysis, (Cambridge University Press, Cambridge, 1990) at 47. Simon Marr, above n 11, at 25.
} 
2000 communication on the precautionary principle: ${ }^{182}$

'Scientific uncertainty results usually from five characteristics of the scientific method: the variable chosen, the measurements made, the samples drawn, the models used, and the causal relationship employed', as well as 'controversy on existing data or lack of some relevant data' and 'uncertainty' related to 'qualitative or quantitative elements of the analysis'

Accordingly, in order to facilitate a better understanding of the principal reason, or rather 'mischief', behind the precautionary principle's existence, the principle itself, and how to ensure it is properly applied, the remainder of this chapter explores important aspects of scientific uncertainty.

1 The scientific process, its limitations, inherent uncertainty, and lack of suitability to environmental decision-making

In order to gain a good appreciation of scientific uncertainty and the issues it creates for decision-makers, it is necessary to have a sufficient grasp on the scientific process (i.e. the typical process through which scientific knowledge accrues). Such an understanding helps one appreciate how:

(a) this iterative process generates information (i.e. scientific understanding) over long periods of time; and

(b) the information that is ultimately produced is often inherently uncertain and sometimes ill-suited to environmental decision-making.

First, it is important to acknowledge that scientific knowledge (e.g. on a given cause and effect relationship) is typically derived over long time periods. This is because such knowledge is usually the product of working one or a multitude of theses through a lengthy and robust process of theorising, experimentation and peer review. Until this process is

182 Steve Maguire and Cynthia Hardy, above n 180, at 17. European Commission Communication from the Commission on the Precautionary Principle, COM(2000) 1 final: 2000 Brussels at 25. 
completed, science is unable to offer the courts anything that they would consider scientific evidence that is capable of proving a causal relationship to the required standard of proof. In providing a high-level summary of this process and the nature of the information it produces, Underwood notes: ${ }^{183}$

A scientific study involves an empirical attempt to falsify a model or theory about some process by demonstrating that its predictions fail to come true. Thus scientists start with observations, our knowledge about the physical world, and then attempt to explain why the observations have been made...There are, however, usually many possible explanations (or theories or models) and some mechanism is needed to distinguish among them.

A logically constructed procedure is to make a hypothesis from each model; that is, predictions about what will be observed under certain conditions not yet seen. These hypothesis are then tested by experiment - the creation of defined conditions so that the accuracy of the predictions can be measured.

Because of the difficulties in proving events, it is usual to design the experiment as a attempt to disprove a null hypothesis - the logical opposite of the hypothesis. Disproof or refutation of the null hypothesis provides support for the hypothesis and the model from which it is derived. If the null hypothesis cannot be disproved, the hypothesis (and therefore the relevant model) is considered to be falsified and must be discarded.

In discussing such difficulties, as well as the wider gestation process of scientific knowledge accrual (i.e. process of moving from mere theory to proof) Shelton makes the following observations: ${ }^{184}$

Theories guide research and experimentations, which become refined, reshaped

\footnotetext{
183 AJ Underwood "Precautionary principles require changes in thinking about planning and environmental sampling" in Ronnie Harding and Elizabeth Fisher, above n 2, at 255-256.

${ }^{184}$ Dinah Shelton, above n 63, at 224.
} 
and ultimately accepted or rejected in light of the observation of results...

Claims are judged in terms of reason and evidence. Scientists evaluate their ideas by criteria of testability, objectivity, impartiality and logic. All evolve along with scientific knowledge. Testing hypothesis by observation and experimentation over time helps eliminate distortions and errors and should enhance their predictive quality.

Acceptance depends on experimental testing over time. The greater the risk from wrong conclusions, the more certainty may be required. Refinement comes from critical review and retesting, for which publication is essential.

...scientific communities interact and...cross-reference each other, generating greater testing and acceptance.

This process, and the nature of the information it generates, is problematic for environmental decision-makers who rely entirely on science to provide the information upon which their decisions are based. ${ }^{185}$ As Von Moltke notes, science offers "a highly imperfect method for making environmental phenomena manifest". Ecosystem complexity aside, this is true for two reasons, namely, statistical uncertainty, and model uncertainty. The following two sections explore these two concepts in more detail and in doing so, identify their implications for environmental decision-making.

\section{Implications of statistical uncertainty}

When a hypothesis is tested in a context of scientific uncertainty, there are in principle at least two possible types of erroneous outcome. In considering such erroneous outcomes in the environmental context: ${ }^{186}$

(1) the first, known as a "type I error" (or "false positive"), is where scientists

${ }^{185}$ Charmian Barton, above n 75, at 511. HL Rouse and N Norton "Managing Scientific Uncertainty for Resource Management Planning in New Zealand" (2010) 17 Australasian Journel of Environmental Management 66 at 66 .

${ }^{186}$ M'Gonigle and others, above $\mathrm{n} 79$, at 104. Arie Trouwborst, above $\mathrm{n} 75$, at 194. 
“...incorrectly conclude[e] that there is an effect when one actually does not exist”; 187 and

(2) the second, known as a "type II error" (or "false negative"), is where scientists; "...incorrectly concluding that there is no effect when one actually exists)". ${ }^{188}$

Both type I and type II errors each give rise to different consequences. First, type I errors result in invalid concerns about an activity (i.e. false assertion that a given activity will cause a given harm), which in turn often lead to the imposition of costly regulatory restrictions that are later shown to be unnecessary. ${ }^{189}$ In short, they lead to unnecessary financial and resource costs. Conversely, type II errors lead to concealment or the overlooking of legitimate ecological impacts or harm. Thus, because of type II errors, "...regulations that should be imposed are not because it is incorrectly assumed that no effect exists" ${ }^{190}$ In turn, type II errors can result in regulators allowing harmful activities to continue without any harm avoidance measures, which would otherwise have be imposed, being put in place. ${ }^{191}$

The problem with science in the ecological setting is that it is particularly prone to type II errors. ${ }^{192}$ This is because scientists are trained to try to "...add only reasonably certain

\footnotetext{
${ }^{187}$ Arie Trouwborst, above n 75, at 194. M'Gonigle and others, above n 79, at 104. See also Ted Schettler and Carolyn Raffensperger, above n 124, at 71 . Kriebel et al "The precautionary principle in environmental science" (2001) 109 Environmental Health Perspectives at 871 to 876. AJ Underwood "Precautionary principles require changes in thinking about planning and environmental sampling" in Ronnie Harding and Elizabeth Fisher, above n 2, at 256-264.

${ }^{188}$ Or as Shettler and Raffensperger provide in defining it generally; “...the mistake of failing to recognise an association or phenomenon when it does exist". As Trouwborst exemplifies; where "...a researcher concludes there is no effect [between chemical $\mathrm{X}$ and alga $\mathrm{Y}$ ] when there actually is one" see M'Gonigle and others, above n 79, at 104; and Arie Trouwborst, above n 75, at 194. Ted Schettler and Carolyn, above n 124, at 71. AJ Underwood "Precautionary principles require changes in thinking about planning and environmental sampling" in Ronnie Harding and Elizabeth Fisher, above n 2, at 256-264.

${ }^{189}$ M'Gonigle and others, above n 79, at 104. Timothy O'Riordan "The Precautionary Principle and Civic Science" in Tim O'Riordan, James Cameron and Andrew Jordan (eds), above n 143, at 102. Ted Schettler and Carolyn Raffensperger, above n 124, at 71.

${ }^{190}$ M'Gonigle and others, above n 79, at 104.

${ }^{191}$ Ted Schettler and Carolyn Raffensperger, above n 124, at 71. M'Gonigle and others, above n 79, at 104.

192 Jamie Benidickson, above n 159, at 237.
} 
information to the body of knowledge as opposed to more speculative knowledge". ${ }^{193}$ As Shettler and Raffensperger suggest, science "generally requires strong evidence that something is scientifically "true" before being willing to say so...", ${ }^{194}$ hence the established view amongst the scientific community that: ${ }^{195}$

...committing a Type I error is worse than committing a type II error...[because i]t is regarded as 'better science' to incorrectly claim there is no effect than to incorrectly claim there is an effect.

For this reason science is inherently geared towards committing type II errors more often that type I errors. ${ }^{196}$ By extension, it can also be said that in the environmental setting, science consciously prefers (i.e. is tilted towards) committing errors that lead to environmental harm over those that result in redundant (i.e. unnecessary) protective measures being imposed. This choice is aptly characterised as selecting a preferred tradeoff. Thus, in making this choice, science makes a significant value judgement in isolation from any transparent and democratic policy or law making process.

In environmental management, this reasoning is applied to the determination of hazards to the environment and human health. ${ }^{197}$ Therefore, when attempting to ascertain

193 John Lemons, Kristin Shrader-Frechette and Carl Cranor "The Precautionary Principle: Scientific Uncertainty and Type I and Type II Errors (1997) 2 Foundations of Science 207 at 227. Joe Tickner and Carolyn Raffensperger, above n 76, at 14.

${ }^{194}$ Ted Schettler and Carolyn Raffensperger, above n 124, at 71. Jamie Benidickson, above n 159, at 237. Joe Tickner and Carolyn Raffensperger, above n 76, at 14.

${ }^{195}$ Kristen Schrader-Frechette "Methodological risks for four classes of scientific uncertainty" in J Lemons Scientific Uncertainty and Environmental Problem Solving (Blackwell, Oxford, 1996) 12 as cited in Timothy O'Riordan "The Precautionary Principle and Civic Science" in Tim O'Riordan, James Cameron and Andrew Jordan (eds), above n 143, at 102. Arie Trouwborst, above n 75, at 194. Ted Schettler and Carolyn Raffensperger, above n 124, at 71. David Gee and Andrew Stirling "Late lessons from early warnings: improving science and governance under uncertainty and ignorance in Marco Martuzzi \& Joel Tickner (eds), above $\mathrm{n}$ 124, at 122. Charmian Barton, above n 75, at 511.

196 John Lemons, Kristin Shrader-Frechette and Carl Cranor "The Precautionary Principle: Scientific Uncertainty and Type I and Type II Errors (1997) 2 Foundations of Science 207 at 227.

${ }^{197}$ Joe Tickner and Carolyn Raffensperger, above n 76, at 14. 
ecological effects: ${ }^{198}$

[s]cientific experiments incorporate this bias. Stringent standards of experimentation and replication are implemented to minimise the possibility of false positives. The burden of proof so to speak, is assigned accordingly to the scientist deviating from the null hypothesis...that is the hypothesis that there is no effect...

This is not unlike the reasoning that lies behind the legal presumption of innocence: the decision-maker will presume there is no guilt or liability, unless and until the accuser proves there is. The justification is that it is more palatable to be wrong about innocence than it is to be wrong about guilt or liability. Explaining how this bias operates in the environmental science context, Kriebel et al makes the following observations: ${ }^{199}$

By convention, Type I...errors are guarded against by setting that error rate low, usually at 5\%. In other words, the finding must be so strong that there is less than a $5 \%$ probability that this result would have been seen by chance alone in a world in which no such phenomenon actually exists. In this case the result is called statistically significant...The Type II error, failing to detect something that actually does exist, is, by convention, often set at $20 \%$...Twenty percent of the time, a real phenomenon will be missed because the data were not strong enough to convincingly demonstrate its existence.

This statistical bias is one instance of a "value-laden judgement" being embedded in the scientific method used in ecosystem risk identification. As Shettler and Raffensperger note: ${ }^{200}$

Establishing type I and type II error rates is a choice that reflects certain biases and is largely done by [scientific] convention, often without considering the

\footnotetext{
${ }^{198}$ Arie Trouwborst, above $\mathrm{n} 75$, at 194.

${ }^{199}$ Kriebel et al "The precautionary principle in environmental science" in Marco Martuzzi \& Joel Tickner (eds), above n 124, at 153-154.

${ }^{200}$ Ted Schettler and Carolyn Raffensperger, above n 124, at 71.
} 
consequences...

Because of this skewed approach, type II errors are frequently "...the inevitable result of a consistent bias towards avoiding type I errors...," ${ }^{201}$ and, in practice, operate as “...a de facto bias in favour of industrial freedom of action", and in turn, against environmental protection. $^{202}$ This approach, therefore, leads to a comparatively detrimental outcome for environmental protection initiatives and objectives.

\section{Model uncertainty}

Ecological modelling has emerged as a predominant tool in predicting environmental outcomes, particularly in relation to marine ecosystem management. "Model uncertainty" or "model error" arises where there are "gaps in scientific theory" (e.g. the thesis that X impact will generate $\mathrm{Y}$ ecological effects), ${ }^{203}$ or "imprecision in the models used to bridge information gaps" (e.g. as to how a given activity will affect a given receiving ecosystem or part thereof). ${ }^{204}$ The result is that the subsequent model fails to accurately identify or specify, or sufficiently capture the relevant causal processes (e.g. between an activity and the subsequent impact induced ecological outcomes that culminate in harm), including the full extent and nature of the subsequent harm. ${ }^{205}$

${ }^{201}$ Kristen Schrader-Frechette "Methodological risks for four classes of scientific uncertainty" in J Lemons Scientific Uncertainty and Environmental Problem Solving (Blackwell, Oxford, 1996) 12 as cited in Timothy O'Riordan "The Precautionary Principle and Civic Science” in Tim O'Riordan, James Cameron and Andrew Jordan (eds), above n 143, at 102. Arie Trouwborst, above n 75, at 194. Ted Schettler and Carolyn Raffensperger, above n 124, at 71. David Gee and Andrew Stirling "Late lessons from early warnings: improving science and governance under uncertainty and ignorance in Marco Martuzzi \& Joel Tickner (eds), above n 124, at 511 .

${ }^{202}$ M'Gonigle and others, above n 79, at 102. Jamie Benidickson, above n 159, at 237-238.

${ }^{203}$ P.A. Larkin, "Concepts and Issues in Marine Ecosystem Management", (1996) 6 Reviews in Fish Biology and Fisheries 139 at 150 . Office of the Parliamentary Commissioner for the Environment Te Kaitiaki Taiao a Te Whare Pāremata "Illuminated or blinded by science? A discussion paper on the role of science in environmental policy and decision-making" (PCE, Wellington, July 2003) at 31. United Nations Conference on Environment and Development, Development, Report, Annex II, 12 August 1992, UN Doc A./Conf. 151/26 (Vol II-IV). D Gascuel "Towards the implementation of an intergrated ecosystem fleet-based management of European fisheries" (2012) 36 Marine Policy 1022 at 1022 to 1032. Hanling Wang, above n 34 , at $42-43$.

204 Joe Tickner and Carolyn Raffensperger, above n 76, at 11.

${ }^{205}$ Douglas Clyde Wilson, above n 159, at 40. 
Scientific modelling entails developing an abstract, usually mathematical, representation of an ecological system, or part of (e.g. equations that "describe" ecosystem phenomena), ${ }^{206}$ or developing a "relative approximation" of that system. ${ }^{207}$ The representation or approximation then attempts to simulate all of the various relevant ecological interactions and their responses to anthropogenic inputs. ${ }^{208}$ As such, modelling requires scientists to accurately identify and define all germane system variables and how they interact, and to subsequently reduce them to mathematical terms in a way that again, operates as a sufficiently accurate relative approximation of the actual ecosystem. This is a difficult task, particularly in the marine space, given:

(1) the ever-present knowledge deficit which typically precedes most attempts to execute such a task;

(2) the complex, multifaceted and variable nature of ecological relationships between ecological components; and

(3) the reality that establishing the role of an ecological component (for example, a given species) "demands long-term detailed observation and...experimental manipulation", something that is typically not possible when conducting a modelling exercise. ${ }^{209}$

Arguably, these difficulties "cripple" scientists' ability accurately to represent the modelled system. ${ }^{210}$ Furthermore, “...complex models can include only a finite number of variables and interactions". As Schettler \& Raffensperger go on to note, such models typically are unable to account for or incorporate all germane ecological variables because: ${ }^{211}$

\footnotetext{
${ }^{206}$ G.M. Watters et al "Decision-making for ecosystem-based management: evaluating options for a krill fishery with an ecosystems dynamics model" (2013) 23(4) Ecological Applications 710 at 711.

${ }^{207}$ P.A. Larkin, "Concepts and Issues in Marine Ecosystem Management", (1996) 6 Reviews in Fish Biology and Fisheries 139 at 141.

${ }^{208}$ G.M. Watters et al "Decision-making for ecosystem-based management: evaluating options for a krill fishery with an ecosystems dynamics model" (2013) 23(4) Ecological Applications 710 at 710.

${ }^{209}$ Malcolm MacGarvin, above n 94, at 77-79.

${ }^{210}$ Adriana Fabra and Viginia Gascon "The Convention on the Conservation of Antarctic marine Living Resources (CCAMLR) and the Ecosystem Approach" (2008) 23 The International Journal of Marine and Coastal Law 567 at 577. Malcolm MacGarvin, above n 94, at 77.

${ }^{211}$ Ted Schettler and Carolyn Raffensperger, above n 124, at 69.
} 
The real world, however, is a confluence of biological, ecological, social, cultural, economic and political systems. No experimental model can fully account for each of these and their interrelationships. Ongoing research, monitoring and refining models may help to reduce uncertainty, but imprecision is inevitable.

In particular, where there are multiple and interacting variables, there is a fundamental uncertainty in the relevant model, even before one takes into account the compounding complexity generated by spatial and temporal dynamics. ${ }^{212}$ Absent an ability to model complete systems and include all of their intricacies and idiosyncrasies, it is difficult - if not impossible - to anticipate anthropogenic impacts on the synergistic properties of ecosystems. $^{213}$

\section{Ecological complexity as a source of uncertainty}

In short, the inordinate complexity, variability, and dynamic and non-linear nature of ecosystems confound the ability of science (i.e. the above scientific process) to comprehend and predict ecological phenomena. ${ }^{214}$ Specifically, because of these ecosystem characteristics, science:

(1) has a considerably limited ability to understand how human impacts resonate throughout ecosystems (namely, the impact on structure and function);

(2) is often unable accurately to determine the assimilative thresholds that a given

\footnotetext{
$\overline{212}$ Ted Schettler and Carolyn Raffensperger, above n 124, at 74. P.A. Larkin, "Concepts and Issues in Marine Ecosystem Management", (1996) 6 Reviews in Fish Biology and Fisheries 139 at 151. International Risk Governance Council, above n 145, at 10.

${ }^{213}$ International Risk Governance Council, above n 145, at 11.

${ }^{214}$ J Steele, above n 50, at 185-192. S Woodley, J Kay and G Francis (eds), above n 50. B G Hatcher "Coral reef ecosystems: How much greater is the whole than the sum of the parts?" (1997) 16 Coral Reefs 77 to 91 as cited in Bruce G Hatcher and Roger H Bradbury "Marine Ecosystem Management: Is the whole greater than the sum of the parts?" as cited in Donald R Rothwell and David L VanderZwaag, above n 145, at 207. Oceans and the Law of the Sea, above n 49, preamble. Decision VII/11, Ecosystem Approach (Kuala Lumpur, 20 February 2004), principle 6 Rationale. Secretariat of the Convention on Biological Diversity, above n 134, at 6. Douglas Clyde Wilson, above n 159, at 170. Thomas Elmqvist et al "Response diversity, ecosystem change, and resilience" (2003) 1, 9 Frontiers in Ecology and the Environment 488 at 488.
} 
ecosystem possesses (i.e. its capacity to absorb, without material harm, a given human impact); ${ }^{215}$ and

(3) is, in turn, often unable to detect, understand and prove the ecological harm, which many proposed activities will or are likely to cause. ${ }^{216}$

Therefore, even though relationships do often exist between an activity and a subsequent harm, in spite of extensive scientific testing, such relationships will often remain largely hidden. $^{217}$

As discussed above, ecological complexity is manifested in ecosystems' innumerable biotic and abiotic parts, bound together by a sophisticated web of intimate and systematic interactions (such as negative and positive feedback loops), which maintain the optimal physical and chemical conditions for life. ${ }^{218}$ These features are present at the global environment, which itself is comprised of a myriad of interdependent and inextricably linked major ecosystems, which again, interact as a functional unit. In addition, complexity arises from the fact that interactions between ecosystem components generate properties and behaviours characteristic of the ecosystem as a whole (i.e. where the properties of the whole are greater than that generated by the sum of its component parts). ${ }^{219}$

Several key ecological characteristics also contribute to the variable nature of ecosystems. First, as noted above, ecosystem processes and functions are also non-linear in nature. In addition, the outcome of such processes is often subject to considerable time lags. As experience has shown, "[t]he result is discontinuities, leading to surprise and

\footnotetext{
${ }^{215}$ Simon Marr, above n 11, at 26.

${ }^{216}$ Ronnie Harding and Elizabeth Fisher, above n 8, at 2. M'Gonigle and others, above n 79, at 108.

${ }^{217}$ M'Gonigle and others, above $\mathrm{n} 79$, at 101.

${ }^{218}$ A Kumar Duralappah, above n 158, at 18. Douglas Clyde Wilson, above n 159, at 170. RL Smith and TM Smith Elements of Ecology ( $4^{\text {th }}$ ed, Pearson Publishing, Virginia, 2000) at 344.

${ }^{219}$ International Risk Governance Council, above n 145, at 33. B G Hatcher above n 212, at 91. Oceans and the Law of the Sea: Report of the Secretary General, above n 49, at [113]. A Belgrano et al "Toward ecosystem-based management for the oceans: a perspective for fisheries in the Bering Sea" In Report of the PICES/NPRB Workshop on Integration of Ecological Indicators of the North Pacific with Emphasis on the Bering Sea. Ed. by G. H. Kruse. North Pacific Marine Science Organization.
} 
uncertainty". Secondly, variability often arises because ecosystem structure and function, and the innumerable sub-components within each, are not static; rather, as a result of ecological processes, they are variable and in flux, with change occurring constantly on a multitude of differing spatial and temporal scales. ${ }^{220}$ Furthermore, at a macro level, entire ecosystems go through "phase transitions" where they naturally alternate between various "alternate stable ecosystem states". ${ }^{221}$ As the Secretariat of the Convention on Biological Diversity of states: ${ }^{222}$

Those changes include shifts in species composition, population abundance, and physical characteristics...Such changes are not necessarily constant, [but are] variable, dynamic and usually difficult to predict at any point in time.

Because of the above: $:^{223}$

...[e]cosystems...have 'moving boundaries'...some habitats may stay relatively stable...other systems... can be highly variable. Changes can occur in the short-term with changes in currents or in line with decadal shifts. Some species inhabit different scales of the ecosystem at different stages of their life cycles, such as a pelagic state

$\overline{220}$ Oceans and the Law of the Sea: Report of the Secretary General, above n 49, at [110] -[113], [150], and [154]. Donna R Christie "Implementing an Ecosystem Approach to Ocean Management: An Assessment of Current Regional Governance Models” (2005) 16 Duke Envtl. L. \& Pol'y F 117 at 128. Karl-Hermann Kock and others, above n 141, at 2342. H Osterblom, above n 135, at 1291. Erik Jaap Molenaar, above n 143, at 583.

${ }^{221}$ Scheffer M et al "Catastrophic shifts in ecosystems" (2001) 413 Nature at 591 to 596. Scheffer, M. \& Carpenter, S. "Catastrophic regime shifts in ecosystems: linking theory to observation" (2003) 18 Trends Ecol. Evol. At 648 to 656, as cited in Michael Litzow and Lorenzo Ciannelli "Oscillating trophic control induces community reorganisation in a marine ecosystem" (2007) 10 Ecology Letters at 1 to 11. Larry Crowder and Elliott Norse, above n 141, at 773. See also Ted Schettler and Carolyn Raffensperger, above n 124, at 64. Donna R Christie "Implementing an Ecosystem Approach to Ocean Management: An Assessment of Current Regional Governance Models” (2005) 16 Duke Envtl. L. \& Pol'y F 117 at 128. Secretariat of the Convention on Biological Diversity, above n 134, at 32.

${ }^{222}$ Secretariat of the Convention on Biological Diversity, above n 134, at 24. Karl-Hermann Kock and others, above $\mathrm{n} 141$, at 2338 .

${ }^{223}$ MRAG \& UNEP-WCMC (2008) Defining concepts of ecosystem structure and function for UK marine monitoring. Joint Nature Conservation Committee, Peterborough. 65 pages. JNCC report No. 397, Annex 1 at para [3.1]. 
during larval stages and a benthic existence as an adult.

Consequently, the parameters of the anthropogenic impact that an ecosystem can tolerate (i.e. a given ecosystem's capacity to assimilate or neutralise harm) “.... are not static but may vary across sites, through time, and in relation to past circumstances and events" (i.e. they are in essence a moving target). ${ }^{224}$

Such ecosystem characteristics generate uncertainty for a multitude of reasons. Speaking at a high level, von Moltke notes uncertainty arises because the scientific process described above: $:^{225}$

...is a highly imperfect method for making environmental phenomena manifest...the best [it] can do is provide a hypothesis which has stood up well under repeated scrutiny... [it] almost never provides clear proof of major environmental impacts because the environment is too complex to be described in strictly scientific terms

As M'Gonigle et al also explain:226

Despite considerable scientific data about the dynamics of natural and humandisturbed environmental systems, large gaps in our understanding still exist. Because of the complexity of most ecological systems, it is sometimes difficult either to identify causes of past observations or to forecast future responses to a proposed activity. Many features of ecological systems can increase the variance of data so as to reduce the statistical power of a study, thus posing interpretive difficulties for regulators who depend on scientific studies.

In discussing the uncertainty that flows from ecosystem complexity and variability, Trouwborst also adds to the above by making the following observations: ${ }^{227}$

\footnotetext{
${ }^{224}$ Secretariat of the Convention on Biological Diversity, above $\mathrm{n}$ 134, at 18 .

${ }^{225}$ Konrad von Moltke, above n 66, at 98.

${ }^{226}$ Michael M'Gonigle and others, above n 79, at 108.

${ }^{227}$ Arie Trouwborst, above n 75, at 75 .
} 
In the multilayered planetary ecosystem with all its cycling and feedback, causes and effects are apparently inseparable, as effects become causes for new effects and so on. Even the question of where to begin scientific examination of such a system is difficult to approach. The more is learnt about the dynamics of ecosystems, the more it is realised how extremely difficult it is to comprehensively understand or even predict them.

In truth, the uncertainties flowing directly from nature's complexity are of such magnitude and variety that they are highly unlikely to ever be significantly reduced, let alone resolved. No environmental study can ever pretend to capture all checks and balances on an ecosystem; invariably there are conditions that escape observation and comprehension, or extend beyond the studied range.

Significantly, while science often excels in the discrete exploration and analysis of individual, minute parts of ecosystems, the scientific process and tools it employs are "often at a loss where it comes to comprehending the intricacies of ecological linkages", and, in turn, the way harm in which communicates through them (e.g. via trophic cascades or similar knock-on effects). By way of example, M'Gonigle et al note that the limited predictive ability of science, and in turn, its often-limited ability to resolve uncertainty, can arise because scientific studies: ${ }^{228}$

(1) can only test a limited number of ecosystem components at a time, under a limited range of conditions, and as a result may: overlook important cumulative or synergistic effects; fail to identify emergent properties or behaviors; ignore impact of a related ecosystem component on that which is being tested; or, given the interconnected nature of ecosystems, fail to notice there may be more than one causative agent for the observed effect.

(2) often focus on the effect a given human interference has on indicator species at a single stage of its life, they are limited in their ability to detect cumulative effects on that

\footnotetext{
${ }^{228}$ For example, as M'Gonigle et al note, where a particular ecosystem function is facilitated by more than one ecological pathway “...the potential effect of a human disturbance that interferes with only one of these pathways may be masked, while a latter disturbance affecting the remaining pathways may have an observable effect - an effect that may be difficult to trace to its source. M'Gonigle and others, above n 79, at 110 .
} 
particular species, and the potential effects on species of different trophic levels.

In addition, establishing cause-and-effect relationships through repeated scientific experimentation can be difficult, or even impossible, because of several factors, namely: ${ }^{229}$

(1) latency periods caused by time delays between human impacts and resulting harm prevent identification by such experiments;

(2) natural variability in ecosystems, as a result, for example, of 'phase transitions', making it difficult to identify clear associations and differentiate between naturally occurring changes and those caused by human activities (that is, differentiating between "phase transitions" and "ecosystem shifts");

(3) the capacity of an ecosystem's species, or of an ecological process, to tolerate interference is a constantly shifting target; and

(4) complex interactions being counterintuitive and not easily foreseeable except by modelling the system as a whole (that is, so as to discern "emergent properties"). ${ }^{230}$

\section{$5 \quad$ Practical implications of scientific uncertainty}

All of the above difficulties led to the scientific community and states acknowledging that the absence of evidence that an may or will activity cause harm cannot be equated with the proof that there is no harm. ${ }^{231}$ It also led to the acknowledgement that, due to the manner and pace at which scientific knowledge accrues and evolves, science is frequently unable to provide decision-makers with the kind of ecological information they need, at the time they need it, in order to conduct an effective risk assessment.

In addition, the information generated by science does not possess the necessary clarity and precision that is required for good environmental decision-making. Science does not put forward unequivocal assertions; ${ }^{232}$ rather, "[t]he best science can do is provide a

\footnotetext{
${ }^{229}$ See Arie Trouwborst, above n 2, ch I. Charmian Barton, above n 75, at 512-514.

${ }^{230}$ International Risk Governance Council, above n 145, at 10.

${ }^{231}$ Steve Maguire and Cynthia Hardy, above n 180, at 69. Ronnie Harding and Elizabeth Fisher, above n 8, at 2 .

${ }^{232}$ Nicolas de Sadeleer, above n 75, at 152-153.
} 
hypothesis which has stood up well under repeated scrutiny". 233

Difficulty also arises in the disjunct between science and time. ${ }^{234}$ As indicated above, "science is a cumulative effort, with answers generated through a long sequence of hypothesis, each moving closer towards a fuller insight”. If, at a particular point in time, science fails to confirm or disprove a hypothesis, scientists may continue to "refine, modify, or discard, variables or models when more information is available" in an effort eventually to prove the causal relationship. Furthermore, "most answers in science are considered subject to revision in light of new evidence" and, as such, may change. Regulators and courts, however, must make a choice based on the existing scientific knowledge at that point in time. This means that environmental decisions often require proof of a causal relationship years or even decades before any semblance of scientific certainty can be achieved. $^{235}$

\footnotetext{
${ }^{233}$ Konrad Von Moltke, above n 66, at 98.

${ }^{234}$ Konrad Von Moltke, above n 66, at 99.

${ }^{235}$ Stephen Dovers and John Handmer, above n 79, at 168. Daniel Bodansky "Scientific Uncertainty and the Precautionary Principle" (1991) 33.7 Environment 4 at 4.
} 


\section{$V$ Introducing the Precautionary Principle}

As discussed in Chapter IV, the precautionary principle arose in response to increasing understanding that the harm inflicted on the environment by human activities can have grave and irreversible consequences in conjunction with: ${ }^{236}$

(1) acknowledgement of the multiple uncertainties surrounding threats to the environment;

(2) the realisation that science often has a limited ability to accurately to predict the effects of human behaviour; and

(3) an understanding of the need to take preventative action to protect the environment in the face of these uncertainties and inabilities (especially in light of the severity of some harms).

Driven by the above collection of insights and realisations, the precautionary principle rapidly emerged as a general principle of international law in the early 1980s. In doing so the precautionary principle (which is often also referred to as the "precautionary approach'), ${ }^{237}$ facilitated a paradigmatic shift in the way states sought to manage environmental threats. ${ }^{238}$ Specifically, this shift entailed a move:

\footnotetext{
${ }^{236}$ Arie Trouwborst, above $\mathrm{n} 2$, at 10.

${ }^{237}$ A comprehensive discussion regarding whether the terms precautionary principle and precautionary approach refer to differing precautionary standards is beyond the scope of this paper. Previously, it was argued that ascribing the label "precautionary approach", instead of "precautionary principle" to a precautionary provision is a clear indication that negotiating states intended to be subject to a less restrictive precautionary standard (that is, the precautionary principle indicated an intention to be bound by a more "hard-line" obligation to take precautionary measures; whereas the precautionary approach indicated a relaxation of the strength of the obligation imposed, thereby preserving negotiating states discretion as to whether precautionary measures are to be adopted or not in a given situation). Now it is widely accepted that such nomenclature has no substantive effect on the strength of a decision maker's obligations to adopt precautionary measures under that provision. An examination of those international instruments containing precautionary provisions and state practice demonstrate use of 'approach' and 'precaution' with indifference to the basic characteristics and legal consequences of a precautionary provisions application. See also: Ellen Hey, above n 79, at 304.

${ }^{238}$ David Vanderzwaag, above n 2, at 166.
} 
(1) from an approach that is: reactive, as protective steps may only be taken after proving causation, a task science typically undertakes in response to suspicion that the given harm is already manifest; and fragmented, as harm is typically proven on an ad hoc basis in relation discrete instances of harm, thereby constraining efforts to implement coordinated protective measures that take a long-term view; and

(2) towards a holistic and anticipatory approach, whereby decision-makers are legally entitled to take action to protect the environment in advance of definitive scientific proof that: ${ }^{239}$ (a) a causal link exists between a suspected activity and resulting harm; and (b) the suspected damage will materialise.

Importantly, this shift was also characterised as facilitating a move "away from a belief in the supremacy of science to accurately gauge the health of the environment", to an understanding that effective environmental decision-making requires regulators to go beyond science. ${ }^{240}$

The precautionary principle thus arose to tackle mischiefs that proved fatal to humankind's ability effectively to manage its impact on the environment, and, in turn, the environment itself. Driven by this, early predictions the precautionary principle would "become the fundamental principle of environmental protection policy and law", were subsequently confirmed by "the speed with which...[it] has been brought on to the international agenda, and the range and variety of international forums which have explicitly accepted it". 241

\section{A Introducing the precautionary principle}

At its core, the precautionary principle advises decision-makers to err on the side of caution where the effects of an activity cannot be predicted with confidence. Applying the

\footnotetext{
${ }^{239}$ David Freestone and Ellen Hey, above n 9, at 13.

${ }^{240}$ PE Taylor "From Environmental to Ecological Human Rights: A New Dynamic in International Law?" (1998) 10 Geo Int'l Env L Rev 309 at 330.

${ }^{241}$ Jonathan Wiener "Precaution" in Daniel Bodansky, Jutta Brunnee and Ellen Hey (eds) The Oxford Handbook of International Environmental Law (Oxford University Press, Oxford, 2007) at 599.
} 
principle means giving the benefit of the doubt to the environment: in dubio pro natura. ${ }^{242}$ In essence, it codifies the common-sense notion of precaution, and in doing so formalises and structures its application to the specific problem area of environmental regulatory decision-making. ${ }^{243}$ In this regard, Stein J notes: ${ }^{244}$

the precautionary principle is a statement of common sense...It is directed towards prevention of serious harm to the environment in situations of scientific uncertainty. Its premise is that where uncertainty or ignorance exists concerning the nature or scope of environmental harm (whether it flows from policies, decisions or activities), decision makers should be cautious.

Despite the fact that some variance in wording exists between the multitude of precautionary principle formulations found in various international and domestic law instruments, at a minimum, all formulations share the same "quintessential elements" and basic structure, ${ }^{245}$ which are explored below.

\section{Common purpose and conceptual core}

The precise stated purpose of different precautionary principle formulations can vary depending on the particular environmental subject dealt with. In spite of this, each formulation shares the common purpose of ensuring the adequate protection of the

\footnotetext{
${ }^{242}$ Arie Trouwborst above $\mathrm{n} 75$, at 184 .

${ }^{243}$ Ellen Hey, above n 79; Jonathan Wiener, above n 241, at 599; Arie Trouwborst, above n 2, at 8. Chris Tollefson and Jamie Thornback "Litigating the Precautionary Principle in Domestic Courts" (2008) 19 JELP 33 at 35; David Vanderzwaag, above n 2, at 166; Gary E Marchant, above n 7, at 1799; Tim O'Riordan, above $\mathrm{n} 2$, at 283.

${ }^{244}$ James Cameron and Juli Abouchar, above n 2, at 46.

245 Per Sandin "Dimensions of the Precautionary Principle" (1999) 5.5. Human and Ecological Risk Assessment: An International Journal 889 at 890. M Matthee and D Vermersch "Are the Precautionary Principle and the International Trade of Genetically Modified Organisms Reconcilable?" (2000) 12 JAEE 59 at 61; A Epiney and M Scheyli "Strukturprinzipien des Umweltvölkerrechts" (Nomos Verlag, Baden-Baden, 1998) at 109-110. James Cameron and Juli Abouchar, above n 2, at 45. Arie Trouwborst, above n 75, at 30. Daniel Bodansky "Deconstructing the Precautionary Principle" in David D Cameron and Harry N Scheiber (eds) Bringing New Law to Ocean Waters (Martinus Nijhoff Publishers, Berkeley/Boston, 2004) 381 at 386; Gary E Marchant, above n 7, at 1800. Stephen Gardiner "A Core Precautionary Principle" (2006) 14(1) J Polit Philos 33 at 36.
} 
environment, and in particular, ecosystem health ${ }^{246}$ both: ${ }^{247}$

(1) as an end in itself, on the basis that there is inherent value in preserving the environment for its own sake; ${ }^{248}$ and

(2) for the benefit of humankind, because the preservation of ecosystems within it, and in particular the life-sustaining services they provide, are critical to the survival and wellbeing of humans. ${ }^{249}$

In pursuit of this purpose, the core notion of the precautionary principle provides: ${ }^{250}$ where there is a threat of environmental harm, the environment and the well-being and interests of future generations can only be adequately protected if decision-makers take protective measures in advance of the establishment of scientific certainty (i.e. proof of causation between, the relevant activity and the potential environmental harm) ${ }^{251}$ As de Saadler further explains: ${ }^{252}$

${ }^{246}$ Christopher C.E. Hopkins "The Concept of Ecosystem Health and Association with the Ecosystem Approach to Management and Related Initiatives" (BSRP Study Group on Baltic Ecosystem Health Issues, November 2004) at 2 to 3.

247 Arie Trouwborst, above n 116, at 108. Arie Trouwborst, above n 2, at 12. James Cameron "The Precautionary Principle: Core meaning, constitutional framework and procedures for implementation" in Ronnie Harding and Elizabeth Fisher, above n 2, at 40. Jacqueline Peel "The Precautionary Principle in Practice: Environmental decision-making and scientific uncertainty” (Federation Press, Melbourne, 2005) at viii.

${ }^{248}$ Arie Trouwborst, above n 2, at 12; James Cameron, above n 247, at 40.

${ }^{249}$ Arie Trouwborst, above n 116, at 108. Arie Trouwborst, above n 2, at 12.

${ }^{250}$ Rosie Cooney, above n 57, at 4. Philippe Sands, above n 9, at 268-279. Arie Trouwborst, above n 2, at 245; James Cameron, above n 247, at 29-36. Andrew Jordan \& Timothy O'Riordan "The precautionary principle: a legal and policy history" in Marco Martuzzi and Joel Tickner (eds), above n 124, at 42. David Freestone and Ellen Hey, above n 9, at 13. John S Applegate, above n 9, at 14. Arie Trouwborst, above n 75, at 245 .

${ }^{251}$ David Freestone and Ellen Hey, above n 9, at 13. John S Applegate, above n 9, at 26. See also James Cameron, above n 247, at 29-36. Andrew Jordan \& Timothy O'Riordan, above n 250, at 42. David Freestone and Ellen Hey, above n 9, at 13. Arie Trouwborst, above n 2, at 245. James Cameron, Will Wade-Gery and Julie Abouchar "Precautionary Principle in Future Generations" in Emmanuel Agius and others Future Generations in International Law (Routledge, London 1998) at 98-99. James Cameron and Juli Abouchar, above $\mathrm{n} 2$, at 46 .

${ }^{252}$ Andrew Jordan \& Timothy O'Riordan, above n 250, at 42. David Freestone and Ellen Hey, above n 9, at 13. 
...precaution means that the absence of scientific certainty - or conversely... scientific uncertainty - as to the existence or the extent of a risk should...no longer delay the adoption of preventative measures to protect the environment. Put simply, the principle can be understood as the expression of a philosophy of anticipated action, not requiring that the entire corpus of scientific proof be collated in order for a public authority to be able to adopt a preventive measure. (emphasis added)

Thus, it can be said that the raison d'être of the precautionary principle is its particular temporal relationship between scientific certainty and regulatory action; namely, that in appropriate cases, regulatory action should precede certainty. ${ }^{253}$

Lead commentators note that, upon examining "the myriad of different definitions found in the numerous agreements, declarations, action programmes, resolutions, decisions, statutes, strategies, judgements and other sources", ${ }^{254}$ it becomes clear that: ${ }^{255}$

[r]egardless of the differences in wording, all...examples can be seen to possess the same three common elements:

1) regulatory inaction threatens non-negligible harm;

2) there exists a lack of certainty on the cause and effect relationships; and

3) under these circumstances regulatory inaction is unjustified.

These elements form a conceptual core.

This "uniform core message" of the precautionary principle is most recognisably reflected in Principle 15 of the Rio Declaration, ${ }^{256}$ which, because of being the most widely accepted

${ }^{253}$ David Freestone and Ellen Hey, above n 9, at 13. John S Applegate, above n 9, at 26.

${ }^{254}$ Arie Trouwborst, above n 2, at 245.

${ }^{255}$ James Cameron and Juli Abouchar, above n 2, at 46. James Cameron "The Precautionary Principle in International Law" in Tim O'Riordan, James Cameron and Andrew Jordan (eds), above n 143, at 116.

${ }^{256}$ Arie Trouwborst, above n 2, at 245. James Cameron, Will Wade-Gery and Julie Abouchar, above n 251, at 46 . 
international formulation of the precautionary principle, is now the most authoritative international statement of the principle. ${ }^{257}$ Specifically, it provides: ${ }^{258}$

[i]n order to protect the environment, the precautionary approach shall be widely applied by States according to their capabilities. Where there are threats of serious or irreversible damage, lack of full scientific evidence shall not be used as a reason for postponing cost-effective measures to prevent environmental degradation.

\section{A common structure}

Comprehensive examination of the various precautionary principle formulations also discloses a common structure. In particular, each is comprised of: ${ }^{259}$

(1) a "precautionary trigger", which prescribes the factors, or rather, risk thresholds, which if met trigger recourse to the precautionary principle (i.e. they stipulate the circumstances when precautionary measures are warranted); ${ }^{260}$ and

(2) a "precautionary response", which prescribes what precautionary action is warranted (i.e. what the decision-maker can or must do when confronted with a given risk). ${ }^{261}$

${ }^{257}$ Daniel Bodansky, above n 245, at 383. Philippe Sands, above n 9, at 269; John S Ahteensuu "The Taming of the Precautionary Principle” 27 (2002) Wm \& Mary Envtl L \& Pol'y Rev 13 at 13. Simon Marr, above $n$ 11 , at 7 .

258 John S Ahteensuu, above n 257, at 13. Simon Marr, above n 11, at 7.

${ }^{259}$ Daniel Bodansky, above n 245, at 386. Commission of the European Communities "Communication from the Commission: on the precautionary principle" (COM 1, Brussels, February 2000) at 13. Noah M Sachs "Rescuing The Strong Precautionary Principle From Its Critics" (2011) (4) University of Illinois Law Review 1285 at 1338; John S Applegate, above n 9, at 17.

${ }^{260}$ Daniel Bodansky, above n 245, at 387.

${ }^{261}$ Daniel Bodansky, above n 245, at 386. Jon M Van Dyke "Evolution and International Acceptance of the Precautionary Principle" in David D Cameron and Harry N Scheiber, above n 245, at 359. Gary E Marchant, above n 7, at 1800. Ronnie Harding and Elizabeth Fisher, above n 8, at 14 and 21. Simon Marr, above n 11, at 79. Stephen Gardiner, above n 245, at 36. 
Pointing to a representative cross-section of precautionary principle formulations, Sandin observes that the precautionary trigger in each can be further broken down into the: ${ }^{262}$

(1) "threat dimension", which specifies the minimum level (i.e. gravity) of the potential harm (or "possible threat") that is required in order to invoke the principle; and

(2) "uncertainty dimension", which specifies the lowest level of knowledge about the threat of harm (e.g. knowledge as to its nature, extent of impact and causal relationship with the activity in question) that is required to invoke the principle.

Furthermore, he notes that the precautionary response in each formulation is also further broken down into the:

(1) "action dimension", which specifies how to respond to the identified threat; and

(2) "command dimension", which specifies the strength of the decision-makers duty to implement the prescribed precautionary action (e.g. whether precautionary action is discretionary a or a compulsory response).

In applying this analytical framework to the Rio Declaration formulation, it can be shown that the precautionary principle entails:

(1) a threat dimension, expressed as "threats of serious or irreversible environmental damage";

(2) an uncertainty dimension, expressed as "lack of full scientific certainty";

(3) an action dimension, expressed as "measures to prevent environmental degradation"; and

(4) a command dimension expressed as "...[uncertainty] should not be used as a reason for postponing".

$\overline{262}$ Per Sandin, above n 245, at 890. Runyu Wang “The precautionary principle in maritime affairs" (2011) 10(2) WMU J Marit Affairs 143 at 149. Daniel Bodansky, above n 245, at 386. 
As will be shown later in this chapter, this analytical framework is extremely useful when applying the precautionary principle in practice. In particular, it provides a structured approach to applying it and, importantly, operates as the starting point for identifying the legal content and parameters of a given formulation.

\section{The essence of the precautionary principle}

Drawing on a comprehensive review of precautionary principle formulations, Freestone and Hey observe that common to each are three elements, which together make up the "essence" of the precautionary principle and key considerations that assist with ascertaining what proper implementation of precaution entails generally. ${ }^{263}$ Logically any meaningful consideration of the precautionary principle and how it ought to be applied must start with a firm understanding of these elements.

\section{(a) First fundamental element}

The first element is a shift from focusing on determining acceptable levels of insult that a receiving ecosystem can assimilate, to an approach that seeks to minimise harm as much as possible. In this regard, the precautionary principle instead looks to practices and technology that will eliminate or at least reduce human impacts. In this regard, as Barton notes, owing to the scientific uncertainty that flows from the limited ability of science: ${ }^{264}$

...to determine accurately the effect of human activities, especially in light of cumulative and synergistic effects...the precautionary principle advocates giving the environment room to manoeuvre and recognizes that environmental tolerance thresholds "should not even be approached, let alone breached.

Thus, stemming from this recognition of uncertainty and limited predictability, proper application of precaution entails "safeguarding ecological space". As Cameron et al note,

\footnotetext{
${ }^{263}$ David Freestone and Ellen Hey, above n 9, at 12-13.

${ }^{264}$ Charmian Barton, above n 75 at 512. Timothy O'Riordan and James Cameron, above n 123, at 17. Simon Marr, above n 11, at 26.
} 
"because we cannot be sure of how tolerant ecosystems are to human intervention, it is necessary to leave ecological space as a buffer against ignorance", by deliberately holding back from possible harmful use of the environment. ${ }^{265}$ This shift is exemplified in the text of the 1991 Convention on the Ban of Import into Africa and the Control of Transboundary Movement and Management of Hazardous Wastes Within Africa, which states: ${ }^{266}$

The parties shall cooperate with each other in taking the appropriate measures to implement the precautionary principle to pollution prevention through application of clean production methods, rather than pursuit of a permissible emissions approach based on assimilative capacity assumptions.

On the above basis, precaution entails a shift away from policies based on "dilute and disperse" and identifying thresholds of harm that ecosystems can tolerate (and in turn allowing activities to operate up to such limits), to those based on "minimisation and containment" of harmful human impacts to ecosystems. Thus, in practice the precautionary principle in part focuses on employing clean methods of production and technological advancement to achieve such minimisation. ${ }^{267}$

\section{(b) Second fundamental element}

The second element is "preventative anticipation". ${ }^{268}$ Decision-makers should not rely on determinations of detrimental effects after an activity has taken place, but instead attempt to ascertain the possible negative impacts prior to the activity taking place and take positive steps to avoid harm in the first place. This rationale for this is explored and explained at length in Chapter IV.

(c) Third fundamental element

\footnotetext{
${ }^{265}$ Tim O’Riordan, James Cameron and Andrew Jordan, above n 143, at 19.

${ }^{266}$ Arie Trouwborst, above n 2, at 19.

${ }^{267}$ David Freestone and Ellen Hey, above n 9, at 12-13.

${ }^{268}$ David Freestone and Ellen Hey, above n 9, at 13. Timothy O'Riordan and James Cameron, above n 123, at 17 .
} 
The third element involves a shift away from the short-term nature of cost-benefit analysis under a traditional approach (i.e. short-term planning horizons that are an inevitable consequence of requiring proof of causation before action) towards recognition of: "the need for long-term, holistic economic considerations, accounting for, among other things, environmental degradation and the costs of waste treatment" ${ }^{269}$ In doing so, it acknowledges that the acceptability of costs associated with environmental protection must be considered within the context of the matters discussed in Chapter IV. In this regard O'Riordan and Cameron note: $:^{270}$

[it] introduces a bias to conventional cost benefit analysis to include a weighting function of ignorance, and the likely dangers for future generations if the life support capacities [of ecosystems] are undermined when such risks could be avoided.

The cost of protective measures therefore needs to be weighted against the long-term nature of harm. Furthermore, precaution acknowledges that, given the potential severity of harm and uncertainty as to whether an activity will cause it to materialise, the cost of taking environmental steps that later prove to be redundant pales in comparison to the cost of failing to act when needed to prevent significant or permanent harm. ${ }^{271}$ On this basis the precautionary principle recognises that it is acceptable for regulators to impose the cost of protective measures, which in time may prove unnecessary, as this is by far the lesser of two evils.

\section{B Going beyond the conceptual core}

Beyond the skeletal framework of the conceptual core and common structure of the precautionary principle, there is little in the way of agreed normative flesh. The main substantive differences that persist between formulations typically relate to or stem from one or more of the four dimensions identified above. Based on such differences,

\footnotetext{
${ }^{269}$ Ellen Hey, above n 79, at 308.

270 Timothy O'Riordan and James Cameron, above n 123, at 17.

271 Timothy O'Riordan and James Cameron, above n 123, at 17. ..
} 
formulations are grouped in terms of the strength of environmental protection they afford and the level of normative character they possess. In this sense versions of the precautionary principle sit along a continuum ranging from weak to strong. ${ }^{272}$

\section{Weak formulations}

Weak formulations offer less environmental protection and closely resemble (or even preserve) the traditional environmental management status quo. Furthermore, they are usually not sufficiently prescriptive to constitute legal norms, but, rather, are guiding principles intended to overlay the application of related legal norms. In terms of the precautionary trigger, such versions typically feature: ${ }^{273}$

(1) a high harm threshold, where the principle is triggered by "threats of serious or irreversible harm", thereby leaving lesser forms of harm to be managed under a traditional approach, presumably on the understanding the assimilative capacity approach adequately manages such lesser forms of harm; and

(2) a higher certainty threshold, which does not go as far as demanding the quality and quantity of scientific evidence required to prove causation, but nevertheless requires such a large body of scientific proof before triggering a precautionary response that in practice it offers little respite from the demands of causation than stronger versions.

As to the "precautionary response", weak versions usually only go as far as stating that lack of scientific certainty shall not be used as a reason for postponing taking steps to avoid harm. ${ }^{274}$ As such, they afford much less in the way of environmental protection, as they do not:

${ }^{272}$ David Flemming “The Economics of Taking Care: An Evaluation of the Precautionary Principle” in David Freestone and Ellen Hey (eds), above n 2, at 147. See also John S Applegate, above n 9.

273 Jonathan Wiener, above n 241, at 604; Daniel Bodansky, above n 245, at 384. See, for example, United Nations Rio Declaration on Environment and Development, Principle 15, UN Doc.A/CONF.151/26 (vol. I) (1992); 31 ILM 874 (1002). Convention on Biological Diversity opened for signature 5 June 1992,1760 UNTS 79, 142 (entered into force 29 December 1993). and United Nations Framework Convention on Climate Change, art 3(3), opened for signature 9 May 1992, 1771 UNTS 10.

274 Daniel Bodansky, above n 245, at 384; Jonathan Wiener, above n 241, at 604. 
(a) prescribe any specific precautionary measures to be taken in response to an identified threat (i.e. measures that are in substance effective and precautionary in nature);

(b) impose a positive duty to act when the trigger thresholds have been met, ${ }^{275}$ rather they merely permit taking action ahead of scientific certainty rather than compel it. ${ }^{276}$

Many commentators assert that due to the above such formulations lack the fundamental character of a legal norm because there is no objective behavioural standard that one is required to meet. ${ }^{277}$

Finally, weak formulations often incorporate considerations of the cost of preventative measures and their alternatives, ${ }^{278}$ thereby elevating the primacy of cost considerations as an express justification for not electing to take anticipatory protection.

\section{Strong formulations}

In contrast, strong formulations offer more environmental protection in a few ways. First, their precautionary trigger typically entails a much lower harm threshold, (i.e. one that is triggered by a much larger range of environmental impacts). In terms of the certainty threshold, strong formulations either: ${ }^{279}$

(1) possess a low certainty threshold, which demands the production of considerably less scientific evidence before the precautionary response is triggered; and/or

\footnotetext{
275 Daniel Bodansky, above n 245, at 384.

276 Jonathan Wiener, above n 241, at 604.

277 Mark Geistfeld "Implementing the Precautionary Principle" (2001) 31 Envtl L Rep 11,326 at 11,326, citing Christopher Stone, above n 159. Konrad Von Moltke, above n 66, at 101.

${ }^{278}$ Catherine J Iorns Magallanes, above n 8, at 5-6.

279 Judith Jones and Simon Bronitt "The burden and standard of proof in environmental regulation: the precautionary principle in an Australian administrative context" in Elizabeth Fisher, Judith Jones and Rene von Schomberg (eds), above n 159, at 137-145. Jamie Benidickson, above n 159, at D-43 to D-44. The Royal Society of Canada Elements of Precaution: Recommendations for the Regulation of Food Biotechnology in Canada (Health Canada, Canadian Food Inspection Agency and Environment Canada, Expert Panel Report, January 2001) at 196 and 201-202. James Cameron and Will Wade-Gery, above n 75, at 18.
} 
(2) reverse the burden of proof, so that it is incumbent on the proponent of an activity to prove that an activity is safe before they may undertake it.

Finally, strong versions also usually entail a prescriptive precautionary response that: stipulates the steps to be taken, which themselves can vary in strength; and, creates a positive duty to act (i.e. take such prescribed precautionary steps), once it has been demonstrated that the precautionary trigger thresholds are met. Such a positive duty may be absolute (i.e. compulsory), or subject to a tightly prescribed discretion (i.e. one that specifies a narrow range circumstances where nonetheless, precautionary measures may be foregone). It is these characteristics, which imbue the strong formulations of the principle with normative character and as such, separates them from those versions that are more characteristic of a guiding principle or aspirational statement.

\section{German origins of the precautionary principle}

A first express articulation of precaution as a legal principle can be traced to German environmental law in the 1970s. ${ }^{280}$ Therefore, it is unsurprising that Germany has done the most in terms of unpacking the substantive content of their formulation of the precautionary principle, known in as the 'Vorsorgeprinzip', and in terms of stepping out what its proper application involves in practice. ${ }^{281}$ The precautionary principle's rapid uptake and in turn rapid emergence as a general principle of international law stemmed from the Vorsorgeprinzip adoption at an international level. Thus, consideration of the principle's incorporation into Germany’s existing risk-based environmental legal system is instructive, because arguably, an equivalent version of the precautionary principle has incorporated directly into New Zealand environmental legislation. ${ }^{282}$

In response to growing claims "over long-term...possibly irreversible habitat damage associated with acid rain", ${ }^{283}$ the Vorsorgeprinzip, which translates to precautionary

\footnotetext{
${ }^{280}$ Arie Trouwborst, above $\mathrm{n} 2$, at 17.

${ }^{281}$ Konrad Von Moltke, above n 66, at 102.

${ }^{282}$ Konrad Von Moltke, above n 66, at 102.

${ }^{283}$ Arie Trouwborst, above n 2, at 17. Claudia Saladin "Precautionary Principle in International Law" (2000) 6 Int J Occup Environ Health 270 at 270. Sonia Boehmer-Christiansen "The Precautionary Principle in
} 
principle, ${ }^{284}$ was codified in air pollution legislation. As Jordan notes, the Vorsorgeprinzip was regarded as a strong formulation of the precautionary principle. ${ }^{285}$ At its core was the belief that regulatory agencies and government should move as early as is possible, to minimise environmental risks by anticipating danger and, if possible, preventing it. ${ }^{286}$ Indeed, the literal meaning of the Vorsorgeprinzip is the principle of "beforehand or prior care or worry". ${ }^{287}$

By 1976, the Vorsorgeprinzip had become the cornerstone of German environmental law enshrined in legislation as a Gebot - "vague legal commandment" - intended to guide administrators in their dealings with polluters. ${ }^{288}$

\section{Nebulous concept}

An important feature of the Vorsorgeprinzip is that it is not a tightly prescribed norm, but, rather, a nebulous principle covering ".... a territory of meaning that combines caution with caring for the future, as well as providing for it..." ${ }^{289}$ As a result, one cannot glean from the basic core definition the full battery of this concepts substantive legal content.

Germany - Enabling Government' in T O'Riordan, T and J Cameron, J (eds) Interpreting the Precautionary Principle (Cameron May, London, 1994) 31 at 31 and 36. James Cameron and Juli Abouchar, above n 2, at 43; Tim O'Riordan, James Cameron and Andrew Jordan "The Evolution of the Precautionary Principle in Tim O'Riordan, James Cameron and Andrew Jordan (eds), above n 143, at 11.

${ }^{284}$ James Cameron and Juli Abouchar "The Precautionary Principle: A Fundamental Principle of Law and Policy for the Protection of the Global Environment" (1991) 14 BC Int'l \& Comp L Rev 1 at 7. Runyu Wang, above $\mathrm{n} 262$, at 143 .

${ }^{285}$ Andrew Jordan “The Precautionary Principle in the European Union” in Tim O'Riordan, James Cameron and Andrew Jordan (eds), above n 143, at 145.

${ }^{286}$ Andrew Jordan and Timothy O'Riordan, above n 250, at 33.

${ }^{287}$ Sonia Boehmer-Christiansen, above n 283, at 31 and 34.

${ }^{288}$ Arie Trouwborst, above n 2, at 17; Sonia Boehmer-Christiansen, above n 283, at 36 to 37; Warwick Gullett "Environmental Protection and the 'Precautionary Principle': A response to scientific uncertainty in Environmental management" (1997) 14 EPLJ 52 at 55.

${ }^{289}$ Sonia Boehmer-Christiansen, above n 283, at 38 . 
Within this territory of meaning, the Vorsorgeprinzip encapsulates "notions of risk prevention, cost effectiveness...ethical responsibilities towards maintaining the integrity of natural systems, and the fallibility of human understanding" ${ }^{290}$ In this regard it: ${ }^{291}$

...[endows] public authorities with the responsibility for the protection of the natural foundations of life and of maintaining the physical world intact for the future and present generations

Inclusion of this principle in the corpus of policy principles amounted to a recognition by the German Government that there were physical limits to economic growth, that humans had a particular moral responsibility for the earth, that there were non-economic values in environmental protection, and that there was a need for ecological understanding. ${ }^{292}$

In addition to the above, the Vorsorgeprinzip had an economic rationale. As one author notes, Vorsorge was a significant component part of a wider set of ideas or an ideology they label "ecological modernization": ${ }^{293}$

This formulation suggests that the relationship between environmental protection and economic development is not necessarily antagonistic, but can, with the right mix of inducements, be mutually supportive.

In short, Germany asserted that high standards of environmental protection provide an opportunity for economic growth, rather than placing a constraint upon it.

\section{Beyond the duty to avoid harm}

The Vorsorgeprinzip imposes a more onerous duty on policy makers and administrators than the traditional tortious legal duty 'sorgfaltspflicht' (duty of care or

$\overline{290}$ Tim O'Riordan, James Cameron and Andrew Jordan "The Evolution of the Precautionary Principle" in Tim O'Riordan, James Cameron and Andrew Jordan (eds), above n 143, at 11.

${ }^{291}$ Sonia Boehmer-Christiansen, above n 283, at 55.

${ }^{292}$ Sonia Boehmer-Christiansen, above n 283, at 41.

${ }^{293}$ Jordan \& O'Riordan above n 250, at 33. 
'duty to take care') to avoid harm. Unlike Vorsorge, the standard duty to take care does not require that the future be taken into account. Conversely, Vorsorge is inherently futurefocused. It requires decision-makers to consider the future risks that may not be apparent at the time of making a decision, due to the limited ability of science to understand and forecast the impacts of our actions.

Accordingly, linked to Vorsorge are concepts such as investment in the future, liability and to the reversal of the burden of proof. In this regard, at a government policy level the Vorsorgeprinzip authorised German regulators to take certain key steps regarded as being integral to any meaningful action to protect the environment. ${ }^{294}$

First, at the core of this early conception of the precautionary principle; “...was the belief that society should seek to avoid environmental damage by careful forward planning, blocking the flow of potentially harmful activities". ${ }^{295}$ In particular, it acknowledged that “...[e]nvironmental policy is not fully accomplished by warding off imminent hazards and the elimination of damage which has occurred, ${ }^{296}$ primarily because harm is often significant and/or irreversible, and furthermore, often:

(1) manifests itself through complex, non-linear, time-delayed, and cumulative ecological processes, often as a result of cumulative human impacts generated by an array of temporally and spatially diffuse activities; and

(2) cannot be predicted or sufficiently proven by science in time.

In turn, the Vorsorgeprinzip recognises that in order to bring such dangers, which have not yet been scientifically proven under some form of environmental control, ${ }^{297}$ regulators must

\footnotetext{
${ }^{294}$ Arie Trouwborst, above n 2, at 17; Andrew Jordan and Timothy O'Riordan, above n 250, at 33; James Cameron and Juli Abouchar, above n 284, at 6-7.

${ }^{295}$ Joe Tickner and Carolyn Raffensperger, above n 76, at 4.

${ }^{296}$ Umbeltbericht ' 76 - Fortschreibung des Umweltprogramms der Bundesregierung of 14 July 1976; English text from Konrad Von Moltke "The Vorsorgeprinzip in West German Environmental Policy", $12^{\text {th }}$ Report of the Royal Commission on Environmental Pollution, HMSO 1988, cited in James Cameron and Juli Abouchar, above $\mathrm{n} 2$, at 31 .

${ }^{297}$ James Cameron and Juli Abouchar, above n 284, at 7.
} 
be able to intervene when the risks of environmental damage "are not [yet] identifiable" in a causal sense. ${ }^{298}$ Furthermore, it recognises that to do so effectively, policy makers must undertake long-term environmental planning that looks ahead and addresses environmental threats at the earliest possible opportunity. In this sense it acknowledges that given the scientific uncertainty and limited predictability of science explored in Chapter IV, the traditional approach of requiring proof of causation ahead of action, severely limits the temporal range of environmental planning (i.e. limits it addressing to more immediate and readily predictable harms). Thus, embedded in the notion of Vorsorge is the view that longterm government planning for the environment (regarding what, in order to protect the environment, should or should not be done) is axiomatic with successfully anticipating and avoiding harm that arises in such a manner. In this respect, Weale contrasts the Vorsorge with a traditional approach stating that, since these ecological realities make it difficult to muster sufficient proof that a particular long-term plan and its associated interventions are necessary, the traditional approach can be: ${ }^{299}$

\begin{abstract}
"characterised...in terms of an absence of explicit and medium- or long-term objectives on one hand, and unplanned, and incremental decision making in which policies are arrived at by a continuous process of adjustment between a plurality of actors on the other"
\end{abstract}

Regarding the types of intervention, closely related to Vorsorgeprinzip is the concept of Gefahrenabwehr, which translates into 'defence against dangers and threats'. ${ }^{300}$ Accordingly, the greater the threat, the greater the need for Vorsorge and, in turn, the more power public authorities will need in order to be able to put in place environmental planning measures that are capable of effectively guarding against such threats.

In support of the need to plan long term, the Vorsorgeprinzip also emphasises the need for "early detection of dangers...through comprehensive research". This is asserted on the basis that such research is critical to such long term planning and anticipation of harm

\footnotetext{
298 Andrew Jordan, above n 285, at 144.

299 A Weale The new politics of pollution (Manchester University Press, London, 1992) at 81.

${ }^{300}$ Sonia Boehmer-Christiansen, above n 283, at 35.
} 
generally. In this regard, the role of science was most important at the earlier stages of policymaking, but less so during implementation of the law produced by such policies (namely, during a consenting process) where the emphasis then shifted to technology (see below).

Linked to the above and the limited predictability of science generally, the Vorsorgeprinzip seeks to reduce the impacts of activities (i.e. prevent them from encroaching on carrying capacity of receiving ecosystems) by promoting technical developments that reduce harm as much as possible. On this note, in contrasting the Vorsorgeprinzip with traditional legal approaches, Boehmer-Christiansen observes: ${ }^{301}$

Vorsorge demands more than care, it goes beyond Sorgflatspflicht, which literally means duty to take care and does not require that the future is taken into account. Vorsorge is readily linked to the concepts of investment...

For this reason it has been used to overcome cost/benefit proportionality requirements, which essentially only take into account short-term considerations that are readily proven, thereby enabling regulators to justify the use of the best available technology (i.e. by reference to longer-tem but less easily proven considerations). ${ }^{302}$

Finally, and above all else, the Vorsorgeprinzip provides that decision-makers must be entitled to act in advance of scientific proof of harm. It recognises that, as scientific uncertainty surrounds the kinds of harm that only long-term planning can address, ${ }^{303}$ imposing an obligation to prove causation through science paralyses regulators' ability to implement those long-term planning and early intervention measures needed to anticipate and avoid such harm. Thus, the Vorsorgeprinzip was prompted by the recognition of the

\footnotetext{
${ }^{301}$ Sonia Boehmer-Christiansen, above $\mathrm{n} 283$, at 38 .

${ }^{302}$ Sonia Boehmer-Christiansen, above n 283, at 50.

${ }^{303}$ A Weale, above $\mathrm{n} 299$, at 80 . As is often the case, future impacts from proposed activities, or impacts from existing activities yet to inflict serious or irreversible damage, are less manifest or have not manifested themselves at all.
} 
German Government that, in order to be capable of anticipating and preventing harm through the above measures, policy-makers must be entitled to: ${ }^{304}$

go 'beyond science', in the sense of being [required or entitled] to make decisions where the consequences of alternative policy options are not determinable within a reasonable margin of error and where potentially high costs are involved in taking action.

\section{$D$ The precautionary principle in international law}

The precautionary principle introduced first at international law in the marine context during the International North Sea Ministerial Conference, where the participating states had convened to formulate a coordinated response to trans-boundary pollution in the North Sea. ${ }^{305}$ At this conference, Germany successfully lobbied for the adoption of a translated version of the Vorsorgeprinzip by the participating states. As a result, the parties implicitly incorporated into the preamble of the 1984 Ministerial Declaration of the parties to the conference. Specifically, this formulation provided: ${ }^{306}$

damage to the marine environment can be irreversible or remedial only at considerable expense and over long periods and that, therefore, coastal states and the EEC must not wait for proof of harmful effects before taking action.

$\overline{304}$ For example: to impose a legal requirement that private individuals undertake precautionary environmental actions such as installing desulphurisation filters in flues. A Weale, above n 303 , at 80 and 81-82.

${ }^{305}$ Sonia Boehmer-Christiansen, above n 283, at 31. Konrad Von Moltke, above n 296, at 57. Andrew Jordan and Timothy O'Riordan, above n 250, at 34. David Freestone and Ellen Hey, above n 9, at 4 and 5. see also Peter Ehlers, "The History of the International North Sea Conferences", in David Freestone and Ton Ijlstra (eds) The North Sea: Basic Legal Documents on Regional Environmental Co-operation (Kluwer Law International, The Hague, 1991) 3 at 5. Simon Marr, above n 11, at 48. Ministry of the Environment and Energy, Danish Environmental Protection Agency "Ministerial Declarations: International Conferences on the Protection of the North Sea; Bremen, Germany, 1984. London, United Kingdom 1987. The Hague, The Netherlands, 1990" (1995) OSPAR Commission. Noelle Eckley and Henrik Selin “All talk, little action: precaution and European chemicals regulation" (2004) 11(1) JEPP 78 at 81. Andrew Jordan, above n 285, at 146. David Freestone and Ellen Hey, above n 9, at 4.

${ }^{306}$ The 1984 Ministerial Declaration of the International Conference on the Protection of the North Sea (1 November 1984), Preamble. 
It is worth noting that the above introduced to international law the idea that the precautionary principle may be justified on economic grounds (that is, preventative measures to avoid harm are less costly than remedial measures). ${ }^{307}$

The 1987 Ministerial Declaration issued following the second North Sea Ministerial Conference contained the first express formulation of the precautionary principle. ${ }^{308}$ Equipped with the conceptual core outlined above, it provides: ${ }^{309}$

...in order to protect the North Sea from possibly damaging effects of the most dangerous substances, a precautionary approach is necessary which may require action to control inputs of such substances even before a causal link has been established by absolutely clear scientific evidence.

If the state of knowledge is insufficient, a strict limitation on emissions of pollutants at source should be imposed for safety reasons...

In concert with adopting this express formulation, the participants also agreed to: ${ }^{310}$

Accept the principle of safeguarding the marine ecosystem of the North Sea by reducing emissions of substances that are persistent, toxic and liable to

\footnotetext{
307 Philippe Sands, above n 9, at 269.

${ }^{308}$ James Cameron, above n 247, at 30-31. David Freestone and Ellen Hey, above n 9, at 5. Philippe Sands, above n 9, at 269. Simon Marr, above n 11, at 5. Lothar Gundling "The Status in International Law of the Precautionary Principle of Precautionary Action" (1990) 23, 24 Int'1 J of Estuarine \& Coastal L 23 at 24.

${ }^{309}$ Ministerial Declaration of the Second International Conference on the Protection of the North Sea, 2425 November 1987, articles VII and XV(i)C10 as cited in Arie Trouwborst, above n 2, at 25.

${ }^{310}$ Ministerial Declaration of the Second International Conference on the Protection of the North Sea, 2425 November 1987, articles VII [XVI]. As Iorns also notes above n 8: "In 1989 the Paris Commission, which was established by the Convention for the Prevention of Marine Pollution from Land-Based Sources, adopted the Principle of Precautionary Action, which incorporated a similar statement. This approach was also adopted in 1989 in relation to the Mediterranean Sea by the parties to the Convention for the Protection of the Mediterranean Sea Against Pollution, opened for signature 16 February 1976, 15 ILM 290 (entered into force 12 February 1978) ('Barcelona Convention') and by the Nordic Council in relation to pollution of the Northern Seas: Nordic Council, International Conference on Pollution of the Seas (October 1989)".
} 
bioaccumulate at source by the use of the best available technology and other appropriate measures. This applies especially when there is reason to assume that certain damage or harmful effects on the living resources of the Sea are likely to be caused by such substances, even where there is no scientific evidence to prove a causal link between emissions and effects ('the principle of precautionary action').

While the above is not legally binding, this weaker precautionary principle formulation operated as a non-binding "hortatory" principle designed to guide regulatory and policy decisions made at the domestic level by each state going forward. ${ }^{311}$ The 1987 declaration also went on to state that marine ecosystems should be safeguarded with the best available technology "even where there is no scientific evidence to prove a causal link between emissions and effects". While declaration's precautionary principle definition does not capture this additional provision, it is linked to the principle's application by member states.

Although the 1987 declaration was regional and dealt entirely with dangerous sea pollutants, most academics acknowledge "its drafting and subsequent ratification marks the beginning of widespread international acceptance and employment of the precautionary principle". 312

Many commentators also note that the precautionary principle gained a footing in international law because of its inclusion in all but name in the 1982 World Charter for Nature. ${ }^{313}$ Specifically Article 11 of the charter contained what was in substance, "a deliberation guiding version of the" precautionary principle. ${ }^{314}$ Specifically, this

\footnotetext{
311 James Cameron and Juli Abouchar, above n 284, at 5; Simon Marr, above n 11, at 48.

${ }^{312}$ Scott Lafranchi "Surveying the Precautionary Principle's Ongoing Global Development: The Evolution of an Emergent Environmental Management Tool” (2005) 32 BC Envtl Aff L Rev 679 at 680. Simon Marr, above $\mathrm{n} 11$, at 47 .

313 Article 11, World Charter for Nature 1982 UN Doc. GA RES 37/7. Simon Marr, above n 11, at 47. Scott Lafranchi, above n 312, at 682.

${ }^{314}$ Simon Marr, above n 11, at 47.
} 
formulation provides as follows: ${ }^{315}$

Activities which might have an impact on nature shall be controlled, and the best available technologies that minimize significant risks to nature or other adverse effects shall be used; in particular:

(a) Activities which are likely to cause irreversible damage to nature shall be avoided;

(b) Activities which are likely to pose a significant risk to nature shall be preceded by an exhaustive examination; their proponents shall demonstrate that expected benefits outweigh potential damage to nature, and where potential adverse effects are not fully understood, the activities should not proceed;

(c) Activities which may disturb nature shall be preceded by assessment of their consequences, and environmental impact studies of development projects shall be conducted sufficiently in advance, and if they are to be undertaken, such activities shall be planned and carried out so as to minimize potential adverse effects.

While Article 11 does not espressly mention precaution it embodies the fundamental precautionary elements that collectively comprise the precautionary principle. Furthermore, it is regarded as one of the strongest formulations of the precautionary principle because it: $^{316}$

(a) reverses the burden of proof by making it incumbent on the proponent of a potentially harmful activity to prove first that the activity is harmless.

(b) bans any potentially harmful activity if there is scientific uncertainty (i.e. regarding its effects) is such that it prevents a complete impact assessment ex ante.

Finally, like the Vorsorgeprinzip, Article 11 expressly calls on policy makers (through subarticles 11(a) to (c)) to take varying levels of environmental action in proportion to the

\footnotetext{
${ }^{315}$ Article 11, World Charter for Nature 1982 UN Doc. GA RES 37/7. Simon Marr, above n 11, at 47.

${ }^{316}$ Sonia Boutillon "The Precautionary Principle: Development of an International Standard" (2002) 23 Mich J Int'l L 429 at 433.
} 
intensity of the risk posed by a given activity.

The Bergen Ministerial Declaration on Sustainable Development was the first international instrument to treat the precautionary principle as a guiding principle of general application and to state that inextricably linked to achieving sustainable development is the proper application of the precautionary principle. ${ }^{317}$ Its formulation provides: ${ }^{318}$

In order to achieve sustainable development, policies must be based on the precautionary principle. Environmental Measures must anticipate, prevent and attack the causes of environmental degradation. Where there are threats of serious or irreversible damage, lack of full scientific certainty should not be used as a reason for postponing measures to prevent environmental degradation.

The declaration was the product of the 1990 Bergen Conference on Sustainable Development, one of a series of regional meetings held in advance of the United Nations Conference on Environmental Development (“UNCED”), which produced Agenda 21 and the Rio Declaration. As Sands explains: $:^{319}$

Central to this text is the element of anticipation, reflecting the need for effective environmental measures to be based upon actions which take a longer-term approach and which might predict changes in the bias of our scientific knowledge.

In addition, it was the first formulation to link the implementation of the principle (that is taking action in spite of uncertainty) to the risk of a "serious or irreversible damage" to the environment. ${ }^{320}$ Regarding this latter substantive element, Boutillon notes, "[t]his baseline for intervention has rapidly become a landmark of the precautionary principle". ${ }^{321}$

\footnotetext{
${ }^{317}$ Philippe Sands, above n 9, at 269. Sue Elworthy and Jane Holder Environmental Protection: Text and Materials (Cambridge University Press, Cambridge, 1997) at 154. J Segal "An Industry Perspective on the Precautionary Principle” in Ronnie Harding and Elizabeth Fisher, above n 2, at 73.

${ }^{318}$ Bergen Ministerial Declaration on Sustainable Development in the ECE Region, 16 May 1990 at [7].

319 Philippe Sands, above n 9, at 269.

${ }^{320}$ Philippe Sands, above n 9, at 269; Sue Elworthy and Jane Holder, above n 317, at 154.

${ }^{321}$ Sonia Boutillon, above n 316 , at 433.
} 


\section{$1 \quad$ Widespread adoption of the precautionary principle}

Since its introduction as an express principle to the sphere of international environmental law, ${ }^{322}$ the precautionary principle has risen rapidly and now enjoys "wide, unprecedented recognition", ${ }^{323}$ so much so that it is frequently heralded as the most fundamental 'norm' of international law to better protect the environment. ${ }^{324}$ As one commentator aptly notes (summarising the view of most), "it occupies a central place in any realistic strategy for the achievement of sustainable development, and particularly sustainable use of the planet's natural resources". 325

The principle's importance is evinced by the fact that, since its emergence at international law, it has featured in almost every international law instrument tasked with regulating human interaction and relationship with the natural environment. ${ }^{326}$ As Lafranchi notes: ${ }^{327}$

These international instruments have addressed a broad spectrum of environmental issues, ranging from general environmental policy to precise issues of environmental concern. Moreover, both soft and hard law instruments have

\footnotetext{
$\overline{322}$ Clauses containing the hallmarks of precaution appeared in international law instruments before the first explicit reference to the precautionary principle in international instruments came about. However it was not until this point in time that it first appeared as an express general principle sui generis. D Freestone and Z Makauch "The New International Environmental Law of Fisheries: The 1995 UN Straddling Stocks Convention" (1996) 7 EIEL 3 at 14; J M Van Dyke "Applying the Precautionary Principle to Ocean Shipments of Radioactive Materials" (1996) 27 ODIL 379 at 390, note 12 as cited in Arie Trouwborst, above n 2 , at 20 , note 88 .

${ }^{323}$ Philippe Sands, above n 9, at 269.

${ }^{324}$ David VanderZwaag "The Precautionary Approach and the International Control of Toxic Chemicals: Beacon of Hope, Sea of Confusion and Dilution" (2011) 33(3) Hous J Int'l L 605 at 607. James Cameron and Juli Abouchar, above n 284, at 2. Ellen Hey, above n 79, at 303. Jonathan Wiener, above n 241, at 599. Gary E Marchant and Kenneth Mossman Arbitrary and Capricious: The Precautionary Principle in the EU Courts (AEI Press, Washington, 2004) at 1. Nicolas de Saadeleer, above n 65, at 184. Daniel Bodansky, above n 245 at 381-386; David Van der Zwaag, above n 5, at 363. Daniel Bodansky, above n 245, at 381.

${ }^{325}$ David Freestone, above n 12, at 134.

${ }^{326}$ Arie Trouwborst, above n 2, at 8. David Freestone and Ellen Hey, above n 9, at 3. David Freestone, above n 12, at 134 and 137. Simon Marr, above n 11, at 2. Arie Trouwborst, above n 75, at 7. David VanderZwaag, above n 5, at 356; Alexandre Kiss and Dinah Shelton, above n 43, at 205.

${ }^{327}$ Scott Lafranchi, above n 312, at 680 .
} 
embraced the precautionary principle, meaning that both binding and nonbinding instruments have endorsed a precautionary approach.

Significantly, the precautionary principle has become an especially prominent feature in international legal instruments established to manage and protect the marine environment. ${ }^{328}$ This is essentially due to the fact scientific uncertainty pervades the ocean space in unparalleled abundance (i.e. by comparison to terrestrial ecosystems), and that (as discussed in Chapters II and IV), owing to the fluid medium of marine ecosystems, harm caused in this space is particularly more mobile in nature. ${ }^{329}$

The subsequent North Sea conferences continued to approve the general application of the precautionary principle as a basis for action. ${ }^{330}$ Extension of the geographic scope of the precautionary principle's application occurred during the Oslo and Paris commissions ("OSPAR"). Specifically, in addition to re-iterating the concept, in 1989 the commission adopted various instruments, which fleshed out how to implement the precautionary principle. Instruments of note include: PARCOM Recommendation 89/2, which imposed the requirement that available technology be applied to land-based sources of pollution; and OSCOM Decision 98/1, which provided the dumping of industrial waste is subject to a "prior justification procedure". The latter requires states that intend to issue a permit for dumping industrial waste to demonstrate there are no practical alternatives on land and that doing so will not cause harm to the marine environment. ${ }^{331}$

The above culminated in the precautionary principle's incorporation into The Convention for the Protection of the marine Environment of the North-East Atlantic (“OSPAR Convention”), which provided: ${ }^{332}$ 
The precautionary principle, by virtue of which preventative measures are to be taken when there are reasonable grounds for concern that substances or energy introduced, directly or indirectly, into the marine environment may bring about hazards to human health, harm living resources and marine ecosystems, damage amenities or interfere with other legitimate uses of the sea, even when there is no conclusive evidence of a causal relationship between the inputs and effects.

Of note is the fact this formulation possesses a low certainty threshold. In particular it provides that "no conclusive evidence of a causal relationship" is required to trigger a precautionary response. Thus, as little in the way of scientific proof is required before precautionary measures can be taken, this version is regarded one of the strongest precautionary principle formulations. ${ }^{333}$

Outside the European Union, the United Nations Environmental Planning (UNEP) governing council adopted the precautionary principle in relation to marine pollution and ocean dumping in $1989 .{ }^{334}$ In the following year, the Meeting of Parties to the London Dumping Convention also agreed to adopt a precautionary principle formulation which provides: ${ }^{335}$

...that in implementing the London Dumping Convention the Contracting Parties shall be guided by the precautionary approach to environmental protection whereby preventative measures are taken when there is reason to believe that substances or energy introduced into the marine environment are likely to cause harm even where there is no conclusive evidence to prove causal relations between inputs and their effects.

\footnotetext{
333 Nicolas de Saadeleer, above n 65, at 189.

${ }^{334}$ United Nations Environmental Planning Governing Council Decision on the Precautionary Approach to Marine Pollution, Including Waste-Dumping at Sea, Decision 15/27, UN GAOR 44 ${ }^{\text {th }}$ sess, Supp No 25 UN Doc A/44/25 152 (25 May, 1989) as cited in Catherine J Iorns Magallanes, above n 8, at 10.

335 Resolution LDC 44(14) on the Application of the Precautionary Approach to Environmental Protection within the Framework of the London Dumping Convention, Annex 2, Doc. LDC 14/16, December 301991.
} 
Again, this formulation indicated a willingness to adopt a strong formulation in relation to activities that result in marine pollution. Notably, this version also elucidated what an appropriate precautionary response entails in considerably more detail than other formulations: $:^{336}$

...the Contracting Parties shall take all necessary steps to ensure the effective implementation of the precautionary approach to environmental protection and to this end they shall:

(a) encourage prevention of pollution at its source, by the application of clean production methods, including raw material selection, product substitution and clean production technologies and processes and waste minimisation throughout society;

(b) evaluate the environment and economic consequences of alternative methods of waste management, including long-term consequences;

(c) encourage and use as fully as possible scientific and socio-economic research in order to achieve an improved understanding on which to base long-term policy options;

(d) endeavour to reduce risk and scientific uncertainty relating to proposed disposal operations;

(e) continue to take measures to ensure potential adverse impacts of dumping are minimised, and adequate monitoring is provided for early detection and mitigation of these impacts.

Following the London Convention, the principle was also adopted in the widely endorsed Rio Declaration (discussed above), and in Agenda 21. Of particular note is Chapter 17 of Agenda 21, which provides: ${ }^{337}$

A precautionary and anticipatory rather than reactive approach is necessary to prevent degradation of the marine environment. This requires inter alia, the

\footnotetext{
${ }^{336}$ Resolution LDC 44(14), above n 335.

${ }^{337}$ Agenda 21: A Programme for Action for Sustainable Development: Report of the UN Conference on Environment and Development, Chapter 22.5,[(c)], UN Doc A./Conf. 151/26 (13 June 1992).
} 
adoption of precautionary measures, environmental impact assessments, clean production techniques, recycling, waste audits and minimisation, construction and/or improvement of waste treatment facilities, quality management criteria for handling of hazardous substances, and a comprehensive approach to damaging impact from air, land and water. Any management framework must include the improvement of coastal human settlements and integrated management and development of coastal areas.

This is significant, not only because it represented global endorsement of the precautionary principle's application to marine management, but also because it ties its application to a number of specific measures that decision-makers must implement in order properly give effect to it. ${ }^{338}$ Commentators note that, although non-binding, Agenda 21 was significant because its adoption by over 165 signatory states indicated its elevation to a truly global level $^{339}$ and, arguably, constituted a salient example of state practice in support of the view that the principle had attained customary status. ${ }^{340}$

The scope of the precautionary principle's application was subsequently broadened to a wider array of environmental management issues because of its inclusion in a number of multilateral agreements that stemmed from Agenda 21 and the Rio Convention. For example, it was included in the United Nations Convention on Climate Change, which is particularly pivotal as it was a binding agreement. Its formulation of the principle was set out at Article 3(3), which provides: $:^{341}$

The Parties should take precautionary measures to anticipate, prevent or minimise the causes of climate change and mitigate its adverse effects. Where there are threats of serious or irreversible damage, lack of full scientific research should not be treated as a reason for postponing such measures, taking into account the

\footnotetext{
338 James Cameron and Juli Abouchar, above n 2, at 42.

${ }^{339}$ David Freestone, above n 12, at 141; James Cameron and Juli Abouchar, above n 2, at 267.

340 James Cameron and Juli Abouchar, above n 2, at 42; James Cameron and Juli Abouchar, above n 2, at 267; David Freestone, above n 12, at 141.

${ }^{341}$ United Nations Framework Convention on Climate Change, above n 273.
} 
policies and measures to deal with climate change should be cost-effective so as to ensure global benefits at the lowest possible cost.

This formulation is regarded as being one of the weakest formulations, primarily because of the text inclusion, which places an overriding emphasis on cost effectiveness. As Iorns notes, this is largely a product of political concern "arising from controversy and debate about the risks and costs of preventative measures and their alternatives". ${ }^{342}$ It is also likely the result of the fact the convention's binding nature.

Also of note was the principle's adoption in the widely endorsed Convention on Biological Diversity where in the preamble it notes: ${ }^{343}$

Where there is a threat of significant reduction or loss of biological diversity, lack of full scientific certainty should not be used as a reason form postponing measures to avoid minimisation of that threat.

Given versions of the principle relating to management of living resources, tend to be cast in weaker terms, the General Assembly Resolution on Driftnet Fishing formulation is particularly noteworthy as it is the first instrument in this setting to contain a formulation that deviates from this trend. Although implicit, its formulation provides that any state wishing to engage in driftnet fishing may do so provided that "management measures be taken based upon statistically sound analysis" in order to "prevent the unacceptable impact of such fishing practices... and ensure the conservation of the living resources".344 Significantly, this version essentially represents the strongest formulation found in the living resource management context, as it is the only precautionary principle found in this setting which shifts the burden of proof to those wishing to undertake the harmful activity.

\footnotetext{
${ }^{342}$ Catherine J Iorns Magallanes, above n 8, at 5-6.

${ }^{343}$ Convention on Biological Diversity opened for signature 5 June 1992, 1760 UNTS 79, 142 (entered into force 29 December 1993).

${ }^{344}$ UN General Assembly Resolution 44/225 on Large-Scale Pelagic Driftnet Fishing and its impact on the Living Marine Resources of the World's Oceans and Sea's, March 15, 1990, (1990) 29 ILM 1555.
} 


\section{Status of the precautionary principle in international law}

The legal status of the precautionary principle in international law is subject to varying opinion, and largely focuses on whether or not it has attained status as a customary law norm. According to well-established legal doctrine, in order for a legal principle to crystallise into customary international law there must be:

(1) constant and uniform state practice, which can only be achieved if the principle has content that is uniform and specific enough to prescribe a particular behaviour; ${ }^{345}$ and

(2) opinio juris sive necessitates, or: "a belief in the legally permissible or obligatory nature of the conduct in question, or its necessity". 346

Principal factors in favour of the precautionary principle having attained customary status include its widespread adoption at international law and the increasing adoption and endorsement at a domestic level. ${ }^{347}$ As Freestone argues, the precautionary principle's: ${ }^{348}$

explicit endorsement by a wide range of international and national bodies, by a large and growing number of international environmental and natural resource treaties, national constitutions, and legislation, as well as by courts and tribunals suggests a pattern of state practice and a breadth of application which must support - a good argument that it has emerged as a principle of customary international law.

Trouwborst's views support this, so much so that he considers that "[s]upport for the precautionary principle is comparable to support for the basic duty of states not to cause transboundary harm", which itself has unequivocally attained this status. ${ }^{349}$ In terms of

$\overline{345}$ David Freestone and Ellen Hey "The Status of the Precautionary Principle in International Law" in David Freestone and Ellen Hey (eds), above n 2, at 35. James Cameron and Juli Abouchar, above n 2, at 263.

${ }^{346}$ MH Mendelson "The Formation of Customary International Law" (1998) 272 RdC at 155. Malcom Evans (ed) International Law ( $3^{\text {rd }}$ ed, Oxford University Press, Oxford, 2010) at 202.

${ }^{347}$ Arie Trouwborst, above n 75, at 9. Simon Marr, above n 11, at 69-98, 111-113, 166-176, and 197-200. Runyu Wang, above n 262, at 162-163.

${ }^{348}$ Philippe Sands, above n 9, at 279. David Freestone, above n 12, at 137.

${ }^{349}$ Arie Trouwborst, above n 75, at 8. Runyu Wang, above n 262, at 162-163. 
opinio juris, states have arguably demonstrated unequivocal belief in the precautionary principle's absolute necessity through: ${ }^{350}$

(1) its rapid rise and adoption by states in response to avoidable but significant global harms arising on an increasingly frequent basis; and

(2) the repeated acknowledgement in the various international instruments that states sign that the principle is integral to achieving sustainable development and intergenerational equity, outcomes which most environmental agreements revolve around.

The main counterargument is that "the great variety of interpretations given to the precautionary principle, and the novel and far-reaching effects of some applications, suggest that it is not yet a principle of international law." ${ }^{351}$ In other words, it is too vague and the content of each formulation applied by states to varied to demonstrate sufficiently uniform and specific behaviour to the extent required to establish state practice.

In spite of this, many lead commentators now accept that "[a]t some level of generality, precaution is undoubtedly a customary rule of international law". As Sands states: ${ }^{352}$

The legal status of the precautionary principle is evolving. At a minimum, however, there is sufficient evidence of state practice to justify the conclusion that the principle, as elaborated in the Rio Declaration and Climate Change and Biodiversity conventions, has now received sufficiently broad support to all a good argument to be made that it reflects a principle of customary law.

In support of this, Cameron and Abouchar also note, that most of the vocal criticism of the precautionary principle occurred during 1990 and 1992 in the lead up to the United Nations

\footnotetext{
$\overline{350}$ Malcom Evans above n 346.

${ }^{351}$ David Freestone and Ellen Hey, above n 345, at 37. Harald Hohmann Precautionary Legal Duties and Principles of Modern International Environmental Law (Martinus Nijhoff, London, 1994). Owen McIntyre and Thomas Mosedale, above n 79, at 235.

${ }^{352}$ Philippe Sands, above n 9, at 213.
} 
Conference on Environment and Development. At this conference, the extensive and uniform nature of the conceptual core was demonstrated through its acceptance by over 160 states in the binding United Nations Convention on Climate Change and Convention on Biological Diversity, as well as in the non-binding Agenda 21 and Rio Declaration on Environment and Development. ${ }^{353}$

In addition to asserting that a high-level and generally applicable formulation of the precautionary principle has attained customary law status, commentators also assert that formulations that are more specific have achieved this status in certain settings. ${ }^{354}$ As Iorns notes, whether states have accepted application of the precautionary principle "across all subject areas of international law, it is widely accepted in the area of marine environmental protection and has been so since the mid-1990s". ${ }^{355}$

In a comprehensive analysis of the precautionary principle's application in the marine setting Marr convincingly demonstrates that the principle "has been implemented differently in various sectors" (e.g. different formulations are applied by international law instruments relating to: the management of pollution; the maintenance of marine biodiversity; hazardous substances; and the conservation and management of living resources). ${ }^{356}$ As Marr asserts, this variance is because: ${ }^{357}$

[i]n some sectors of environmental law the effects of human activity on the environment and health are sometimes easier to predict than others. Also the scope and intensity of environmental precautionary action could be completely divergent in different sectors.

\footnotetext{
353 James Cameron and Juli Abouchar, above n 2, at 337 - 338.

${ }^{354}$ See Simon Marr, above n 11. Jonathan Wiener, above n 241, at 600. Serge Garcia "The Precautionary Approach to Fisheries and its Implications for Fisheries Research, Technology and Management: An Updated Review" in FAO Fisheries Technical Papers 350/2 (FAO, 1993) at 9. Catherine J Iorns Magallanes, above $n$ 8, at 5-6.

${ }^{355}$ David Freestone, above n 12, at 137.

${ }^{356}$ Simon Marr, above n 11, at 2.

${ }^{357}$ Simon Marr, above n 11, at 3.
} 
In short, Marr aptly concludes that the strength or weakness of the particular formulation that states, and subsequently domestic regulators, are in the practice of applying, essentially "depends on the subject matter of the relevant instrument, and the corresponding level of scientific uncertainty and potential harm". ${ }^{358}$ Fisher shares this view, ${ }^{359}$ which Garcia illustrates well through identifying the stark difference between the strength of the precautionary principle formulation applied in the fisheries setting on the one hand and, in the pollution setting on the other. In doing so, Garcia notes that ${ }^{360}$

In considering the introduction of more precaution in fisheries management and development, the main differences between fisheries impacts and chemical industries pollution (for the control of which the precautionary principle was created) must be kept in mind:

- the assimilative capacity in relation to fisheries impact (i.e., the quantities of fish that can be removed without damaging the system's productivity) exists without doubt and can be determined with some accuracy, even though it varies, and

- the impacts are, in most cases, reversible and, as a result, the potential consequences of an error would rarely be dramatic, even though they can be significant in socio-economic terms.

This paper agrees with this approach. This is largely because it accords with the principles underpinning its existence, as set out in Chapter IV. As such, this approach is strongly aligned with, and gives effect to, the precautionary principle's purpose, particularly so far as it relates to sustainable development (i.e. which entails balancing protection and use, whereby protection limits use only insofar as it is necessary to preserve the sustainability of ecosystems).

\footnotetext{
${ }^{358}$ Catherine J Iorns Magallanes, above $\mathrm{n} 8$, at 5 .

359 Elizabeth Fisher "Precaution, Precaution Everywhere: Developing a 'Common Understanding' of the Precautionary Principle in the European Community" (2002) 9 Maastricht J Eur \& Comp L 7 at 15.

${ }^{360}$ Serge Garcia, above n 354, at 10-11.
} 


\section{E Relationship with other environmental norms}

In large measure, the above stated precautionary principle derives its purpose from the fact its application is widely regarded as being essential for the achievement of sustainable development. ${ }^{361}$ As discussed in Chapter II, sustainable development is typically the principle objective of those legal environmental management regimes that the principle features in. ${ }^{362}$ Sustainable development is underpinned by corollary objectives, which the precautionary principle also serves and which inform its normative character. ${ }^{363}$ As one author notes, the precautionary principle rarely stands alone, but rather is articulated with other norms or processes. ${ }^{364}$ Consequently, "the norms of sustainable development thus make up part of the institutional context within which precautionary decision-making takes place". ${ }^{365}$ Furthermore, because these norms influence one and other because the share many substantive links and overlap. Thus, commentators assert that once cannot consider the precautionary principle cannot in isolation from sustainable development and the principles derived from it. ${ }^{366}$

As noted above, New Zealand's legislative regimes such as the Fisheries Act 1996 and the EEZ Act expressly reflect the close pairing of these fundamental environmental norms

\footnotetext{
${ }^{361}$ Ellen Hey, above n 79, at 311. Arie Trouwborst, above n 116, at 108. Arie Trouwborst, above $\mathrm{n} 2$, at 12. Jacqueline Peel, above n 247, at 25. David Vanderzwaag, above n 2, at 175. Andrew Jordan \& Timothy O'Riordan, above n 250, at 42. Ronnie Harding and Elizabeth Fisher, above n 8, at 6. Rosie Cooney, The Precautionary Principle in Biodiversity Conservation and Natural Resource Management (IUCN Policy and Global Change Series No. 2) IUCN, 2004, 5-6 at 14.

${ }^{362}$ David Vanderzwaag, above n 2, at 175. Jacqueline Peel, above n 247, at 25. Rosie Cooney, above n 361, at 14 .

${ }^{363}$ David Vanderzwaag, above n 2, at 175. Jacqueline Peel, above n 247, at 25.

${ }^{364}$ Sonia Boutillon, above n 316, at 433.

365 Jacqueline Peel, above n 247, at 25. David Vanderzwaag, above n 2, at 175. Andrew Jordan \& Timothy O'Riordan, above n 250, at 42. John Paterson "Sustainable development, sustainable decisions and the precautionary principle" (2007) 42 Natural Hazards 515 at 517. Marco Martuzzi \& Joel Tickner "Introduction - the precautionary principle: protecting public health, the environment and the future of our children" in Marco Martuzzi \& Joel Tickner (eds), above n 124, at 7.

${ }^{366}$ Stephen Dovers "Precautionary policy assessment for sustainability" in Elizabeth Fisher, Judith Jones and Rene von Schomberg (eds), above n 159, at 88. See also Benedicte Sage-Fuller The Precautionary Principle in Marine Environmental Law (Routledge, London, 2013) at 76 and 93.
} 
(more specifically the precautionary principle and sustainable management). ${ }^{367}$ On this basis, consideration of sustainable development and its derivative norms is instructive to understanding the principle generally, the exercise of expounding precautionary principle's legal content, and the task of determining how to apply the principle in practice.

\section{$1 \quad$ Sustainable development}

As touched on in Chapter II, in broad terms sustainable development entails managing the use, development, and protection of ecosystems in a way and at a rate that enables the present generation to meet its needs, while maintaining environmental resources and ecological processes, so that future generations can also meet their needs and enjoy similar levels of environmental quality. ${ }^{368}$ As such, sustainable development requires decisionmakers to balance often-competing ecological, social and economic factors when assessing whether to grant a proposed activity consent. ${ }^{369}$ As Sage-Fuller notes, in doing so this concept: ${ }^{370}$

seeks to set standards to ensure that development projects are carried out with due regard to longevity and durability, not just immediate profit and necessity. The precautionary principle can therefore assist in setting standards and guidelines for sustainable development where the impacts of activities... may result in damage to the environment... without conclusive scientific evidence of such damage or of its occurrence.

In other words, the principle is essential to achieving sustainable development because, absent scientific certainty as to how an activity impacts proper functioning, essential processes or the overall integrity of receiving ecosystems, decision-makers are blind as to where the balance between environmental protection and use must be struck (i.e. in order

\footnotetext{
367 See for example s 10 of the Fisheries Act 1996, s 10 and s 31 and 61 of the EEZ Act.

368 Report of the World Commission on Environment and Development GA Res, 42/187 XLII annex to A/42/427 (1987). David Vanderzwaag, above n 2, at 175. Arie Trouwborst, above n 116, at 108.

${ }^{369}$ Ronnie Harding and Elizabeth Fisher, above n 8, at 6.

${ }^{370}$ Benedicte Sage-Fuller, above n 366, at 93.
} 
to secure sustainable development outcomes). ${ }^{371}$

In terms of its influence on the precautionary principle, Marr and Vanderzwagg note that the need to balance competing economic and environmental considerations that sustainable development places in tension informs determination of the appropriate precautionary response (i.e. the action dimension of the principle). ${ }^{372}$ In particular such considerations assist to avoid an excessively harsh response in terms of restrictions on development.

\section{Intergenerational equity}

Viewed either as a central component of sustainable development or as a stand-alone principle sui generis, the principle of inter-generational equity is also tightly intertwined with the precautionary principle. ${ }^{373}$ Generally speaking, intergenerational equity requires each generation to use and develop the environment and its resources in a way or at a rate that enables them to be passed onto future generations in no worse condition that they were received. ${ }^{374}$ In particular this concept: ${ }^{375}$

(1) envisages partnership between generations and thus raises the issue of the temporal allocation of environmental resources;

(2) recognises that the world's ecosystems and economies are interconnected and as such the generational partnership is global; and

(3) recognises that each generation inherits the environment and on this basis, is obligated to pass it on in a comparable state to that when it was received from the previous

\footnotetext{
${ }^{371}$ David Vanderzwaag, above n 2, at 166 and 175. Sonia Boutillon, above n 316, at 433.

372 Simon Marr, above n 11, at 42. David Vanderzwaag, above n 2, at 166 and 175.

${ }^{373}$ MD Young "The Precautionary Principle as a key element of ecologically sustainable management" in Ronnie Harding and Elizabeth Fisher, above n 2, at 127.

${ }^{374}$ Alan Boyle and David Freestone "Introduction" in Alan Boyle and David Freestone (eds), above n 12, at 12. Jacqueline Peel, above n 247, at 25-26. See for example: United Nations Rio Declaration on Environment and Development, Principle 3, UN Doc. A/CONF.151/26 (vol. I) (1992); 31 ILM 874 (1002). MD Young, above n 373, at 127.

${ }^{375}$ MD Young, above n 373, at 127.
} 
generation.

From a purely economic perspective the principle also asserts that ecological goods that will have an equal or higher value later, should be preserved today and that failure to do so (i.e. as a result of allowing avoidable environmental degradation to occur) will be very $\operatorname{costly.~}^{376}$

As explored in Chapter IV, it is difficult to predict ecological impacts of human activities. Such difficulty proliferates when asked to predict the longer-term impacts of activities. This is because such impacts are less manifest and readily predictable. In turn, the ability of science to prove inter-generational impacts of a given activity diminishes when asked to predict such harm over generational timescales. ${ }^{377}$ For this reason the precautionary principle is integral to achieving intergeneration equity, as without the ability to act in advance of scientific certainty, uncertain long-term ecological gains by way of obviated long-term or irreversible harm, will often be discounted and give way to certain short to medium term economic losses. ${ }^{378}$ Chapter VI below discussed the normative influence that intergenerational equity has on the implementation of the precautionary principle.

\section{$3 \quad$ Ecosystem approach}

Within this context the precautionary principle is also closely linked to the 'ecosystem approach'. Born of the virtually the same scientific insights that gave rise to the precautionary principle, ${ }^{379}$ the ecosystem approach "is generally associated with management based on the "best understanding of the ecological interactions and processes necessary to sustain ecosystem structure and function". Its fundamental purpose or goal is

\footnotetext{
376 Sonia Boutillon, above n 316 , at 433.

${ }^{377}$ John Paterson, above n 365, at 517. David Farrier, above n 51, at 106. MD Young, above n 373.

${ }^{378}$ David Farrier, above n 51, at 114.

379 Arie Trouwborst "The Precautionary Principle and the Ecosystem Approach in International Law: Differences, Similarities and Linkages" (2009) 18 RECIEL (1) 26.
} 
long-term sustainable development. ${ }^{380}$ In providing a representative example of its purpose, the United Nations ICP-7 report expresses what in ecological terms must be achieved to secure sustainability. In doing so it states: ${ }^{381}$

...the aim of ecosystem approaches [is] to manage the interaction between often conflicting environmental, economic and social values and interests in order to maintain the integrity of the structure and functioning of ecosystems, while also allowing the sustainable use of marine living resources.

This purpose is premised on the understanding that maintaining ecosystem integrity is desirable because doing so in turn preserves the continued delivery of ecological services on which both biological organisms ' and people depend to survive, and in the case of humans, derive economic and other benefits. ${ }^{382}$

\footnotetext{
380 Which is also expressed in synonymous terms such as: "sustainable development" "long-term sustainability of natural resources" Jakarta Mandate Objective 2.1 see https://www.cbd.int/decision/cop/?id=7742 http://www.ngo.grida.no/wwfneap/Projects/Reports/jakmand.pdf, Oceans and the Law of the Sea, above n 49, at [119(b)]. United Nations General Assembly, Open-ended Informal Consultative Process on Oceans and the Law of the Sea (2006) at its 7th Meeting in New York, U.N. Doc. A/61/156 17 July 2006) ICP Report7 at para 5(a). A/RES/62/215 at para [99(c)]. Oceans and the Law of the Sea: Report of the Secretary General, above $\mathrm{n} 49$, at [123]. Hanling Wang, above n 34, at 44 and 51. Ocean Affairs and the Law of the Sea United Nations Ecosystem Approaches and Oceans E.07.V.4 (2007) at 164. Oceans and the Law of the Sea: Report of the Secretary General, above n 49, at [121]. Report of the United Nations Conference on Environment and Development, Rio de Janeiro, 3-14 June 1992 (United Nations publication, Sales No. E.93.I.8 and corrigenda) at principle 4. David Freestone "Principles Applicable to Modern Oceans Governance" (2008) 23 The International Journal of Marine and Coastal Law 385 at 389.

${ }^{381}$ United Nations General Assembly, Open-ended Informal Consultative Process on Oceans and the Law of the Sea (2006) at its $7^{\text {th }}$ Meeting in New York, U.N. Doc. A/61/156 17 July 2006) ICP Report-7 at [28]. See also Convention on Biological Diversity 1760 UNTS 79, 142 (opened for signature 5 June 1992, entered into force 29 December 1993). Statement on the ecosystem approach to the management of human activities, First Joint Ministerial Meeting of the Helsinki and OSPAR Commissions, Bremen, Germany, 25-26 June 2003. R Schlaepfer, above n 46, at 9 and 16 www.iufro.org/download/file/556/387/op6_pdf/ Benedicte Sage-Fuller, above $\mathrm{n}$ 366, at 198. Declaration of the Joint Ministerial Meeting of the Helsinki and OSPAR Commissions, Bremen, 25 June 2003 p 1 to 2.

${ }^{382}$ Secretariat of the Convention on Biological Diversity, above n 134, at 12. Decision V/6 by the Conference of the Parties to the Convention on Biological Diversity at its fifth meeting, above $\mathrm{n} 53$, principle 5. See for example Secretariat of the CBD, Addis Ababa Principles and Guidelines for the e Use of Biodiversity (CBD
} 
Specifically, the ecosystem approach states that environmental management must employ an integrated and holistic approach. Under this approach, decisions must be based on the best understanding of an ecosystem's full array of species, processes, structures and their interrelationships as an integrated management unit. ${ }^{383}$ Furthermore, such decisions must also take into account the cumulative effects generated by all activities that impinge on the receiving ecosystem at a given time. As noted in Chapter II, such matters are the exclusive domain of science. Thus, the ecosystem approach is science-based. Consequently, the main modes of implementing it include: ${ }^{384}$

(1) scientific research and analysis of the components of the ecosystem, their interaction and functioning;

(2) assessment of the status or condition of ecosystems, using the best information and practice available;

(3) establishment of ecological and operational objectives to maintain biodiversity, productivity, habitat quality and so on;

(4) identification of human pressures and impacts on the ecosystem;

(5) selection of ecological indicators to ensure that ecological objectives are being met and that the monitoring of changes in ecosystems and the effects of management measures through monitoring of ecological indicators;

Secretariat, 2004), at 2 Oceans and the Law of the Sea: Report of the Secretary General, above n 49, at [115]. Decision V/6 by the Conference of the Parties to the Convention on Biological Diversity at its fifth meeting, above n 53, principle 1. Arie Trouwborst, above n 379, at 32. See also Günther Handl "Declaration Of The United Nations Conference On The Human Environment (Stockholm Declaration), 1972 And The Rio Declaration On Environment And Development, 1992" United Nations Audiovisual Library of International Law at 3.

383 Oceans and the Law of the Sea: Report of the Secretary General, above n 49, at [137]: Arie Trouwborst, above n 379, at 28. Hanling Wang, above n 34, 41 at 46.

384 J Brunée and S Toope, "Environmental Security and Freshwater Resources: A Case for International Ecosystem Law," (1994) 5 Yearbook of International Environmental Law 41 at 53 as cited in DEJ Currie Ecosystem-Based Management in Multilateral Environmental Agreements: Progress towards Adopting the Ecosystem Approach in the International Management of Living Marine Resources WWF, Rome, $58 \mathrm{pp}$ http://www.cbd.int/ecosystem/links.shtml. and Owen McIntyre "Environmental Protection of International Watercourses Under International Law" (Ashgate Publishing, Hampshire, 2007) at 287. http://www.msfd.eu/knowseas/library/PB2.pdf at 4. Oceans and the Law of the Sea: Report of the Secretary General, above n 49, at [116] and [138]. 
(6) management systems and tools that (due to inability of science ability to deal with ecosystem complexity and variability up front) employ adaptive management techniques, where activities are allowed to occur but are periodically monitored, reassessed and the applicable management strategies or measures are updated in response to feedback; and

(7) the application of the precautionary principle where the scientific uncertainty cannot be adequately addressed via the above methods.

Collectively the ecosystem approach and the precautionary approach effected the paradigmatic shift in the way states sought to manage environmental threats from reactive and fragmented approaches to those that are holistic and anticipatory. ${ }^{385}$ While both concepts contributed to this shift as a whole:

(1) the precautionary principle is viewed as being primarily responsible for affecting the reactive to anticipatory shift; and

(2) the ecosystem approach is viewed as facilitating the shift from a fragmented (i.e. sectorial or species specific approaches) to a holistic approach that accounts for the true battery of ecological impacts caused by activities. ${ }^{386}$

The implications of this distinction in function relate to the implementation of the precautionary principle and are discussed in Chapter IV.

\footnotetext{
${ }^{385}$ David Vanderzwaag, above n 2, at 166.

386 Arie Trouwborst, above n 379. Edward Maltby Using the Ecosystem Approach to Implement the Convention on Biological Diversity: Key Issues and case Studies (IUCN, Cambridge, 2003) at 17. Oceans and the Law of the Sea: Report of the Secretary General, above n 49, at [137]. DA Laffoley and others The ecosystem approach: Coherent actions for marine and coastal environments. A report to the UK Government (English Nature, Peterborough, 2004), at 7. Hanling Wang, above n 34, at 46.
} 


\section{$V$ Implementing the Precautionary Principle}

In the context of applying the principle at the domestic level, a frequently cited English judgement of the Queen's Bench identifies that which this paper asserts is the root cause of difficulty in applying the precautionary principle. In doing so the Queen's Bench notes: ${ }^{387}$

There is, at present, no comprehensive and authoritative definition of the precautionary principle. It is an expression which has in recent years been used in a number of international declarations, conventions and treaties...In none of these documents is the principle comprehensively defined, although often the document describes what the principle is intended to mean in the context of the subject matter concerned.

Lead commentators agree, noting that, once you go beyond its basic conceptual core it is difficult to obtain a clear "normative fix" on the precautionary principle because so many aspects of its substantive content and issues associated with how it ought to be applied remain uncertain or await clarification. ${ }^{388}$ Hey observes that, given that most commentators and states now regard the precautionary principle as being "the most important new policy approach in international environmental cooperation", such doctrinal and application uncertainty is especially regrettable. ${ }^{389}$

\section{A Definitional ambiguity and its implications}

The lack of clarity seems largely due to the fact the various international law formulations that represent our understanding of what precaution entails and, upon which

\footnotetext{
${ }^{387} R v$ Secretary of State for Trade and Industry ex parte Duddridge [1994] Env LR 226 (QB), J. Smith as cited in LJ Farquharson and J Dmith "The Status of the Precautionary principle in International Law: $R v$. Secretary of State for Trade and Industry ex parte Duddridge and Others" (1995) 7(2) Journal of Environmental Law at 224. [Court of Appeal decision, The Times, 26th October 1995].

${ }^{388}$ David Vanderzwaag, above n 2, at 166. Simon Marr, above n 11, at 2. John S Applegate, above n 9, at 14.

${ }^{389}$ Ellen Hey, above n 79, at 303.
} 
our domestic formulations are based, intentionally lack detail and precision. This is because many initial formulations were only intended to serve as a "declaratory" statement or guiding principle and as such, were cast in broad and flexible terms. ${ }^{390}$ In addition, subsequent formulations that are intended to operate in a more binding fashion (i.e. as a legal norm), prompted considerable disagreement between negotiating states. Thus, in order to achieve a formulation that participating states would agree to, vague and highlevel language that leaves contentious definitional aspects unresolved and provides little in the way of objective standards (against which states behaviour can be measured), were employed. Thus, the resulting precautionary principle definitions were impregnated with considerable uncertainty regarding their normative meaning and application.

Fisher also asserts that much of this definitional uncertainty is likely also in part due to the fact that, beyond the simple direction to act in advance of science: ${ }^{391}$

...what is deemed to be the appropriate basis for a decision and the appropriate measures to be taken will vary depending on the circumstances...It will be influenced by legal and socio-political culture, the specific statutory regime, the nature of the particular environmental or public health problems, the availability and ease of implementation of 'precautionary measures', and more general understanding of legitimate decision-making"

As noted in Chapter IV, in addition to being caste in high-level terms, difficulty arises when trying to pin down what the precautionary principle entails (i.e. beyond its core definition) because it is an inherently nebulous concept, not a neatly defined and selfcontained concept. As the examination of its origins in Chapter V illustrates (and as this chapter will do further), the full principle is most aptly described as a "territory of meaning”. In particular, it houses a multitude of subset notions. Furthermore, it also interacts intimately with overlapping environmental principle and norms (e.g. sustainable

\footnotetext{
${ }^{390}$ Derek Nolan, above n 15.

${ }^{391}$ Elizabeth Fisher and Ronnie Harding "The precautionary principle and administrative constitutionalism: the development of frameworks for applying the precautionary principle" in Elizabeth Fisher, Judith Jones and Rene von Schomberg (eds), above n 159, at 113 and 116.
} 
development, intergenerational equity and the ecosystem approach), which also inform its substantive content and how it ought to be applied. ${ }^{392}$ In failing to be more prescriptive, existing formulations are silent as to precisely what this broad array of substantive legal content entails and how it is drawn on and comes together under the various strong and weak formulations when applied in practice by decision-makers.

\section{Lack of normative character}

For the above reasons commentators now recognise that by definition the international versions of the precautionary principle are not operational. Rather, such definitions are "situated at a meta-level" and for this reason "require[] explication and operationalization", the process of which involves determining the precautionary principle's "relationship to legal norms and economic analysis". ${ }^{393}$ Citing Bodansky, in the context discussing international precautionary principle formulations of the kind explored in Chapter V, Sandin asserts that: ${ }^{394}$

"[I]t is too vague to serve as a regulatory standard because it does not specify how much caution should be taken." In another article, he writes that the Precautionary Principle "provides a useful overall orientation, [but] is an insufficient basis for policy and largely lacks legal content"

Others support this view. ${ }^{395}$ They note that the precautionary principle's lack of a clear and sufficiently detailed definition, and sufficiently detailed exposition of its normative content and parameters, renders it difficult to operationalise and, in turn, apply during a decisionmaking process. ${ }^{396}$ As Stone notes: ${ }^{397}$

\footnotetext{
$\overline{392}$ Tim O'Riordan, James Cameron and Andrew Jordan, above n 143, at 19. Sonia Boehmer-Christiansen, above $\mathrm{n} 283$, at 38 as cited in Arie Trouwborst, above n 2, at 7.

${ }^{393}$ Konrad Von Moltke, above n 66, at 101. James Cameron and Will Wade-Gery, above n 75, at 37-38.

${ }^{394}$ Per Sandin, above n 245 at 890

395 Gary Marchant and K Mossman, above n 324, at 11.

${ }^{396}$ David Freestone and Ellen Hey, above n 9, at 14. John S Applegate, above n 9, at 13. Stephen Dovers, above n 366, at 89. Gary Marchant and K Mossman, above n 324, at 11.

${ }^{397}$ Mark Geistfeld, above n 277.
} 
if the core aspects of the principle cannot yield a well-defined decision rule-if the essential, widely agreed upon aspects of the principle do not translate into a coherent set of performance obligations - the hard question arises whether the precautionary principle is anything more than sentiment or political slogan.

In direct response to this issue, Boutillon states: ${ }^{398}$

"[t]he issue is to determine the legal implications of the principle. What level of risk should trigger the implementation of the principle? Which costs should be offset, as against the environmental damage? Is the principle a procedural obligation, or does it carry an obligation to attain a certain result in terms of environmental protection?

On this point, Hickey suggests that such operational detail should entail criteria objective enough to enable any actor or decision-maker to determine in advance whether the contemplated activity triggers precautionary measures under the agreement (i.e. criteria which assist a decision-maker to ascertain when a given formulations threat and uncertainty thresholds have been met). ${ }^{399}$ Where such objective criteria are not provided, the precautionary principle is not considered 'operationalised'.

Commentators agree that a failure to provide objective criteria undermines the efficacy of the precautionary principle and threatens its continued status as a respected principle. As Hickey and Walker note for example: ${ }^{400}$

[v]ague references to covered activities can undermine a primary objective of the precautionary approach by creating the possibility that an activity is not known to be covered until after the environmental harm occurs. Identification of specific activities to which precaution applies enables private and governmental actors to plan their conduct, and provides them due notice concerning potential costs and penalties. Specification also helps to ensure that obligated states do not construe

\footnotetext{
398 Sonia Boutillon, above n 316, at 431.

399 James E Hickey and Vern R Walker, above n 74, 445. Arie Trouwborst, above n 75, at 132.

${ }^{400}$ James E Hickey and Vern R Walker, above n 74, at 445.
} 
the covered activities too narrowly or too broadly.

Conversely, excess discretion afforded by the absence of operational detail or guidance can also result in excessively precautionary or restrictive outcomes that: (a) defeat the principle's ability to strike the appropriate balance between use and protection and thereby serve its ultimate purpose of achieving sustainable development; and (b) operate to undermine its credibility amongst political, economic and public stakeholders. ${ }^{401}$ Thus, attempting to apply vague and substantively undercooked formulations creates a live risk, that when applying the principle, regulators will impose too little or too much in the way of environmental protection measures.

In light of this, the pithy definitions of the precautionary principle found in international instruments should at best be treated as summaries of, or rather mere shorthand references to, the much wider conceptual whole of the precautionary principle. ${ }^{402}$ Furthermore, these factors indicate that the precautionary principle is yet to become a properly developed operational legal norm, as its normative boundaries are not ye articulated in a manner that confers the requisite clarity, certainty and rigor expected of a legal rule. ${ }^{403}$

\section{Relevance to New Zealand environmental law}

The first express adoption of the precautionary principle was in 1995 when the Ministry for the Environment incorporated it by express reference it in the "Environment 2010 Strategy" as a general environmental policy. ${ }^{404}$ The strategy first acknowledges that there is often: ${ }^{405}$

\footnotetext{
${ }^{401}$ Stephen Gardiner, above n 245, at 36. HL Rouse and N Norton, above n 185, at 66.

402 Elizabeth Fisher, above n 35, at 318-319. This view was supported in the Australian cases Vertical Telecoms Pty Ltd v Hornsby Shire Council [2000] NSWLEC 172 and Miltonbrook Pty Ltd v Kiama Municipal Council [1998] NSWLEC 281.

403 James E Hickey and Vern R Walker, above n 74, at 437; Sonia Boutillon, above n 316, at 451.

${ }^{404}$ Ministry for the Environment Environment 2010 Strategy: A Statement of the Government's Strategy on the Environment (1995) at 14 as cited in Alexander Gillespie, above n 15, at 374.

${ }^{405}$ Ministry for the Environment, above n 404, at 374.
} 
...limited knowledge or understanding about the potential for adverse environmental effects or the risks of serious or irreversible environmental damage... We cannot anticipate all possible environmental effects of our action.

On this basis, the strategy goes on to provide: ${ }^{406}$

Where there is limited information available to decision-makers, or limited understanding of the possible effects of resulting from an activity and there are uncertain risks or uncertainties (for example, over the extent of environmental damage), a precautionary approach should be applied.

In terms of legislation, the Resource Management Act 1991 is regarded as being New Zealand's first statute to incorporate the precautionary principle. While it does not expressly referenced the precautionary principle by name, the courts have consistently ruled that the precautionary principle is inherent in the Act's provisions. ${ }^{407}$ As Nolan and Williams summarise, in enacting the Resource Management Act 1991:408

Parliament...has chosen to include elements of the precautionary principle in the s 104 considerations (which in turn call into consideration definitions of the term "effect" and the "environment"). These include concepts such as "future effect" and "potential" effects of a "low probability but high potential impact" and sustaining resources "to meet the reasonably foreseeable needs of future generations (etc). There are precautionary aspects which are quite properly taken into account".

In the course of seeking to interpret and infer what substantive content this implicit

\footnotetext{
${ }^{406}$ Ministry for the Environment, above n 404, at 374.

${ }^{407}$ Vernon Rive, above n 31, at 1185; Alexander Gillespie, above n 15, at 375. Linda Cameron, above n 13, at 15. Derek Nolan and Martin Williams "Electromagnetic Radiation Emissions and the "precautionary principle" (1996) 16 NZRMB 215 at 216 to 217. Rotorua Bore Users Association Inc v Bay of Plenty Regional Council NZEnvC Auckland A 138/98, 27 November 1998 at 49. Shirley Primary Schoolv Christchurch City Council (1999) NZRMA 66 (EnvC) at [114]. Golden Bay Marine Farmers v Tasman District Council EnvC Christchurch W42/2001, 27 April 2001 at [421]-[423].

${ }^{408}$ Derek Nolan and Martin Williams, above n 407, at 216-217.
} 
formulation entails the Courts have typically resorted to and taken their cues from the weaker formulations that simply assert scientific uncertainty is not a reason to postpone action, but give no direction on how to respond when confronted with uncertainty. ${ }^{409}$

The precautionary principle is also imported into the Resource Management Act 1991 consent framework through its express inclusion in the substantive provisions of the New Zealand Coastal Policy Statement ("NZCPS"). ${ }^{410}$ Although referred to as a statement of policy, this instrument is arguably part of the mandatory legal framework, as section 104(1)(b)(iv) stipulates that decision-makers "...must have regard to..." the policy when considering consent applications. ${ }^{41}$ This includes policy 3, which in the applicable circumstances requires decision-makers to: ${ }^{412}$

1. Adopt a precautionary approach towards proposed activities whose effects on the coastal environment are uncertain, unknown, or little understood, but potentially significantly adverse.

2. In particular, adopt a precautionary approach to use and management of coastal resources potentially vulnerable to effects from climate change, so that:

a. avoidable social and economic loss and harm to communities does not occur;

b. natural adjustments for coastal processes, natural defences, ecosystems, habitat and species are allowed to occur; and

c. the natural character, public access, amenity and other values of the coastal environment meet the needs of future generations.

There are several matters of note about the NZCPS precautionary principle. First, as will be considered further below, policy 3 is characteristic of a strong version of the

$\overline{{ }^{409}}$ See for example Shirley Primary School v Christchurch City Council (1999) NZRMA 66 (EnvC) at [219][220].

${ }^{410}$ Department of Conservation New Zealand Coastal Policy Statement (2010), policy 3 at 12.

${ }^{411}$ Resource Management Act 1991, section 104(1)(b)(iv). Sustain Our Sounds Inc v the New Zealand King Salmon Company Ltd [2014] NZSC 40; (2014) 10 BRMB 137.

${ }^{412}$ New Zealand Coastal Policy Statement, above n, 410. 
precautionary principle. Secondly, the Supreme Court has arguably further strengthened the cautious nature further when it recently held that (emphasis added): ${ }^{413}$

Policy 3 of the New Zealand Coastal Policy Statement requires a precautionary approach to managing activities in the coastal environment when the effects of those activities are uncertain, but potentially significantly adverse.

Thirdly, it is worth noting that the revision of the NZCPS, which occurred in 2010 following a Department of Conservation and Independent Board of Inquiry review of its predecessor's effectiveness. Following the review the precautionary principle was elevated to a substantive policy set out at the beginning of the core policies in the 2010 version. In revising the NZCPS, the Minister of Conservation noted that these changes were made in response to the need for the statement's aim "to be clearer and stronger... and address new issues that have become more pressing over the past decade". The issues referred to primarily stemmed from the increased industrial and technological uses of the coastal marine area (such as the proliferation of aquaculture) and climate change. ${ }^{414}$

The Hazardous Substances and New Organisms Act 1996 ("HSNO") is one of the first domestic statutes to expressly adopt the precautionary principle and is the only statute to do so by name. The HSNO does so in section 7, which provides: ${ }^{415}$

\section{$7 \quad$ Precautionary approach}

All persons exercising functions, powers, and duties under this Act...shall take into account the need for caution in managing adverse effects where there is scientific and technical uncertainty about those effects.

\footnotetext{
${ }^{413}$ Sustain Our Sounds Inc v the New Zealand King Salmon Company Ltd, above n 411, at [127].

414 Hon Steve Chadwick, Minister of Conservation "New Zealanders to have their say on coastal development" media release, 10 March 2008 as cited in Derek Nolan \& Claire Kirman, above n 31, at 333. Department of Conservation "Monitoring the Effectiveness of the New Zealand Coastal Policy Statement: Views of Local Government Staff" 2003 at 31.

${ }^{415}$ Hazardous Substances and New Organisims Act 1996, s 7.
} 
In the same year that the HSNO was enacted the Fisheries Act 1996 ("Fisheries Act") also expressly adopted the precautionary principle in all but name. Despite being titled “information principles", it is readily acknowledged that section 10 of the Fisheries Act expressly incorporates the precautionary principle by providing: ${ }^{416}$

All persons exercising or performing functions, duties, or powers under this Act... shall take into account the following information principles:

(a) decisions should be based on the best available information:

(b) decision makers should consider any uncertainty in the information available in any case:

(c) decision makers should be cautious when information is uncertain, unreliable, or inadequate:

(d) the absence of, or any uncertainty in, any information should not be used as a reason for postponing or failing to take any measure to achieve the purpose of this Act.

As Iorns notes, "[i]nterestingly, the approach is not expressly labelled as a precautionary approach but is instead titled 'Information Principles"'. However, as she points out, the Minister of Fisheries when introducing the Bill expressly recognised section 10 as implementing the precautionary approach. In doing so, Hon Don Kidd MP stated that section 10 was intended: ${ }^{417}$

[ $\mathrm{t}$ ]o help decision makers to achieve the purpose of the Bill, guidance is provided through the statement of high-level principles...the clause provides information principles. This allows the adoption of precautionary approaches. It recognises the limits of scientific information...

Finally, the most recent, and arguably, notable statutory inclusion of the precautionary

\footnotetext{
${ }^{416}$ Iorns above $\mathrm{n} 8$.

${ }^{417}$ Hon Don Kidd MP (6 December 1994) 45 NZPD 5390.
} 
principle is in the EEZ Act, where two express formulations are included. ${ }^{418}$ As both formulations are largely analogous, for the purpose of this paper, I will focus on section 61.

In the context of comparing the precautionary principle related statutory provisions, the recent Trans-Tasman Resources decision observed that; "[s]ection 61 is unlike any provision in the Resource Management Act 1991. It is directive". ${ }^{19}$ Titled "information principles", it provides: ${ }^{420}$

(1) When considering an application for a marine consent, the Environmental Protection Authority must -

(a) make full use of its powers to request information from the applicant, obtain advice, and commission a review or a report; and

(b) base decisions on the best available information; and

(c) take into account any uncertainty or inadequacy in the information available.

(2) If, in relation to making a decision under this Act, the information available is uncertain or inadequate, the EPA must favour caution and environmental protection.

(3) If favouring caution and environmental protection means that an activity is likely to be refused, the EPA must first consider whether taking an adaptive management approach would allow the activity to be undertaken.

(4) Subsection (3) does not limit section 63 or 64.

(5) In this section, best available information means the best information that, in the particular circumstances, is available without unreasonable cost, effort, or time.

\footnotetext{
${ }^{418}$ Specifically, it is included in section 31, which prescribes how the Minister for the Environment must deal with scientific uncertainty when promulgating regulations; and another, in section 61, which prescribes how the Environmental Protection Authority must respond when confronted with scientific uncertainty during the decision-making process.

${ }^{419}$ Environmental Protection Authority, Trans-Tasman Resources Ltd Marine Consent Decision, June 2014 at [116].

${ }^{420}$ Exclusive Economic Zone and Continental Shelf (Environmental Effects) Act 2012, s 61.
} 
Interestingly Parliament consciously decided to import the substance of the precautionary principle into the EEZ Act expressly without ascribing it the labels precautionary 'approach' or 'principle'. As the explanatory note explains this was done on the basis that employing such labels would tempt unnecessary litigation over the subsequent meaning to be derived from the section's content. ${ }^{421}$ This statement is particularly helpful as it operates as a strong indication of Parliament's acknowledgement that there is no substantive difference between the precautionary principle and precautionary approach.

In essence, the EEZ Act's formulation of the precautionary principle is spread across sections 61(1)(c) and 61(2). Although this chapter explores the dimension of this formulation later, at a glance s 61 appears to contain the strongest domestic formulation of the precautionary principle, primarily because the formulations strong command dimension creates an obligatory duty to act once the Act's precautionary trigger thresholds a met. ${ }^{422}$ As noted above, in Trans-Tasman Resources decision, the committee distinguishes it from the RMA formulation on the basis that it makes environmental action in response to uncertainty compulsory. On this point the decision-making committee notes: $^{423}$

Section 61(2) contains an important direction. We must "favour caution and environmental protection" where the information is uncertain or inadequate. This provision is an explicit statement that, within the context of the EEZ Act, the promotion of sustainable management requires a cautious approach. The taking of risks in this environment is not encouraged, and we note that this direction is not

\footnotetext{
${ }^{421}$ Exclusive Economic Zone and Continental Shelf (Environmental Effects) Bill 2011(321-1) (explanatory note) at 3; Ministry for the Environment Departmental Report on the Exclusive Economic Zone and Continental Shelf (Environmental Effects) Bill (March 2012) at 12.

${ }^{422}$ This view is supported by Greg Severinsen "A cautionary tale: treatment of uncertainty under the EEZ Act" (2015) 11 BRMB 22. However, it is argued in Ceri Warnock "Regulating the environmental impact of oil and gas activities in the exclusive economic zone and extended continental shelf" (2011) 9 BRMB 76 that with this formulation in fact "the legislature has chosen to adopt a weak form of precaution by prescribing an adaptive management approach to be taken in the event of uncertainty". See Daniel Bodansky, above n 245, at 387. Daniel Bodansky, Jutta Brunnee and Ellen Hey, above n 67, at 599.

${ }^{423}$ Exclusive Economic Zone and Continental Shelf (Environmental Effects) Bill 2011(321-2) (explanatory note).
} 
to be traded off against the attainment of economic wellbeing. In other words, the requirement to favour caution and environmental protection in the face of uncertain or inadequate information is an absolute one, and we remind ourselves of section 10(3), which makes it clear that applying the information principles in section 61 is one of the ways the purpose of the EEZ Act is achieved.

In addition to this, the EEZ Act formulation is of note as it likely represents Parliament's most decisive effort to create an operational precautionary principle. In part, this is evidenced through the structural changes made between the first and second readings of the Exclusive Economic Zone and Continental Shelf (Environmental Effects) Bill. Specifically, the precautionary principle was moved from the "Purpose and principles" subpart in the Bill's preliminary provisions, ${ }^{424}$ to the operational "Marine Consents" "Decisions" provisions. ${ }^{425}$ In explaining these changes the Local Government and Environment Committees notes under the heading "Achieving the purpose of the Bill": 426

Moving the requirements in clauses 12 and 13 to the substantive decision-making clauses of the bill would strengthen the connection between decision-making and the relevant considerations, including the need for caution in the event of uncertainty. We note that the need for caution would only apply to... and the consideration of consent applications or reviews...

The prominence accorded to the precautionary principle and the strength of the formulation implemented under this Act is appropriate. First, it aligns with international law instruments relating to management of the marine space, which as noted in Chapter V, tend to adopt stronger precautionary provisions. Secondly, the strength and status of the EEZ Act formulation appears to have been calibrated to suit the specific threat and uncertainty circumstances it is required to operate in. In terms of the threat circumstances, as repeatedly emphasised in the "Managing Our Oceans" discussion document, which gave

${ }^{424}$ EEZ Bill 321-1, cl 13 (in Part 1, Sub-part 2).

${ }^{425}$ EEZ Bill 321-2, cl 60A (in Part 2, Sub-part 2).

${ }^{426}$ EEZ Bill 321-2, at 3. 
rise to the EEZ Act, the principal reason for its enactment were the facts that: ${ }^{427}$

(1) the technological, novel and inherently risky activities governed by the Act are likely to increase; and

(2) in turn, the significant risk of "...environmental harm, affecting marine life, habitats and biodiversity" associated with the activates will also increase.

Thirdly, it is also likely due to Parliament's recognition of the fact that scientific uncertainty is considerably more abundant in marine context. As Quinn notes, discussing section 10 of the Fisheries Act upon which section 61 of the EEZ Act was based: ${ }^{428}$

It is appropriate that the precautionary principle has first been applied to the marine environment and its resources. In general, far less is known about marine ecosystems than terrestrial ones, and it is this uncertainty and ignorance which necessitates a precautionary approach.

\section{Legislative recognition of the link with sustainable development}

Like the international formulations that the New Zealand precautionary principle formulations were adopted from, or inspired by, the above legislation closely pairs sustainable management (New Zealand's domestic equivalent to sustainable development), and the precautionary principle, in a manner that indicates Parliament is of the view that achieving sustainable management relies on proper application of the precautionary principle. For example, in section 10(1) of the EEZ Act it expressly states "[t]he purpose of this Act is to promote the sustainable management of the natural resources of the [EEZ]" and that "[i]n order to achieve the purpose, decision-makers must... apply the information principles..." (i.e. the precautionary principle) "to the consideration of applications for a

\footnotetext{
${ }^{427}$ Ministry for the Environment "Managing our Oceans", above n 16, at 9.

${ }^{428}$ Marguerite Quin, above n 27. Specifically, like section 10 of the Fisheries Act 1996, section 61 of the Exclusive Economic Zone and Continental Shelf (Environmental Effects) Act 2012: is titled "information principles"; contains both "information management" principles and the precautionary principle; and employs similar language to expresses these components (as was recognised by Hon Dr Nick Smith during the third reading of the Exclusive Economic Zone and Continental Shelf (Environmental Effects) Bill).
} 
marine consent". ${ }^{429}$ Similarly, the Fisheries Act 1996 ties achievement of its sustainability purpose to the application of the precautionary principle as articulated in s 10 of that Act. ${ }^{430}$ Although achieved by way of less express coupling, the same linkage also exists in the Resource Management Act 1991. ${ }^{431}$

\section{$4 \quad$ New Zealand's use of the precautionary principle}

Speaking generally, Tollefson and Thornback note that a distinction can be made between implementing the precautionary principle: "as a discretionary consideration or background interpretive cannon" on the one hand; and, doing so "in a more doctrinal fashion" whereby it is given "some specific work to do" on the other.

This paper asserts that, based on the above discussion of the precautionary principle's inclusion in this domestic environmental management and decision-making legislation, it is clear that Parliament has elected to implement it in the latter fashion. This is particularly the case for the EEZ Act. In particular, this is demonstrated by the:

(1) explanation behind the legislature's decision to re-house the EEZ Act's precautionary principle formulation found in the two primary operative decision-making parts of the Act;

(2) express acknowledgement that the precautionary principle's proper application is integral to achieving the EEZ Acts purpose; and

(3) fact ss 31 and 61 impose a legal duty to act and do not confer discretion in this regard.

As noted above, the King Salmon decision states Principle 3 of the NZCPS "requires

\footnotetext{
$\overline{429}$ EEZ Act, s 10.

${ }^{430}$ Fisheries Act 1996, s 10.

${ }^{431}$ As discussed a pages 101 to 103 , the conceptual core of the precautionary principle was deemed to be inherent in "risk management" language adopted in the Acts sustainable development purpose (which is "forward-looking...preventative, precautionary and proactive"), definition of "effect" in s 103 and section 104. See Shirley Primary School v Christchurch City Council (1999) NZRMA 66 (EnvC) at [114]. Rotorua Bore Users Association Inc v Bay of Plenty Regional Council NZEnvC Auckland A 138/98, 27 November 1998 at 49.
} 
a precautionary approach" when the threat and certainty thresholds are met. Like the EEZ Act, application of this precautionary principle formulation is imported directly into the key decision-making provisions of s 104 of the Resource Management Act. Furthermore, given that the courts have repeatedly determined that the precautionary principle is inherent in s 104, the decision to import a more prescribed and directive express formulation into the decision-making process under this section demonstrates that it is intended to operate in a more doctrinal fashion. Although cast in less directive terms, similar arguments can be made in relation to the principle's inclusion in the Fisheries Act 1996 and HSNO on account of the express and intimate link between proper application of the precautionary principle and achievement of the respective Acts' sustainability based purposes.

To make comparison easier and to aid the discussion below, the following table breaks down these domestic precautionary principle formulations into the four dimensions discussed in Chapter V. In doing so, this table also categorises each New Zealand formulation on the basis of precautionary strength and juxtaposes them with those international formulations deemed emblematic of each corresponding strong and weak formulations:

\begin{tabular}{|c|c|c|c|c|c|}
\hline \multicolumn{6}{|c|}{ Strong precautionary principle formulations } \\
\hline Formulations & $\begin{array}{l}\text { Threat } \\
\text { Dimension }\end{array}$ & $\begin{array}{l}\text { Certainty } \\
\text { Dimension }\end{array}$ & & $\begin{array}{l}\text { Command } \\
\text { Dimension }\end{array}$ & Action Dimension \\
\hline $\begin{array}{l}\text { EEZ Act, s 61(2): } \\
\text { If [when] making } \\
\text { a decision under } \\
\text { this Act... }\end{array}$ & $\begin{array}{l}\text { [significant } \\
\text { adverse effects] }^{432}\end{array}$ & $\begin{array}{l}\text { "information } \\
\text { available } \\
\text { uncertain } \\
\text { inadequate" }\end{array}$ & $\begin{array}{l}\text { is } \\
\text { or }\end{array}$ & "the EPA must" & $\begin{array}{l}\text { "favour caution and } \\
\text { environmental protection" }\end{array}$ \\
\hline
\end{tabular}

$\overline{432}$ As discussed below, at a minimum, all formulations, including those which are silent, possess this minimum harm threshold. 


\begin{tabular}{|c|c|c|c|c|}
\hline $\begin{array}{l}\text { NZCPS, principle } \\
3\end{array}$ & $\begin{array}{l}\text { "Effects on the } \\
\text { coastal } \\
\text { environment [that] } \\
\text { are potentially } \\
\text { significantly } \\
\text { adverse. }\end{array}$ & $\begin{array}{l}\text { "effects [that] are } \\
\text { uncertain, } \\
\text { unknown, or little } \\
\text { understood" }\end{array}$ & $\begin{array}{l}\text { "[required } \\
\text { adopt" }\end{array}$ & $\begin{array}{l}\text { "a precautionary approach } \\
\text { towards proposed } \\
\text { activities" }\end{array}$ \\
\hline $\begin{array}{l}\text { London Protocol, } \\
\text { Article 3(1): In } \\
\text { implementing this } \\
\text { protocol... }\end{array}$ & \multicolumn{2}{|c|}{$\begin{array}{l}\text { "when there is reason to believe that } \\
\text { wastes or other matter introduced into } \\
\text { the marine environment are likely to } \\
\text { cause harm even when there is no } \\
\text { conclusive evidence to prove a causal } \\
\text { relation between inputs and their } \\
\text { effects." }\end{array}$} & $\begin{array}{l}\text { "contracting parties } \\
\text { [(i.e. their decision- } \\
\text { makers)] shall apply" }\end{array}$ & $\begin{array}{l}\text { "a precautionary approach } \\
\text { to environmental } \\
\text { protection... whereby } \\
\text { appropriate preventative } \\
\text { measures are taken" }\end{array}$ \\
\hline \multicolumn{5}{|c|}{ Moderate to weak precautionary principle formulations } \\
\hline $\begin{array}{l}\text { Fisheries Act } \\
\text { 1996: Where } \\
\text { there are... }\end{array}$ & $\begin{array}{l}\text { "in relation to the } \\
\text { utilisation of } \\
\text { fisheries } \\
\text { resources" }\end{array}$ & $\begin{array}{l}\text { "when } \\
\text { information is } \\
\text { uncertain, } \\
\text { unreliable, or } \\
\text { inadequate" }\end{array}$ & $\begin{array}{l}\text { "should be } \\
\text { cautious...[and]... } \\
\text { "should not be used as } \\
\text { a reason for } \\
\text { postponing or failing } \\
\text { to take" }\end{array}$ & $\begin{array}{l}\text { "any measure to achieve } \\
\text { the purpose of this Act" }\end{array}$ \\
\hline HSNO, section 7: & "adverse effects" & $\begin{array}{l}\text { " scientific and } \\
\text { technical } \\
\text { uncertainty about } \\
\text { those effects." }\end{array}$ & $\begin{array}{l}\text { "shall take into } \\
\text { account the need for } \\
\text { caution" }\end{array}$ & $\begin{array}{l}\text { "caution in managing } \\
\text { adverse effects" }\end{array}$ \\
\hline $\begin{array}{l}\text { Rio Declaration, } \\
\text { Principle 15: } \\
\text { Where there are... }\end{array}$ & $\begin{array}{l}\text { "threats of serious } \\
\text { or irreversible } \\
\text { damage" }\end{array}$ & $\begin{array}{l}\text { "lack of full } \\
\text { scientific } \\
\text { certainty" }\end{array}$ & $\begin{array}{l}\text { "shall not be used as a } \\
\text { reason for } \\
\text { postponing" }\end{array}$ & $\begin{array}{l}\text { cost-effective measures to } \\
\text { prevent environmental } \\
\text { degradation" }\end{array}$ \\
\hline
\end{tabular}

As the above comparison between New Zealand's statutory precautionary principle formulations and their international law counterparts demonstrates, Parliament has employed the verbatim transfer approach discussed by Fisher and others above. ${ }^{434}$ Thus,

433 "Required" inserted to the actual text on the basis of the Supreme Court's interpretation of Principle 3. See Sustain Our Sounds Inc v the New Zealand King Salmon Company Ltd [2014] NZSC 40; (2014) 10 BRMB 137.

434 Elizabeth Fisher, Judith Jones and Rene von Schomberg "Implementing the precautionary principle: perspectives and process" in Elizabeth Fisher, Judith Jones and Rene von Schomberg (eds), above n 159, at 1. 
despite Parliament's clear intention that the precautionary principle operate in an operational, or rather normative fashion, it has chosen to adopt wording similar to those international law formulations, which were never intended, or equipped, to operate in this fashion. Furthermore, in importing these high-level international formulations Parliament has also not taken the requisite next step of unpacking (i.e. operationalising) them by providing sufficient direction as to what they require of decision makers in practice. In taking this short cut approach New Zealand has subsequently inherited the full array of application difficulties identified above that flow from the precautionary principles definitional ambiguity and lack of normative character.

This paper asserts that in addition to inheriting such difficulties, this cut-and-paste approach, coupled with a failure to operationalise the precautionary principle, has also led to decision-makers and the courts:

(1) underestimating the precautionary principle's substantive content;

(2) overlooking Parliament's intention that it be applied as a legal rule in a more structured manner; and

(3) mistakenly treating the precautionary principle as something more akin to a mere background principle or "interpretive cannon".

A strong argument can be made that this is indicated in the majority of New Zealand cases because in almost every instance, the courts do not look beyond the "meta-level" formulation when applying precautionary principle, or seek to elucidate (i.e. drill down into) a given formulations more detailed substantive and operational content. A representative example of this unstructured and high-level approach typically taken by New Zealand decision makers and the Courts is provided in the Aquamarine Limited $v$ Southland District Council decision, which provides (emphasis added): ${ }^{435}$

In McIntyre and Others the Court referred amongst others to a judgment of the Land and Environment Court of New South Wales in Leatch $v$ National Parks and

\footnotetext{
$\overline{435}$ Aquamarine Limited $v$ Southland District Council [1997] NZEnvC Invercargil C126/97 at 145.
} 
Wildlife Service and Shoalhaven City Council (1993) 81 LGERA 270. In this case Stein $\mathrm{J}$ said this at page 282:

"In my opinion the precautionary principle is a statement of common sense and has already been applied by decision-makers in appropriate circumstances prior to the principle being spelt out. It is directed towards the prevention of serious or irreversible harm to the environment in situations of scientific uncertainty. Its premise is that where uncertainty or ignorance exists concerning the nature or scope of environmental harm (whether this follows from policies, decisions, or activities), decision makers should be cautious ".

With respect we consider this to be a helpful and lucid exposition of the precautionary principle and we gratefully adopt it.

While the application of the precautionary principle has been subject to some relatively ad hoc high-level refinements, ${ }^{436}$ the courts continue to treat and apply the precautionary principle in this way. ${ }^{437}$ The recent King Salmon litigation, which contains what is arguably the most comprehensive judicial scrutiny of the precautionary principle to date, largely demonstrates this. ${ }^{438}$ The recent decisions under the EEZ Act also illustrate a tendency to take this approach. For example, in the Trans-Tasman Resources decision (despite being confronted with considerable scientific uncertainty), the decision-making committee applies the precautionary principle as contained in s 61 of the EEZ Act without any consideration of its legal parameters or content. In addition, they do not take a structured

$\overline{436}$ See for example Sea-Tow Limited v Auckland Regional Council EnvC A066/06 at [462] where the Environment Court sets out several "general principles" derived from a number of Environment Court and High Court decisions to guide the application of the precautionary principle.

${ }^{437}$ Examples include: Squid Fishery Management Co Ltd v Minister of Fisheries [2003] NZHC WN CP 20/03 (Unreported, Ronald Young J, 11 April 2003) at [53] to [54]. Shirley Primary School v Christchurch City Council [1999] NZEnvC Christchurch C136/98 at [218] to [221].

438 Final report of the Board of Inquiry New Zealand King Salmon Requests for Plan Changes and Applications for Resource Consents, 22 February 2013 at [173] to [178]. Environmental Defense Society v The New Zealand King Salmon Company Limited NZHC [2013] 1992 at [73] to [75] where the court sets out what it considers to be the legal content of the precautionary principle. In Sustain Our Sounds Inc v The New Zealand King Salmon Company Ltd [2014] NZSC 40 at 544 to 554 the Court engages in a more in-depth analysis of adaptive management and in doing so delves into the precautionary principle in more depth. 
approach to applying it (e.g. by working through each of its trigger and response dimensions and applying them to the facts at hand). ${ }^{439}$ However, in doing so the Tribunal wholesale adopts the Supreme Court's reasoning in King Salmon regarding adaptive management. ${ }^{440}$ Unsurprisingly in the Chatham Rock Phosphate decision that followed shortly after, the decision-making committee largely followed the Trans-Tasman Resources decision so far as application of the precautionary principle was concerned. ${ }^{441}$

By failing to explore the full substantive content of the precautionary principle and pin down its substantive normative content and parameters first, decision-makers and the courts are blind to what the precautionary principle means (i.e. what is captured within the wider territory of meaning beyond the meta-level definition) and in turn, what is required of them when applying it. One can make a strong argument that this, in addition to Parliament's cut-and-paste approach to incorporating it into domestic law is the primary cause of confusion amongst New Zealand regulators and the Courts (i.e. in terms of how the precautionary principle ought to be interpreted and applied). As identified in Chapter I, such confusion is evidenced through the plethora of ad hoc, inconsistent and often-incorrect applications of the precautionary principle as reflected in the resulting "range of inconsistent judicial approaches" to its application in regulatory decision-making context. $^{442}$

\section{$B \quad$ Initial steps towards an operational definition}

In response to the above, this chapter employs the analytical framework developed by Sandin and others, ${ }^{443}$ whereby the principle is broken down into the four constituent dimensions (outlined in Chapter $\mathrm{V}$ above). This chapter will explore each of these

\footnotetext{
$\overline{439}$ Environmental Protection Authority, Trans-Tasman Resources Ltd Marine Consent Decision, June 2014 at [798].

${ }^{440}$ At [800] to [802].

${ }^{441}$ Environmental Protection Authority, Chatham Rock Phosphate Limited Decision, February 2015.

${ }^{442}$ See Catherine J Iorns Magallanes, above n 8. Alexander Gillespie, above n 15. Greg Severinsen, above n 15. Joan Forret, above n 15, at 51; McIntyre v Christchurch City Council [1996] 2 ELRNZ 84 at 99. Derek Nolan, above $n 15$.

${ }^{443}$ Note that this framework is discussed in Chapter V "Introducing the precautionary principle".
} 
dimensions in more detail in order to ascertain what additional normative content can be reasonably inferred. As outlined in Chapter V, when applying the precautionary principle decision-makers must:

(1) ascertain whether the harm and certainty dimensions (or risk thresholds) of the principle (which together comprise the "precautionary trigger"), have been met; and

(2) in the event the trigger thresholds are met, determine the appropriate "precautionary response", which is prescribed by the action and command dimensions.

It is hoped that this process of unpacking each of the four dimensions that make up the principle's core skeletal structure will help: identify in detail, the principle's normative substance; and, in doing so, produce a more operational authoritative formulation of the principle. It is also hoped that such efforts will:

(1) facilitate a more meaningful and correct application of the principle and in turn enable the principle to operate more effectively in New Zealand going forward; and

(2) in turn enhance the ability of decision-makers to fulfil the sustainable management objective of the various environmental legislative regimes it is applied under.

\section{Operationalising the harm dimension}

As discussed in Chapter V, the "threat dimension" concerns the potential ecological harm that may result if the activity in question is allowed to continue or proceed (that is, possible ecological harm which may materialise if there is regulatory inaction). ${ }^{444}$ In particular, it stipulates how severe a potential harm must be in order to trigger precautionary action. For those formulations that address specific subject matter, it can also limit the harm trigger to specific types of harm (for example, pollution or impacts of

\footnotetext{
$\overline{444}$ Per Sandin, above n 245 at 890 . Adrian Deville and Rodney Harding "Applying the Precautionary Principle" (The Federation Press, Sydney, 1997) at 25. M Matthee and D Vermersch above n 245 at 61. A Epiney and M Scheyli anove n 245 at 109 to 110. James Cameron and Juli Abouchar above $\mathrm{n} 2$ at 45. Arie Trouwborst, above $\mathrm{n} 75$ at 30. James Cameron and Will Wade-Gery, above n 75, at 11. James Cameron and Juli Abouchar, above n 284 at 21.
} 
releasing greenhouse gas). ${ }^{445}$

\section{Gravity of harm: imposing a harm threshold}

It is understood that the severity of human impacts can vary. Harm may be of an increasing magnitude ranging upwards from negligible to minimal to moderate to considerable or catastrophic. ${ }^{446}$ As is evident from the various versions, many harm dimensions include qualifiers that stipulate minimum thresholds damage based on severity. The purpose of this is to exclude from the principle's reach those harms that do not warrant precautionary action, hence the use of thresholds that limit its application "to threats that raise special environmental concerns because of their magnitude and/or type". ${ }^{47}$

The rationale behind this limitation to the precautionary principle's application is that the taking of all risks cannot be banned completely. While every ecological change induced by human activity may not necessarily manifest itself in anthropogenic damage, most human activities do. ${ }^{448}$ Consequently, as long as humans exist, it is impossible and not desirable to prevent all levels of harm regardless of magnitude. ${ }^{449}$ Thus, a line has to be drawn somewhere. ${ }^{450}$ For this reason, most international law formulations include harm dimensions that sit on a continuum between:

(1) High gravity harm thresholds (which, as noted above, reduce the protective strength

\footnotetext{
445 Per Sandin, above n 245, at 890 to 892. Daniel Bodansky, above n 245, at 387.

446 Joe Tickner and Carolyn Raffensperger above n 76, at 8.

Per Sandin, above n 245, at 889 at 891.

${ }^{447}$ Daniel Bodansky above n 245, at 891. Arie Trouwborst, above n 75, at 43. Julian Morris Rethinking Risk and the Precautionary Principle (Butterworth-Heinemann, Oxford, 2000) at 14. James Cameron, above $n$ 247, at 36. Andre Nollkaemper "What you risk reveals what you value, and Other Dilemmas Encountered in the Legal Assault on Risks" in David Freestone and Ellen Hey (eds) The Precautionary Principle and International Law: The Challenge of Implementation (Kluwer International, Hague, 1996) 73 at 82.

${ }^{448}$ Per Sandin, above n 245, at 889 at 891 . Arie Trouwborst, above n 75 at 43. Julian Morris, above n 447, at 14. James Cameron above n 247, at 36. Andre Nollkaemper, above n 447, at 82.

449 Andre Nollkaemper, above n 447, at 83.

${ }^{450}$ At 83 .
} 
of the formulation), ${ }^{451}$ that require the presence of "threats of serious or irreversible damage"; ${ }^{452}$ "damage to the marine environment [that] can be irreversible or remediable only at considerable expense and over long periods"; 453 and

(2) comparatively lower gravity harm thresholds (which conversely strengthen the protective nature of the formulation) ${ }^{454}$ which merely require the presence of a threat, such as: "threat of a significant reduction or loss of biological diversity"; ${ }^{455}$ and "significant risks to nature or other adverse effects". ${ }^{456}$

These thresholds can be compared to those that feature in various New Zealand precautionary principle formulations identified above:

(1) "adverse environmental effects or the risks of serious or irreversible environmental damage" (Environment 2010 Strategy);

(2) "Effects on the coastal environment [that] are potentially significantly adverse" (NZCPS);

(3) "adverse effects" (HSNO); and

(4) "significant adverse effects" (sections 31 and 61 of the EEZ Act).

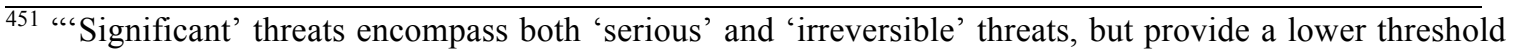
than those terms" in Richard Hildreth, Casey Jarman and Maggie Langlas "Roles for a Precautionary Approach in U.S. Marine Resources Management" (2004) 19 Natural Resources \& Environment No. 1 at 64 to 67. See also Arie Trouwborst, above n 75, at 63, Figure 2, which lists the terms in ascending order of gravity, and 64, which states that Figure 2 "accurately reflects the reality of positive international law in that the various thresholds with their consequences have been placed in the correct order".

452 Rio Declaration on Environment and Development, Principle 15, June 14, 1992, U.N. Doc. A/Conf.151/5/Rev.1 (1992) Reprinted in 31 I.L.M. 874, 879 (1992). Bergen Ministerial Declaration on Sustainable Development in the European Commission for Europe (ECE) Region, UN Doc A/CONF.151/PC/10 (1990). Cartagena Protocol on Biosafety to the Convention on Biological Diversity, arts 10 and 11, 39 ILM 1027 (opened for signature 29 January 2000, entered into force 11 September 2003).

${ }^{453}$ Ministerial Declaration of the First International Conference on the Protection of the North Sea, 31 October - 1 November 1984.

454 “'Significant' threats encompass both 'serious' and 'irreversible' threats, but provide a lower threshold than those terms" Richard Hildreth, Casey Jarman and Maggie Langlas above n 451, at 64 to 67. See also Arie Trouwborst, above $\mathrm{n} 75$, at 63 .

${ }^{455}$ Convention on Biological Diversity 1760 UNTS 79, 142 (opened for signature 5 June 1992, entered into force 29 December 1993), preamble.

${ }^{456}$ World Charter for Nature, Art 11, GA A/RES/37/7 48th plenary meeting28 October 1982.
} 
But for the non-legally binding Environment 2010 Strategy harm threshold, each of the New Zealand formulations either expressly stipulate that 'significant' harm required to trigger application of their respective precautionary response, or are silent on the level of harm required to do so. In any case, where a harm threshold has been specified, it is clear that Parliament, or, in the case of the NZCPS, the Minister, have set the threshold low. On this basis, this paper goes on to consider what "significant effects" means.

\section{Significant effects}

The Concise Oxford Dictionary defines significant as "not insignificant or negligible". In the international setting, commentators assert that the threshold of 'significant' harm is met when the harm an activity may inflict is more than minor, insignificant, or trivial, but something less than 'serious' or 'substantial'. ${ }^{457}$ Thus, under such a threshold, all harm that is considered to be more than negligible ought to be capable of triggering a precautionary response (i.e. assuming that the uncertainty threshold is also met).

The lower cut-off point makes sense. The principle arose to counter the mischief of longer-term harm that has implications for sustainability and intergenerational equity. Furthermore, given the principle's primary objective is to facilitate sustainable

development; ${ }^{458}$ it would be incongruent with the principle's purpose if it were to apply to lesser forms of harm that do not threaten the health and integrity of ecosystem structure and function. This is because doing so would: result in excessive limits being placed on activities; and, in turn, prevent sustainable management objectives being achieved, as the incorrect balance between use and protection will have been struck. Employing this

$\overline{457}$ Alexandre Kiss and Dinah Shelton, above n 43, at 269. R Lefeber "Transboundary environmental interference and the Origin of State Liability" (1996). See also ILC Draft Articles on International Liability, UN Doc A/CN 4/428 (1990) and on International Watercourses, IIYbLC (1984) Pt 1, 112. UNGA Report of the $6^{\text {th }}$ Committee, UN Doc A/51/869 (1997) 5. ILC Report (2001) 388, [4] to [7] as cited in Patricia Birnie, Alan Boyle and Catherine Redgewell International Law and the Environment (3 ${ }^{\text {rd }}$ ed, Oxford University Press, Oxford, 2008) at 186.

458 See discussion above regarding the link between sustainable development and the operation of the precautionary principle under the Exclusive Economic Zone and Continental Shelf (Environmental Effects) Act 2012, the Resource Management Act 1991 and the Fisheries Act 1996. 
reasoning, commentators have also asserted that, where a threat dimensions are silent as to the threshold of harm required to trigger its application, a threshold of significant harm is implicit and therefore must be read in. ${ }^{459}$

This interpretation appears congruent with the New Zealand legislative regimes discussed above. For example, the Resource Management Act 1991 pitches the level of harm that it seeks to manage under its consenting regime (for the purpose of ensuring sustainability) at "more than minor". ${ }^{460}$ The same threshold operates under the EEZ Act also. ${ }^{461}$ This is likely to be the reason why the New Zealand legislature has refused to incorporate the much higher harm threshold of "serious or irreversible damage" that features in the most widely endorsed international law formulations of the precautionary principle $^{462}$ and has instead favoured the lower threshold of significant harm. This latter point is something that decision-makers and the courts must keep in mind when resorting to international law precautionary principle formulations to aid their interpretation of that found in s 61 of the EEZ Act.

\section{Irreversible effects}

Although the New Zealand threat dimension formulations do not expressly include the qualifier that threats must be irreversible, it is worth considering what this entails in practice because:

\footnotetext{
$\overline{459}$ Elizabeth Fisher, above n 359, at 15. Arie Trouwborst, above n 75, at 44. European Environment Bureau, 1999 at paragraph 3.2 .

460 Resource Management Act 1991, s 95A.

${ }^{461}$ Ministry for the Environment above n 421. EEZ Act, s 83.

462 See for example Rio Declaration on Environment and Development, Principle 15, June 14, 1992, U.N. Doc. A/Conf.151/5/Rev.1 (1992) Reprinted in 31 I.L.M. 874, 879 (1992). Bergen Ministerial Declaration on Sustainable Development in the European Commission for Europe (ECE) Region, UN Doc A/CONF.151/PC/10 (1990). Protocol to the 1979 Convention on Long-Range Transboundary Air Pollution on Further Reduction of Sulphur Emissions UN Doc EB.AIR/R. 84 (opened for signature 14 June 1994 , entered into force 5 August 1998). United Nations Framework Convention on Climate Change 31 ILM 854 (opened for signature 9 May 1992, entered into force 21 March 1994). Convention to Ban the importation into Forum Islands Countries of Hazardous and Radioactive wastes and to control the transboundary movement and management of wastes within the South Pacific Region (Opened for signature 16 September 1995, entered into force 21 October 2001).
} 
(1) significant effects can also be irreversible, something which informs how significant an effect in fact is;

(2) given intergenerational equity is at the core of the precautionary principle, where such potential effects are in play, the purpose of the precautionary principle further directs decision-makers to take precautionary action; and

(3) presence of such a threat has significant implications for determining the appropriate precautionary response.

Irreversible effects are those that allow no practical opportunity to correct the environmental damage once it has occurred. ${ }^{463}$ The notion of irreversibility and what must be met before an effect is deemed to be irreversible has some difficulties. As Morris notes, in a scientific sense, all change is irreversible because the precise structure of the world that pertained before "cannot come into being". ${ }^{464}$ On this basis he asserts this "ultimately negates the utility of including 'irreversibility' as a criterion as distinct from 'serious", 465 Conversely, over long time-scales, many impacts can remediate naturally. ${ }^{466}$ Furthermore, harm may not be irreparable for physical reasons (that is, technically it may be possible to remediate); however, the cost of doing so may be so prohibitive that in all practically it is irreversible. ${ }^{467}$ In light of such difficulties, commentators argue that irreversibility means the that: ${ }^{468}$

Long-term damage that is non in stricto senso irreversible, is nonetheless so enduring and/or unlikely to be undone that it is deemed "practically", "virtually", apparently", "essentially" or "effectively" irreversible. Thus, the 1982 CCAMLR and 1985 ASEAN Agreement on the Conservation of Nature and Natural

\footnotetext{
${ }_{463}$ James E Hickey and Vern R Walker, above n 74, at 446

${ }^{464}$ Julian Morris, above n 447, at 14.

${ }^{465}$ At 14 .

${ }^{466}$ European Environmental Agency Late Lessons from Early Warnings: The Precautionary Principle 1986 to 2000, Environmental Law Issues Report No. 22 Copenhagen 2001 at 171. I M Goklany "Applying the Precautionary Principle in a Broader Context" in Julian Morris, above n 447.

${ }^{467}$ Arie Trouwborst, above $\mathrm{n} 75$, at 61 .

${ }^{468}$ At 61 (citations omitted).
} 
Resources, both of which are among the first international instruments to introduce the concept of irreversibility in to their operative terms, respectively require parties to prevent changes or minimise the risk of changes to ecosystems "which are not potentially reversible over two or three decades" and which are not reversible over a reasonable time.

Given that securing inter-generational equity is at the core of the precautionary principle's purpose, the adoption of such a workable approach makes sense, particularly as part of an operational definition. In any case, this gives a further indication of how irreversibility may be used to inform the severity of harm, and in turn, when and to what extent precautionary action is required in order to ensure sustainable management outcomes. ${ }^{469}$

\section{Objective criteria for decision-makers}

Commentators note that determining what constitutes "serious" can be subjective, value-laden exercise. However, in response to the call for objective criteria, commentators have come up with the following mostly objective indicia for ascertaining: ${ }^{470}$

(1) "spatial scale of harm"; whereby the extent of a given harms geographical spread operates as an indication of severity (for example, local, regional, national or global); ${ }^{471}$

(2) "temporal scale of harm"; whereby persistence of harm over time (namely, whether effects are immediate, short term, mid-term, long-term, intergenerational or irreversible) also operates as an indicator of severity;

\footnotetext{
$\overline{469}$ Adrian Deville and Rodney Harding, above n 444, at 25. Daniel Bodansky above n 245, at 387. Per Sandin above n 245, at 889 at 891 to 892. Nicholas de Saadler above n 75, at 16.

${ }^{470}$ Adrian Deville and Rodney Harding above n 444, at 25. Daniel Bodansky above n 245, at 387. Per Sandin above n 245, at 891 to 892. Andreas Klinke and Ortwin Renn "Prometheus Unbound: Challenges of Risk evaluation, risk classification and risk management" (Working Paper No 153, Akademie für Technikfolgenabschätzung in Baden-Württemberg, Stuttgart, 1999) http://elib.unistuttgart.de/opus/volltexte/2004/1712/pdf/ab153.pdf. Arie Trouwborst, above n 75, at 57. Graeme Parkes "Precautionary fisheries management; the CCMLR approach" (2000) 24 Marine Policy 83 at 84.

${ }^{471}$ Arie Trouwborst, above $\mathrm{n} 75$, at 56 to 57
} 
(3) the potential magnitude of an ecological impact on "genetic, species, or ecosystem abundance or diversity and processes such as atmospheric, water and nutrient cycles" and their subsequent impact on human health, wellbeing, enjoyment and economic interests;

(4) the perceived value of threatened environment (i.e. that which will be subject to harm), whereby impacts on highly valued environments (for example, pristine environments, those valued for conservation, or critical human activities and so on) are more readably viewed severe in nature;

(5) the connectivity of a receiving ecosystem (for example, via complex interactions, multiple feedbacks and other linkages) indicates a propensity for pervasive effects (note that this may also go to the spatial scale of harm); and

(6) reversibility of the potential harm (i.e. whether it is permeant in nature), for example will it result in species loss, an ecosystem shift, or the release of persistent harmful substances.

\section{Operationalising the certainty dimension}

As discussed in chapters IV and V, the main thrust of the principle is that it entitles regulatory action to be taken, despite "a lack of certainty about cause and effect relationships, or the nature and extent of environmental harm". ${ }^{472}$ In legal terms, this (contrary to the traditional approach) entitles regulators to act without first having to prove causation (namely, that the activity they seek to regulate will cause harm in the absence of regulatory action). As noted in Chapter III, the standard of proof which regulators were required to meet in order to discharge this burden is proof on the balance of probabilities.

\section{General operation of the certainty threshold}

Subject to the limited number of formulations that operate from the starting point of reversing the burden of proof (i.e. where an activities proponent must to prove its safe before it can be undertaken), most precautionary principle formulations reduce the burden

\footnotetext{
472 James Cameron above n 247, at 35. Arie Trouwborst, above n 75, at 71. Ronnie Harding and Elizabeth Fisher above n 8 , at 10 .
} 
placed on regulators by the need to prove causation. This is done by relaxing the standard of proof that a regulator must meet before they are entitled to implement protective measures.

The certainty dimension built into each formulation of the precautionary principle prescribes the extent to which this standard of proof is relaxed for a regulator wishing to restrict an activity or member of the public wishing to oppose one during a consenting process on the basis of an asserted effect. ${ }^{473}$ In other words, this second component of the "precautionary trigger" stipulates a lesser level or threshold of knowledge as to the possible harm to the environment, which must be met before protective measures are taken, or in other words, before the precautionary response is triggered. As Bodansky notes, however: ${ }^{474}$

this leaves open the question: Is any scientific evidence at all required of a potential threat before precautionary action is warranted, or justified, or required? And, if so, how much evidence? Or can mere speculation or fear trigger application of the precautionary principle?

As the precautionary principle represents a shift away from needing to prove causation, the degree of certainty demanded by any given formulation must therefore reside somewhere between the following levels of scientific confidence: ${ }^{475}$

(1) at the lowest end of the spectrum: "no rational basis in sound science data at all", whereby concerns about environmental impacts are based on mere speculation and unfounded assertions; and

\footnotetext{
$\overline{473}$ Judith Jones and Simon Bronitt above n 279, at 137 to 145. Jamie Benidickson et al above n 159, at D-43 to D-44. The Royal Society of Canada Elements of Precaution: Recommendations for the Regulation of Food Biotechnology in Canada (Health Canada, Canadian Food Inspection Agency and Environment Canada, Expert Panel Report, January 2001) at 196 and 201 to 202. James Cameron and Will Wade-Gery, above n 75 , at 18.

${ }^{474}$ Daniel Bodansky above n 245, at 388.

${ }^{475}$ Adrian Deville and Rodney Harding above n 444, at 33. Arie Trouwborst, above n 75, at 103. Alexander Gillespie, above n 15, at 372. Simon Marr, above n 11, at 25 to 26.
} 
(2) at the highest possible end of the spectrum: proof on the balance of probabilities. ${ }^{476}$

In an effort to identify an appropriate lesser alternative to balance of probabilities (i.e. an objective lesser standard of proof that sits at some point along the above continuum), commentators have attempted to elucidate what the substitute knowledge thresholds (i.e. certainty dimensions) of various existing precautionary principle formulations require. For example, in considering the thresholds of "reasonable scientific possibility" and "reasonable scientific probability" two lead authors note: ${ }^{477}$

A reasonable scientific possibility could be said to exist whenever empirical scientific data (as opposed to mere hypotheses, speculation, or intuition) provide a rational basis that warrants drawing the conclusions from the data, even though reasonable scientific experts might disagree on whether that conclusion is the only valid, inference from the data. A reasonable scientific probability (or likelihood) exists whenever scientific experts generally agree that the available data and methods used to interpret the data are valid and reliable, and when there is also general acceptance by the relevant scientific community of the specific conclusions drawn from the data. "General acceptance" means something less than unanimity, but more than a minority opinion.

Discussing the level at which the certainty threshold is likely pitched by any given formulation Sandin points out "the greater the uncertainty allowed, i.e., the less plausible the threat has to be, the stronger (in the sense of more cautious) is the principle". ${ }^{478}$ In other words, the lower the level of certainty demanded, the more precautionary a formulation is. ${ }^{479}$ In this regard, Applegate notes that "[d]ifferent formulations of precaution envision different relationships between the existence or finding of uncertainty and the obligation to

\footnotetext{
476 Arie Trouwborst, above n 75, at 103. Alexander Gillespie, above n 15, at 372.

${ }^{477}$ James E Hickey and Vern R Walker above n 74, at 499 to 450. Adrian Deville and Rodney Harding above $\mathrm{n}$ 444, at 33. Arie Trouwborst, above n 75, at 103. Alexander Gillespie, above n 15, at 372. Simon Marr, above $\mathrm{n} 11$, at 25 to 26 .

${ }^{478}$ Per Sandin above $\mathrm{n} 245$, at 889 at 893.

${ }^{479}$ Per Sandin above n 245, at 892 to 893.
} 
take regulatory action". 480

At this point it is worth observing that, regardless of the specific point at which a revised lower threshold is set, relaxing the standard of proof that a regulator or opponent is subject to creates what is referred to as a "shifting" or "swinging" (as distinct from reversed) burden of proof, whereby: ${ }^{481}$

(1) a regulatory or opponent is required to discharge their burden of proof to a lower standard by adducing some scientific evidence that meets the standard (i.e. but which itself, would not be sufficient to discharge proof on the balance of probabilities); and

(2) once such evidence is adduced (i.e. to the satisfaction of the lower precautionary standard) the burden then shifts to the proponent of the activity to rebut the presumption in favour of declining or restricting the activity.

\section{Deriving an alternative threshold}

To an extent, the certainty dimensions of the various international law formulations at least give an initial steer as to where on the above continuum the particular revised threshold to be met has been set. Like the harm threshold, these can be disaggregated into strong and weak formulations. Common examples of weak formulations that impose a high threshold (i.e. those that reside further towards the "balance of probabilities" end of the spectrum) include "lack of full scientific certainty" (arguably the most widely endorsed internationally); ${ }^{482}$ and "scientific research has not fully proved a causal link". ${ }^{483}$

\footnotetext{
$\overline{480}$ John S Applegate, above $\mathrm{n} 9$, at 28.

481 Judith Jones and Simon Bronitt above n 279, at 141. Nicholas Ashford "A conceptual framework for the use of the precautionary principle in law" in Carolyn Raffensperger and Joel Tickner (eds) above n 88, at 204. Warwick Gullett “Environmental Protection and the 'Precautionary Principle': A response to scientific uncertainty in Environmental management" (1997) 14 EPLJ 52 at 59.

482 Rio Declaration on Environment and Development, Principle 15, June 14, 1992, U.N. Doc. A/Conf.151/5/Rev.1 (1992) Reprinted in 31 I.L.M. 874, 879 (1992). United Nations Framework Convention on Climate Change, art 3, 31 ILM 854 (opened for signature 9 May 1992, entered into force 21 March 1994) and Convention on Biological Diversity 1760 UNTS 79, 142 (opened for signature 5 June 1992, entered into force 29 December 1993), preamble.

483 United Nations Convention on the Protection and Use of Transboundary Watercourses and International Lakes, opened for signature 17 March 1992, 31 ILM 1316 (1992) (entered into force 6 October 1996); 1994
} 
Stonger formulations that exist towards the mere assertion end of the spectrum however appear not to impose any thresholds at all. ${ }^{484}$ For example, the German Vorsorge (which gave rise to the international law iterations of the precautionary principle), provides that decision-makers may "[act] when conclusively ascertained understanding of science is not yet available". ${ }^{485}$ As indicated above, such lower thresholds (which typically feature in formulations that arise in marine dumping, hazardous substances and modified organisms context) allow precautionary action to be taken: ${ }^{486}$

(1) "when there is reason to believe that wastes or other matter introduced into the marine environment are likely to cause harm even when there is no conclusive evidence to prove a causal relation between inputs and their effects;

(2) "without waiting for scientific proof";

(3) despite a "[l]ack of scientific certainty due to insufficient relevant scientific information and knowledge regarding the extent of the potential adverse effects.

While the above certainty dimension examples prima facie do not impose a minimum proof threshold, it is increasingly accepted that "the plain theoretical possibility of

Agreement on the Protection of the River Scheldt, opened for signature 26 April 1994, 34 ILM 851 (1995); 1994 Agreement on the Protection of the (River) Meuse, opened for signature 26 April 1994, 34 ILM 851 (1995).

${ }^{484}$ Arie Trouwborst above $\mathrm{n} 75$, at 103.

${ }^{485} 1984$ Report from the Government to the Federal Parliament on the Protection of Air Quality, BMI 1984 as cited in Sonia Boehmer-Christiansen "The Precautionary Principle in Germany - Enabling Government" in T O'Riordan and J Cameron (eds) Interpreting the Precautionary Principle (Cameron May, London, 1994) at 37 .

${ }^{486} 1996$ Protocol to the Prevention of Marine Pollution by Dumping of Wastes and other Matter, 1972 and Resolutions Adopted by Special Meeting 36 ILM 7 (opened for signature 7 November 1996, not yet in force). For examples of other marine dumping formulations also see the Convention on the Protection of the Marine Environment of the Baltic Sea Area, art 3(2), BNA 35:0401 (opened for signature 9 April 1992, entered into force 17 January 2000), which instructs decision-makers to act "when there is reason to assume" harm will result. Ministerial Declaration of the Third International Conference on Protection of the North Sea, 7-8 March 1990, which allows action "even where there is no scientific evidence to prove a causal link between emissions and effects...". the Convention for the Protection of the Marine Environment of the North East Atlantic, opened for signature September 22 1992, 32 ILM 1069, Art 2 (entered into force 25 March 1998) ('OSPAR Convention'), which entitles action where "there are reasonable grounds for concern". 
environmental damage is not sufficient to trigger the application of the precautionary principle...". 487 This position was asserted and accepted during the "MOX" plant case where Ireland contested the lawfulness of the United Kingdoms' new nuclear processing plant on a British coastline that was proximate to Ireland. In this case the United Kingdom asserted: ${ }^{488}$

[T]he risk of harm occurring must in some measure be a real risk. It cannot be simply the merest suggestion that harm might occur. While this is not to suggest that the threshold is one of the probability of harm occurring, it must be more than the hypothetical or remote possibility of such harm.

The above internationally certainty threshold examples can be compared with those that feature in the EEZ Act, the NZCPS, the Fisheries Act and HSNO, which respectively, are as follows:

(1) "when information is uncertain, unreliable, or inadequate"; 489

(2) "effects [that] are uncertain, unknown, or little understood"; 490

(3) "information available is uncertain or inadequate"; 491 and

(4) "scientific and technical uncertainty about those effects" ${ }^{492}$

Based on this comparison, it is apparent that the New Zealand thresholds do not include the high threshold qualifiers such as 'full scientific certainty', which are found in the weaker international formulations. However, as noted above, some minimal threshold is likely implicit in each.

\footnotetext{
${ }^{487}$ Charles Weiss "Scientific Uncertainty and Science Based Precaution" (2003) 3 Politics Law and Economics 137. Arie Trouwborst, above n 75, at 107. P.L. De Fur "Implementing the Precautionary Principle: Application to Policies Regarding Endocrine-Disrupting Chemicals" in Carolyn Raffensperger and Joel Tickner (eds), above n 88, at 337.

${ }^{488}$ Written Response of the United Kingdom, dated 15 November 2001 at [184].

${ }^{489}$ Fisheries Act 1996, s 10.

${ }^{490}$ NZCPS, principle 3 .

${ }^{491}$ EEZ Act, s 61(2).

${ }^{492}$ HSNO, s 7.
} 
The problem however, is that it is difficult to derive from the certainty threshold wording in the above domestic legislative formulations, an understanding as to where they reset the standard of proof. Bodansky notes that this is because they do not go beyond a purely negative formulation of defining the type of evidence or proof that is not required, and as such "do not define what positive evidence of an environmental risk is needed in order to trigger application of the precautionary principle". ${ }^{493}$ As such, one must look beyond the specific wording in order to identify what alternative standard of proof is demanded.

\section{Deriving an alternative New Zealand threshold}

The above however does not take us very far. It is beyond the scope of this paper to consider at length the Court's approach to evidence, the process and criteria employed to ascertain admissibility of evidence, and what constitutes proof. However, suffice to say, this paper asserts that when applying the precautionary principle the Courts ought to:

(1) carefully consider what in practice these rules require in order to prove harm on the balance of probabilities; and

(2) work back from this point by reference to the specific mischiefs identified in Chapter IV, in order to identify what certainty threshold will actually be capable of acting in anticipation of harm.

Regarding the latter, this exercise should be conducted by reference to how weak or strong the overall formulation is intended to be. As noted above, a given formulation is only as strong as its weakest dimension. Thus, by implication, a strong overall formulation demands a strong certainty dimension. Strength of a formulation can be discerned from the strength of the other dimensions as well as context it is to be applied in (e.g. if intended for application to dumping of waste, the overall formulation is typically intended to be strong).

\footnotetext{
${ }^{493}$ Daniel Bodansky, above n 245, at 388.
} 
By way of example, when considering what revised threshold (i.e. standard of proof) a given certainty dimension requires in practice, one can look to the Daubert criteria, ${ }^{494}$ which the New Zealand courts have sometimes employed to determine admissibility of evidence. These factors include: ${ }^{495}$

(a) The degree of testing to which the theory or technique has undergone;

(b) The extent of peer review and the publication of the theory or technique;

(c) The known or potential margin of error for a particular technique together with its methodological reliability

(d) The level of general acceptance within the relevant scientific community.

Without exploring each of these criteria in detail, it is worthwhile noting those occasions where the precautionary principle is asserted is likely to involve the offering of novel scientific evidence, otherwise there would not be uncertainty and in turn an need to invoke the principle. Considering this, the Courts should consider the extent to which the application of such criteria:

(1) is likely to give rise to those mischiefs identified in Chapter IV which collectively gave rise to the need to act in advance of scientific proof;

(2) takes them closer towards the balance of probabilities end of the spectrum and thus further away from actually acting in a precautionary manner in advance of science;

(3) is likely to frustrate a regulators capacity to act in advance of harm.

\section{E Command dimension}

As Sandin notes, the command dimension prescribes "what the status of the action is, for example, if the action is allowable, justified, recommended, or mandatory" ${ }^{496}$ In other words this dimension establishes whether the applicable version of the precautionary

\footnotetext{
$\overline{494}$ Daubert v Merrell Dow Pharmaceuticals Inc (1993) 125 L Ed 2d 469 at 480 as cited in Joan Forret above n 15 , at 52 .

${ }^{495}$ Joan Forret, above n 15, at 53.

${ }^{496}$ Per Sandin, above n 245, at 895.
} 
principle: ${ }^{497}$

(1) imposes a positive legal duty on the decision-maker to implement precautionary or protective measures (i.e. to take positive steps); or

(2) merely confers the decision-maker discretion to implement such measures if they so choose.

Strong formulations adopt the former approach. In doing so they employ obligatory language like "shall...take preventative measures", "preventive and abatement action must be taken", "should be taken" and so on. ${ }^{498}$

There are two tiers of weak command dimensions. The weakest tier does not create an affirmative duty to act but rather dispel the ability to rely on scientific uncertainty to justify inaction. ${ }^{499}$ These formulations typically employ ubiquitous triple-negative popularised by the Rio Declaration version of the precautionary principle, which provides: "lack of scientific certainty shall not be used as a reason for postponing cost-effective measures to prevent environmental degradation". The other tier simply emphasise the need to take action when the given precautionary trigger is met. However, in doing so they employ permissive wording that confers the decision-maker discretion to decide whether to do as such. Furthermore, as will be shown in the action dimension below, many weak formulations also often make the taking of precautionary action contingent on cost. ${ }^{500}$

As illustrated in the table on page 111, when comparing such international command dimensions to those that that feature in New Zealand precautionary principle formulations, the following observations cam be made:

(1) It is clear that the EEZ Act sits at the obligatory end of the spectrum by providing that

\footnotetext{
${ }^{497}$ At 895. Rosie Cooney, above n 361

${ }^{498}$ Sachs above n 259, at 1295. Daniel Bodansky, above n 245, at 386. Jonathan Wiener, above n 247, at 604 to 605 . Gary E Marchant, above $\mathrm{n} 7$

${ }^{499}$ Jonathan Wiener, above n 247, at 604. Daniel Bodansky, above n 245, at 384.

${ }^{500}$ Arie Trouwborst, above n 75, at 122. Jonathan Wiener, above n 247, at 605. Daniel Bodansky, above above $\mathrm{n} 245$, at 385 .
} 
where there is uncertainty (more specifically, where the precautionary trigger is met): "the EPA must favour caution and environmental protection".

(2) Similarly, NZCPS formulation, as interpreted by the Supreme Court in the King Salmon decision likewise provides that a decision-maker "[must a]dopt a precautionary approach towards proposed activities whose effects on the coastal environment are [uncertain]", 501

(3) The HSNO formulation appears to occupy a middle ground. While it is more 'directive' in nature, the wording clearly retains an element of discretion on the part of the decision-maker by providing that they "shall take into account the need for caution in managing adverse effects". 502

(4) Similarly, the Fisheries Act employs the discretionary directive at s 10(c), which provides "decision makers should be cautious when information is uncertain, unreliable, or inadequate". This wording arguably creates a stronger command dimension to the HSNO formulation because it goes further than asking the decisionmaker to simply "take into account" a need for caution by stating that they "should be cautious".

Notwithstanding the prima facie retention of decision-maker discretion, the HSNO and Fisheries Act formulations still likely restrain a decision-maker's legal ability to not take precautionary action when faced with uncertainty. These formulations apply to administrative decisions made by officials. The general administrative law principle that the exercise of such discretionary power must be reasonable may be used to set aside a decision where the decision-maker: ${ }^{503}$

(1) in exercising that power, pursues an improper purpose, or fails to take into account relevant considerations, or takes into account irrelevant considerations; or

(2) has made a decision that is so absurd that no sensible person could ever dream that it lay within its powers

\footnotetext{
$\overline{501}$ Department of Conservation New Zealand Coastal Policy Statement (2010), policy 3 at 12. Sustain Our Sounds Inc v the New Zealand King Salmon Company Ltd [2014] NZSC 40; (2014) 10 BRMB 137.

502 HSNO, s 7.

${ }^{503}$ Philip A Joseph Administrative Law (7 May 2015) Lexis Nexis at [100].
} 
Thus, when faced with scientific uncertainty and an activity that has the capability to cause significant harm, a decision-maker will need:

(1) to take these factors together with the strong legislative direction to favour caution in the HSNO and Fisheries Act formulations into account; and

(2) in order to justify not favouring caution, point to a rational basis as to why, in spite of the precautionary triggers being met, such action is not warranted or required. ${ }^{504}$

Regarding the latter, the strength of Parliament's direction (i.e. "should be cautious" vs "shall take into account the need for caution") will likely influence how strong the requisite justification for not favouring caution must be.

\section{F Action dimension}

As noted in Chapter V, the action dimension prescribes the protective measures that are to be taken in response to an identified threat that has triggered a precautionary response. ${ }^{505}$ As illustrated in the course of discussing the various versions of the precautionary principle considered so far, the particular 'precautionary' actions required by each formulation (i.e. in terms of measures prescribed by a given action dimension) can vary in strength and specificity.

Weak action dimensions essentially fall into two camps. One group states that uncertainty is not a basis for postponing action, but does not go as far as to direct that action be taken or specify what types of action are precautionary in nature. Those that fall into this group are in a sense silent as to the nature and extent of the response expected where the precautionary trigger is met. ${ }^{506}$ The second group simply states action should be taken,

\footnotetext{
${ }^{504}$ See Elizabeth Fisher, above $\mathrm{n} 75$ at 83 to 98 . Note that the New Zealand formulations are more directive than the formulations that Fisher examines in the context of judicial review on the basis of failure to apply the precautionary principle in Australia. As such, they arguably provide more robust grounds for judicial review.

${ }^{505}$ See Chapter V discussion on this point. Also refer to Daniel Bodansky above n 245, at 387 and discussion on this point in the New Zealand Context in Alexander Gillespie "Precautionary New Zealand" (2011) 24 NZULR 3364 at 371 to 373.

${ }^{506}$ Daniel Bodansky, above n 245, at 383
} 
but qualifies this by stating that actions must also be cost effective before they may be imposed. This cost qualification is best represented by the widely endorsed Rio Declaration action dimension which directs decision-makers to take "cost-effective measures to prevent environmental degradation" in response to the precautionary trigger thresholds being met. Logically such provisions weaken the precautionary principle, as they provide that its application be linked to economic concerns, thereby subjecting the taking of precautionary measures to a cost-benefit analysis. In turn, this significantly weakens the protective nature of the principle by allowing economic considerations to be used as an excuse to avoid or stop regulatory action. ${ }^{507}$ In particular, this qualification gives rise to a similar cost/benefit analysis to that conducted under the traditional approach, which as noted above, pitches more immediate readily identifiable and readily proven economic loss against often less immediate readily identifiable and readily proven long-term environmental loss.

In most formulations however, the phrases used are not very specific and are expressed in terms such as "precautionary measures", "preventative measures" or like general phrases. ${ }^{508}$ This arguably accords with the idea that what is ultimately required will always

${ }^{507}$ Per Sandin, above n 245, at 894. Catherine J Iorns Magallanes, above n 8, at 6. Michelle Campbell \& Vernon G. Thomas "Implementing the Precautionary Approach: Towards Enabling Legislation for Marine Mammal Conservation In Canada" in DM Lavigne (ed) Gaining Ground: In Pursuit of Ecological Sustainability (Guelph, Ontario, 2006) 321 at 323.

508 Agenda 21: A Programme for Action for Sustainable Development: Report of the UN Conference on Environment and Development, Chapter 22.5,[(c)], UN Doc A./Conf. 151/26 (13 June 1992). Vienna Convention on the Protection of the Ozone Layer, opened for signature 22 March 1985, 1513 UNTS 293 (entered into force 22 September 1988). Montreal Protocol on Substances that Deplete the Ozone Layer, opened for signature 16 September 1987, 1522 UNTS 3 (entered into force 1 January 1989) (as amended 29 June 1990, 25 November 1992, 17 September 1997, and 3 December 1999). United Nations Framework Convention on Climate Change, opened for signature 9 May 1992, 31 ILM 854 (1992) (entered into force 21 March 1994). International Convention on Oil Pollution Preparedness, Response, and Co-operation, opened for signature 30 November 1990, 1891 UNTS 51 (entered into force 13 May 1995). The 1984 Ministerial Declaration of the International Conference on the Protection of the North Sea (1 November 1984). Convention on the Protection of the Marine Environment of the Baltic Sea Area, opened for signature 9 April 1992, BNA 35:0401 (entered into force 17 January 2000). Convention for the Protection of the Marine Environment of the North East Atlantic, opened for signature 22 September 1992, 32 ILM 1069 (entered into force 25 March 1998). 1996 Protocol to the Convention on the Prevention of Marine Pollution by Dumping of Wastes and Other Matter, 1972 and Resolutions Adopted by the Special Meeting, opened for signature 7 November 1996, 36 ILM 7 (not yet in force). 
depend on the circumstances and often cannot be readily ascertained in advance due to scientific uncertainty. It also accords with Fisher's view that the question as to what steps ought to be taken is a value laden one and thus, it is more appropriate that it is answered by each state. Thus, more prescriptive action dimension is not useful or may be limiting. ${ }^{509}$ However, as such formulations do not specify what steps are to be taken they are difficult to class as being strong or weak. ${ }^{510}$

The action dimensions in the various New Zealand precautionary principle formulations largely resemble those vague international law action dimensions described above that are equivocal in terms of precautionary strength. For example, upon triggering a precautionary response the:

(1) HSNO version prescribes "the need for caution in managing adverse effects";,"511

(2) NZCPS version prescribes the adoption of "a precautionary approach towards proposed activities"; and

(3) EEZ Act stipulates that decision-makers must: "favour caution and environmental protection".

Significantly, unlike the most popular precautionary principle formulations found in widely adopted international law instruments such as the Rio Declaration and Convention on Biological Diversity, New Zealand's formulations do not include a cost-effective qualification. ${ }^{512}$ On this basis, the New Zealand courts ought to be careful when looking to such international formulations for guidance when determining what precautionary action should be taken when applying New Zealand formulations. The exclusion of cost considerations aligns with the German Vorsorgeprinzip, which provides (in the context of irreversible harm caused by acid rain) that cost-benefit analysis ought to be excluded from decision-making on the basis such harm ought to be avoided regardless of cost. This view

\footnotetext{
${ }_{509}$ Per Sandin, above n 245, at 894. Elizabeth Fisher and Ronnie Harding above n 391, at 113 and 116.

${ }^{510}$ Per Sandin, above n 245, at 894.

${ }^{511}$ HSNO Act, section 7, above n 415.

${ }^{512}$ See page 85 discussion on cost-effectiveness.
} 
accords with the inter-generational equity notion that underpins the precautionary principle (i.e. that the actions of humans today should not compromise the interests of future generations), and the view that ecosystems should be protected from being compromised permanently because of their intrinsic value. On this basis, a strong argument can be made that the New Zealand legislative precautionary principle formulations, like the Vorsorgeprinzip, contemplate decision-makers and the courts making decisions that:

(1) entail investment in the future, whereby it is appropriate to impose conditions that may involve a significant cost to implement but which are necessary to adequately guard against long-term harm arising; or

(2) involve significant opportunity costs resulting from refusal of consent because the potential harm may impact future generations.

In terms of specific differences, the EEZ Act's emphasis on favouring "environmental protection" in addition to caution likely further strengthens the protective nature of this versions action dimension. A good argument can be made that this additional wording suggests Parliament intended to place considerable emphasis on the need to act early in the marine environment in the face of uncertainty, and as such demands more in terms of action. Such an approach would accord with the sectorial approach described in Chapter $\mathrm{V}$, whereby the strength of the given precautionary formulation is tailored to the specific risk (i.e. harm and uncertainty) that a given sector of environmental management must grapple with. ${ }^{513}$ This view appears to have been accepted in the Trans-Tasman Resources marine consent application because, in discussing the requirement to favour caution under s 61, the decision-making committee states: ${ }^{514}$ "this provision is an explicit statement that, within the context of the EEZ Act, the promotion of sustainable development requires a cautious approach". Furthermore, they go on to note: ${ }^{515}$

\footnotetext{
${ }^{513}$ See discussion in Chapter V under "Status of the precautionary principle in international law".

${ }^{514}$ Environmental Protection Authority, Trans-Tasman Resources Ltd Marine Consent Decision, June 2014 at [139].

${ }^{515}$ Above at [774].
} 
Section 61(2) is an important section of the EEZ Act and a significant difference from the RMA. Caution and environmental protection are specifically stated and is a 'lens' through which we must view the proposal to determine if it meets the purpose of the Act (section 10).

In Chatham Rock Phosphate, the decision-making committee also appears to adopt the same view. ${ }^{516}$

The Fisheries Act is similar in that at s 10(c) it states that decision-makers "should be cautious" when confronted with uncertainty thereby employing an action dimension that is neutral in terms of strength. However, at s 10(d) it goes on to state that uncertainty "should not be used as a reason for postponing or failing to take any measure to achieve the purpose of this Act". Thus, (in contrast to the EEZ Act version) it is more akin to weaker formulations that merely permit precautionary action, rather than requiring it. Arguably the prima facie weaker s 10 (d) action component does not weaken the overall action dimension established in s $10(\mathrm{c})$, but rather simply re-enforces the precautionary imperative imposed on the decision-maker. To date, case law discussing s 10 has not examined it in this level of detail. $^{517}$

\section{$1 \quad$ Precautionary measures}

The range of measures that can be undertaken in order to implement the precautionary principle are not novel and do not fall within the exclusive domain of the principle. ${ }^{518}$ Whether a given environmental measure is, if implemented, truely precautionary in nature, depends on whether in the circumstances it is effective at giving effect to the precautionary principle's purpose (i.e. operates to address the mischief the precautionary principle seeks

\footnotetext{
${ }^{516}$ Environmental Protection Authority, Chatham Rock Phosphate Limited Decision, February 2015, at [827]. ${ }^{517}$ See for example Squid Fishery Management Company Ltd v Minister of Fisheries CA 39/04 13 July 2004 and Roaring Forties Seafood Limited v Minister of Fisheries HC Wellington CIV-2003-485-2706, 11 - 12 February 2004.

${ }^{518}$ Arie Trouwborst, above n 75, at 179. Freestone above n 12, at 141. Nollkaemper above n 447, at 80.
} 
to avoid). ${ }^{519}$ As Freestone notes: ${ }^{520}$

the distinctive feature of the precautionary principle/approach is not that it dictates specific regulatory measures: many different types of measures can be used to implement it. The distinctive characteristic is the way in which, and the time at which, the measures are to be adopted.

On the above basis this paper does not explore various measures at length but rather focuses on the substantive characteristics that a given measure should possess.

\section{Effectiveness as a general consideration}

As Trouwborst notes, in determining "how should we go about taking precautionary action, "effectiveness" the fundamental determining factor; the condition of effectiveness is so logically apparent that it arguably exists within the precautionary principle tacitly by necessary implication. ${ }^{521}$

A measure is effective if it is likely to produce the desired outcome. ${ }^{522}$ Whether "the measures envisaged...make it possible to achieve the appropriate level of protection", depends on their ability to anticipate (i.e. intervene in advance of) the given harm and prevent it before it occurs, rather than react to harm ex post facto. ${ }^{523}$ On this basis, an action is only truly precautionary in nature if it operates as an effective remedy to the harm and uncertainty mischiefs identified in Chapter IV that the precautionary principle ultimately exists to prevent. ${ }^{524}$

\footnotetext{
${ }_{519}$ Patricia Birnie and Alan Boyle International Law and the Environment (Oxford University Press, Oxford, 2002) at 676.

${ }^{520}$ Freestone above $\mathrm{n} 12$, at 141 .

${ }^{521}$ Arie Trouwborst above $\mathrm{n} 75$, at 147 to 148 .

522 European Commission Communication from the Commission on the Precautionary Principle, $\operatorname{COM}(2000) 1$ final: 2000 Brussels at 18. Rene Lefeber Transboundary Environmental Interference and the Origin of State Liability (Kluwer Law International, The Hague, 1996) at 61. Arie Trouwborst above n 75, at 147 to 148 .

${ }^{523}$ De Saadler above n 75, see introduction section.

${ }^{524}$ Arie Trouwborst, above n 75, at 147 to 148 .
} 
As Kaiser states it must be: "designed to effectively reduce the likelihood of the perceived harm occurring". ${ }^{525}$ Thus given the above, what constitutes an effective precautionary measure will depend on the circumstances, and in particular:

(1) the specific characteristics and idiosyncrasies of the receiving ecosystem;

(2) the kind of harm that is to be prevented or abated (e.g. the gravity and nature of the harm); the extent of the uncertainty that the decision maker is faced with; and

(3) the relevant limitations of science (e.g. if one must rely on modelling to determine ecological impacts then the limitations must be kept in mind).

On the above basis, it can be argued that in order for a decision-maker to be able to effectively determine what action constitutes an appropriate "precautionary measure" or amounts to "favouring caution" they must:

(1) have a detailed understanding of those matters outlined in Chapter IV, which the precautionary principle seeks to overcome; and

(2) proposed actions ought to be sense checked against these factors in order to ascertain whether a proposed precautionary action is in fact capable of overcoming such matters or mischief.

\section{Other general considerations}

In terms of further general substantive points, it is clear, particularly in stronger formulations of the precautionary principle, that precautionary measures entail not only caution but also an almost perpetual effort to actively take positive steps to avert harm. ${ }^{526}$ This is demonstrated in the Vorsorgeprinzip, which demands that decision-makers take "active measures". ${ }^{527}$ Specifically, as outlined in Chapter V, in terms of intervention, the German formulation requires regulators to:

\footnotetext{
$\overline{525}$ Matthias Kaiser "Fish-Farming and the Precautionary Principle: Context and Values in Environmental Science for Policy" (1997) 2FS Environmental Science for Policy 307 at 328.

${ }^{526}$ Arie Trouwborst, above n 75, at 148 to 149 . Adrian Deville and Rodney Harding above n 444, at 37 to 78 .

${ }^{527}$ See Chapter V discussion on the German formulation of the precautionary principle.
} 
(1) be actively looking to the future;

(2) engaging in long-term planning that looks ahead to address harm as early as is possible;

(3) actively attempt to detect dangers through ongoing research; and

(4) require ongoing investment in measures designed to avoid and abate harm.

As noted in Chapter V, the Vorsorgeprinzip is closely related to the concept of Gefahrenabwehr, which translates into 'defence against dangers and threats', a concept, which inherently contemplates active and vigilant regulatory behaviour. ${ }^{528}$ Chapter V tracks migration of the majority of the Vorsorgeprinzip's substantive content from German law into the international law formulations. Thus, on this basis, it may be argued that this informs the action dimension of any given international precautionary principle formulation. In terms of the active element of the required precautionary action, this is arguably demonstrated through the widely adopted Bergen Declaration, which as Trouwborst notes: "[stipulates] that precautionary measures "must anticipate, prevent, and attack the causes of environmental degradation"".529 Given that New Zealand's has essentially cut and pasted those international precautionary principle versions that were inspired by the Vorsorgeprinzip into its environmental legislation, a good argument can be made that this active steps notion was also carried over into the action component of New Zealand's domestic formulations as well.

That precautionary actions must be proportional is also implicit in the action dimension. ${ }^{530}$ This concept, which is of considerable importance to the principle's function essentially operates as a counter-balance to the effectiveness requirement. ${ }^{531}$ As Trouwborst summarises (emphasis added): ${ }^{532}$

\footnotetext{
${ }^{528}$ Arie Trouwborst, above n 75, at 148 to 149 .

529 At 149.

530 Timothy O'Riordan and James Cameron “The Precautionary Principle in Contemporary Environmental Law and Politics" in Raffensberger and Tickner, above n 88. David Vanderzwaag, above n 2, at 167. Fisher above $\mathrm{n} 35$, at 320 .

${ }^{531}$ Arie Trouwborst, above n 75, at 149.

532 At 150 .
} 
Effectiveness ensures that the relevant purpose is served; proportionality ensures that this is all that happens and no more than that, by adjusting the means to the objective...From the start, proportionality has been a critical feature in the application of the precautionary principle...the notion is firmly anchored in pertinent state practice...The more significant or the more serious the expected environmental impact, the more rigorous the abatement measures may, respectively be.

In addition, Deville and Harding assert that the more uncertain the threat is the more cautious we must be. ${ }^{533}$ This feature of the principle accords with the precautionary principle's core task of ensuring that the necessary steps are taken in order to avoid harm before it occurs. Logically, one can only achieve this if the precautionary measures taken are commensurate with the uncertainty faced, otherwise one is effectively back to operating on a traditional approach basis, whereby the requisite steps are only taken after one has proof that they are necessary to avoid harm. Furthermore, this also accords with sustainable management purpose that the precautionary principle ultimately seeks to serve, which itself entails finding the appropriate balance between protective measures and use.

Implicit in the requirement of effectiveness is the need to ensure that measures are comprehensive, integrated and account for the connected nature of ecosystems and temporal issues such as the time-delayed and non-linear nature of ecosystem changes ${ }^{534} \mathrm{In}$ this regard the precautionary principle is closely linked to the ecosystem approach. ${ }^{535} \mathrm{As}$ such, for an action to be truly precautionary, it must for example, take into account whether the chosen precautionary measure is in fact capable of:

(1) guarding against time delayed and non-linear harm - e.g. will imposing monitoring requirements as a precautionary measure successfully enable detection of such harm

\footnotetext{
${ }_{533}$ Deville and Harding above $\mathrm{n} 444$ at 37.

${ }^{534}$ Hey above n 79, at 308. Arie Trouwborst, above n 75, at 183.

${ }^{535}$ Tickner above n 76, at 6. N.A. Robinson "Legal Proceedures for Ecosystem Management: Environmental Law's First Challenge of the New Millennium” (2000) 5 APJEL 203. Trouwborst above n 379.
} 
and thus, operate as an effective means of bridging the knowledge gap that is responsible for uncertainty;

(2) taking into account the innumerable ecological connections than may be affected by a given impact; and

(3) adequately protecting such ecological connections from an ultimate harm that may manifest as a product of a culmination of of knock on impacts being communicated through such connections.

Finally, critical to aiding the selection of the appropriate and effective response is the need to impose measures that are bias towards environmental protection. Drawing on factors such as scientific biased against finding causal relationships (i.e. between an activity and resulting harm) that is inherent in statistical analysis, ${ }^{536}$ and the need to safeguard ecological space, ${ }^{537}$ measures should play it safe by favouring environmental protection. ${ }^{538}$

\section{Adaptive management}

In the consenting context in New Zealand, particularly in the marine space, decisionmakers and the courts have often asserted that allowing an activity for which consent is sought to occur under an adaptive management approach amounts to a precautionary response (i.e. proper application of the precautionary principle). ${ }^{539}$ In addition, the EEZ Act closely pairs the precautionary principle and adaptive management in s 61(3) which as noted above provides: ${ }^{540}$

If favouring caution and environmental protection means that an activity is likely

\footnotetext{
${ }^{536}$ See discussion at pages 51 to 54 above.

${ }^{537}$ See discussion at pages 68 to 69 .

538 Van Dyke above n 322, at 330. E.J. Molenaar “Addressing Regulatory Gaps in High Seas Fisheries" (2005) 20 IJMCL 533 at 537. David Vanderzwagg "The Implications for the Canadian Environmental Protection Act (CEPA)" (1994)

539 See for example Kuku Mara Partnership (Beatrix Bay) v Marlborough District Council (No 2) EnvC W 39/2004 at [35(g)], [221], [229] and [717], which when read together demonstrate the Court considers requiring adaptive management equals proper application of the precautionary principle. Golden Bay Marine Farmers v Tasman District Council (No 2) W19/2003 at Chapter 5.

${ }^{540}$ EEZ Act, s 61.
} 
to be refused, the EPA must first consider whether taking an adaptive management approach would allow the activity to be undertaken.

In other words, s 61(3) states that if, in light of the uncertainty and harm associated with an activity for which consent is sought (i.e. which has triggered application of the precautionary principle), decision-makers think the appropriate precautionary response is to refuse the activity, the EPA must first consider whether taking an adaptive management approach would allow the activity to occur.

Given the above, it is worthwhile examining the adaptive management measure and considering the application of the "effectiveness" and other criteria above, in order to see whether employing adaptive management in response to the Act's precautionary triggers being met truly amounts to proper application of the precautionary principle.

While a universal definition of adaptive management does not exist, the definition cited by the Environment Court in Clifford Bay Marine Farms Limited is representative: $:^{541}$

Adaptive Management: An experimental approach to management, or "structural learning by doing". It is based on developing dynamic models that attempt to make predictions or hypotheses about the impacts of alternative management policies. Management learning then proceeds by systematic testing of these models, rather than by random trial and error. Adaptive management is most useful when large complex ecological systems are being managed and management decisions cannot wait for [mal research results.

In practice, adaptive management entails allowing an activity that has uncertain ecological effects to start on a smaller scale than is ultimately sought under an application for consent

${ }^{541}$ Clifford Bay Marine Farms Limited v Marlborough District Council EnvC C 131/2003 at [151]. Golden Bay Marine Farmers v Tasman District Council NZEnvC Wellington W 19/03, 27 March 2003 at [78] to [79]. See also Anne-Marie Smit "Adaptive monitoring: an overview" (DOC Science Internal Series 138, October 2003). Benidickson et al above n 159, at A-2. R.E. Grumbine "What is Ecosystem Management?" (1994) 8:1 Conservation Biology 27 at 31. 
subject to the following: $:^{542}$

(1) the collection of baseline information about the receiving ecosystem upon which subsequent adaptive monitoring is based (e.g. information about the health and population of species that are believed to indicate an ecosystems health or natural state prior to the proposed activity taking place);

(2) scientific monitoring of the smaller scale version of the proposed activity's impact on the receiving environment overtime in order to detect, for example: (a) changes or deviations from the baseline ecological starting point; and (b) if relevant, levels of specified chemicals or substances introduced or generated in the receiving environment as a result of the activity;

(3) thresholds (in terms of deviation from an identified ecological indicator baseline), at which remedial action is triggered, which are set on the basis that taking action at this point allows sufficient time to react before the impact becomes overly damaging or irreversible harm; and

(4) the activity being allowed to expand in timed stages, typically over the course of several years, towards the full activity for which consent was sought, provided that the relevant thresholds are not triggered; and

(5) if triggered, a prescribed management response is initiated, which may entail reassessment of the activity, implementation of prescribed mitigation measures or the requirement that the activity be ceased.

This paper asserts that while adaptive management may form part of a precautionary response, this tool in and of itself is not inherently precautionary in nature for the following reasons. First, adaptive management emerged as the primary means of implementing the ecosystem approach, which recognises that as a result of the multitude of ecosystem links and processes explored in chapter IV:

\footnotetext{
$\overline{542}$ Board of Inquiry's decision in New Zealand King Salmon Requests for Plan Changes and Applications for Resource Consent Blenheim, 22 February 2013 at [181]-[182]. Crest Energy Kaipara Ltd v Northland Regional Council [2011] NZEnvC 26 at [8]. Golden Bay Marine Farmers above n 541. Derek Nolan \& Claire Kirman, above n 31, at 384 to 386. Grumbine above n 541. Benidickson et al above n 159, at A-2.
} 
(1) activities undertaken in one location may have unforeseen consequences elsewhere, often far away and many years later; ${ }^{543}$ and

(2) fragmented sectoral and species-specific approaches to environmental management fail to adequately protect the environment (i.e. as they are blind, and thus fail to account for, the wider ecosystem impact of an activity and the cumulative effects of multiple activities on the receiving environment). ${ }^{544}$

As explained in chapter $\mathrm{V}$, the ecosystem approach responds to the above by taking an integrated and holistic approach, whereby decision-makers are required to take into account "all of the components of an ecosystem, both physical and biological, of their interaction and of all activities that could affect them". 545 Thus, while the ecosystem approach has some functional overlap with the precautionary principle, ${ }^{546}$ it serves an entirely different primary functional purpose to the precautionary principle. In particular, the ecosystem approach is designed to facilitate a shift from fragmented to holistic environmental management practices, whereas the precautionary principle is intended to facilitate a shift from reactive to anticipatory practices. ${ }^{547}$

Within the above context, the ecosystem approach acknowledges there will often be uncertainty as to how the impacts of a given activity will communicate throughout the receiving ecosystems. ${ }^{548}$ As such, it employs an adaptive management method of "learning by doing" to assist with discerning an activities wider impacts so that holistic management

\footnotetext{
${ }^{543}$ Secretariat of the Convention on Biological Diversity above n 134, at 1. Trouwborst above n 379, at 28. ${ }^{544}$ Wang above $\mathrm{n} 34$, at 46.

545 Owen McIntyre "The Emergence of an 'Ecosystem Approach' to the Protection of International Watercourses under International Law" (2004) 13 (1) RECIEL 1 at 1. Maltby above n 386, at 17. Report of the Secretary General above n 49, at [137]. DA Laffoley and others above n 386, at 7. Wang above n 34, at 46.

${ }^{546}$ For example, as discussed in chapter $\mathrm{V}$, at a meta level application of the precautionary principle entails ongoing research to continue to develop our understanding of the impact activities have on the ecosystem.

${ }^{547}$ Trouwborst above $\mathrm{n} 379$.

${ }^{548}$ McIntyre above $\mathrm{n} 545$. Maltby above $\mathrm{n} 386$. Report of the Secretary General above $\mathrm{n} 49$. Wang above $\mathrm{n}$ 34. Sustain Our Sounds Inc $v$ the New Zealand King Salmon Company Ltd [2014] NZSC 40; (2014) 10 BRMB 137. Environmental Protection Authority, Trans-Tasman Resources Ltd Marine Consent Decision, June 2014.
} 
practices can follow. On this basis it can be said, the purpose that adaptive management is also designed to achieve is holistic, as opposed to anticipatory, environmental decisionmaking. ${ }^{549}$ In turn, the tools used to implement it, principally adaptive management, are geared towards effecting a functional shift to holistic, not anticipatory environmental management practices.

In addition, based on the following, a strong argument can be made that adaptive management possesses all the hallmarks of the traditional approach. As noted in chapter $\mathrm{V}$, adaptive management is an entirely science based approach (i.e. all decisions as to whether or not an activity is allowed are based entirely on scientific findings). In this regard adaptive management: ${ }^{550}$

(1) relies on science to measure the 'baseline' conditions of the receiving ecosystem (i.e. typically by measuring the presence and condition of indicator species), and over time, monitors impact of the activity by measuring deviations from the baseline ecological state (i.e. the pre-activity ecological status quo); ${ }^{.51}$

(2) sets impact thresholds (i.e. levels of insult that science believes the receiving ecosystem can tolerate) and assumes that there will be sufficient time to react and avoid significant harm if action is taken when these thresholds are breached; and

(3) allows the activity to proceed, be it in a staged manner over several years, unless there is scientific proof that it is causing harm.

Based on the above, it may be said that adaptive management is subject to the full battery of limitations explored in chapter IV that render science often incapable of anticipating harm. While extensive analysis of the scientific limitations associated with adaptive management is beyond this paper, the following factors count against its capacity

\footnotetext{
549 Ibid.

${ }^{550} \mathrm{~J}$ Brunée and S Toope, above n 384, at 41 onwards, as cited in DEJ Currie above n 384. Owen McIntyre above n 384. http://www.msfd.eu/knowseas/library/PB2.pdf at 4. Oceans and the Law of the Sea: Report of the Secretary General, above n 49. Randall Peterman and Michael M'Gonigle "Statistical Power Analysis and the Precautionary Principle (1992) 24, No 5 Marine Pollution Bulletin 231. M'Gonigle above n 79 551 Ibid.
} 
to anticipate harm:

(1) By monitoring deviations from baseline measurements of ecological indicators, adaptive management employs the standard scientific process of disproving a null hypothesis. $^{552}$

(2) Despite being an exercise of ascertaining wider ecosystem effects, it focuses on the relatively discrete analysis of indicator species, and in doing so it: assumes such species operate as a representative indication of all potential impacts the activity in question has on the receiving ecosystem's components; may overlook synergistic and cumulative effects; and, may also ignore impacts on related ecosystems and so on. ${ }^{553}$

(3) It relies on statistical analysis to prove or disprove the null hypothesis, and in doing so becomes subject to the bias in favour of type II errors.

(4) Despite being conducted over a period of several years, is likely unable to overcome the impediment to predicting and proving causal relationships brought about by factors such as temporal delays between impacts and the manifestation of harm, oscillating ecosystem processes, and other non-linear effects.

Based on the above a strong argument can be made that in essence, adaptive management is simply a staged version of the traditional approach. The fundamental difference being that it eliminates some scientific uncertainty as it affords the proponent of an activity more time to gathering information regarding ecological impacts, and allows them to use monitoring of real effects rather than scientific modelling alone, which as noted in chapter IV is fraught with uncertainty.

To conclude, this paper asserts that such an approach to vetting the precautionary pedigree of a potential measure ought to be taken when applying the action dimension of the precautionary principle. In doing so the effectiveness of the measure ought to be considered in light of the circumstances (e.g. the nature of the activity and uncertainties that are being contended with.

\footnotetext{
552 Ibid.

553 See Chapter IV which explains this in detail.
} 


\section{Conclusion}

As this paper has demonstrated, the precautionary principle has clearly evolved far beyond the common sense notion that the legal principle was originally derived from. In doing so it has:

(1) grown into a rich territory meaning;

(2) developed from an aspirational notion into either, depending on the given formulation, a legal principle or binding legal rule; and

(3) become inextricably entangled with other fundamental environmental law norms that are at the core of most environmental management legislative regimes.

Although the principle has developed considerably in both international law and domestic legal systems (particularly in terms of its application with respect to domestic systems) it still has a long way to go before it may be properly regarded as a fully developed legal norm. This development deficit is problematic as it creates pressing issues for decision makers and the courts when the precautionary principle is incorporated into legislation in a rule like manner without first addressing this development, or rather operationalising issue.

In spite of this issue and notwithstanding its active role in the precautionary principle's development at international law, New Zealand's approach to implementing the principle domestically has from the start been fundamentally flawed. As outlined above, this is the result of what appears to be a demonstrable failure to properly engage with, understand, and operationalise the principle (i.e. unpack the international law 'summary' definitions when incorporating them into legislation) before applying it domestically.

As examined in chapter VI, failure to operationalize the precautionary principle and establish a structured uniform approach to applying it, can lead to its misapplication. In the consenting context, this can in turn result in the approval of activities that cause significant and irreversible harm. Such an outcome operates to undermine the ability of the legislative 
environmental management regime that it is applied under, to serve its overall purpose of sustainable management and associated objectives (e.g. intergenerational equity and maintenance of the life supporting capacity of ecosystems).

In light of the above, it is imperative that New Zealand operationalises the domestic formulations of the precautionary principle, which are applied under the various legislative regimes that it features in and establishes a robust and uniform approach to its application. As noted in chapters I and VI, this is particularly important in the marine setting due to: the mass prevalence of scientific uncertainty associated with marine ecosystems and the impact that human activities inflict when conducted in this space; and, the elevated potential for such activities to cause widespread significant and irreversible harm. In considering how this is achieved it is worth noting the:

(1) the disparity between the approaches taken to applying the precautionary principle in New Zealand in various cases that have applied it to date; and

(2) considerable disagreement both internationally and nationally as to what the wider substantive content of the precautionary principle entails; and

(3) fact that operationalising the precautionary principle entails making various value judgements in respect of the levels of risk that New Zealand is willing to assume (i.e. as a result of electing to incorporate into a given formulation, operational detail that strengthens or weakens the given formulation).

Given the above factors, it is unlikely that the monumental task of "opeationalising" the precautionary principle can or should be achieved through the courts' efforts of interpreting the existing high-level definitions and elucidating their substantive content. Arguably, such disparity demonstrates that a strong legislative steer is required to establish a standardised approach to applying the precautionary principle. Furthermore, while the courts may be well placed to elucidate the burden and standard of proof issues, resolving many of the other definitional ambiguities imbedded within the principle will likely entail value judgements that should only be made by elected officials. Furthermore, the task of clarifying, operationalizing, and properly embedding the precautionary principle into 
existing risk management regimes will require considerable coordination. On this basis the only viable way to resolve the fundamental issues identified by this paper will be though the development of policy by central government and the implementation of it through legal instruments such as legislation, regulations and policy documents like the NZCPS. 


\section{Bibliography}

\section{A Cases}

$1 \quad$ New Zealand

Bleakley v Environmental Risk Management Authority (2005) 11 ELRNZ 289

Golden Bay Marine Farmers v Tasman District Council NZEnvC Christchurch W42/2001, 27 April 2001.

McIntyre v Christchurch City Council [1996] 2 ELRNZ 84 at 99

Rotorua Bore Users Association Inc v Bay of Plenty Regional Council NZEnvC Auckland A 138/98, 27 November 1998

Shirley Primary School v Christchurch City Council (1999) NZRMA 66 (EnvC).

Sustain Our Sounds Inc v the New Zealand King Salmon Company Ltd [2014] NZSC 40; (2014) 10 BRMB 137.

Vertical Telecoms Pty Ltd v Hornsby Shire Council [2000] NSWLEC 172 and Miltonbrook Pty Ltd v Kiama Municipal Council [1998] NSWLEC 281.

\section{B Legislation \\ $1 \quad$ New Zealand}

(a) Bills

Economic Zone and Continental Shelf (Environmental Effects) Bill 2012 (321-1). Economic Zone and Continental Shelf (Environmental Effects) Bill 2012 (321-2). Economic Zone and Continental Shelf (Environmental Effects) Bill 2012 (321-3). Fisheries Act Amendment Bill 1996. 
(b) Acts

Economic Zone and Continental Shelf (Environmental Effects) Act 2012.

Fisheries Act 1996.

Hazardous Substances and New Organisms Act 1996.

Resource Management Act 1991.

\section{International Law \\ $1 \quad$ Conventions}

Cartagena Protocol on Biosafety to the Convention on Biological Diversity, arts 10 and 11, 39 ILM 1027 (opened for signature 29 January 2000, entered into force 11 September 2003).

Convention on Biological Diversity opened for signature 5 June 1992, 1760 UNTS 79, 142 (entered into force 29 December 1993).

Convention for the Protection of the Marine Environment of the North East Atlantic, opened for signature September 22 1992, 32 ILM 1069

United Nations Convention on the Law of the Sea, opened for signature 10 December 1982, 1833 UNTS 3 (entered into force 16 November 1994).

United Nations Rio Declaration on Environment and Development, Principle 15, UN Doc. A/CONF.151/26 (vol. I) (1992); 31 ILM 874 (1002).

Convention for the Protection of the Marine Environment of the North East Atlantic, opened for signature September 22 1992, 32 ILM 1069, Art 2 (entered into force 25 March 1998) (OSPAR Convention“).

United Nations Framework Convention on Climate Change, art 3(3), opened for signature 9 May 1992, 1771 UNTS 10. 
Agenda 21: A Programme for Action for Sustainable Development: Report of the UN Conference on Environment and Development, Chapter 22.5,[(c)], UN Doc A./Conf. 151/26 (13 June 1992).

Bergen Ministerial Declaration on Sustainable Development in the ECE Region, 16 May 1990

Convention on Biological Diversity 1760 UNTS 79, 142 (opened for signature 5 June 1992, entered into force 29 December 1993).

The 1984 Ministerial Declaration of the International Conference on the Protection of the North Sea (1 November 1984) Preamble, available at Government of Sweden < http://www.sweden.gov.se $>$.

15 Declaration of the Second International North Sea Conference on the Protection of the North Sea (25 November 1987) (_London Declaration“) [VII].

Oceans and the law of the sea Report of the Secretary General GA Res 69(a) A/61/63, (2006).

The 1984 Ministerial Declaration of the International Conference on the Protection of the North Sea (1 November 1984).

Ministerial Declaration of the Second International Conference on the Protection of the North Sea, 24-25 November 1987.

Report of the World Commission on Environment and Development GA Res, 42/187 XLII annex to $\mathrm{A} / 42 / 427$ (1987)

United Nations Environmental Planning Governing Council Decision on the Precautionary Approach to Marine Pollution, Including Waste-Dumping at Sea, Decision 15/27, UN GAOR 44th sess, Supp No 25 UN Doc A/44/25 152 (25 May, 1989).

United Nations Rio Declaration on Environmental Development, Principle 15, UN Doc. A/CONF.151/26 (vol. I) (1992); 31 ILM 874 (1002)

World commission on Environment and Development, Our Common Future: From One Earth to One World (The Brutland Report) 1987. 
World Charter for Nature 1982 General Assembly Resolution 37/7, Report of the United Nations Conference on Environment and Development, Rio de Janeiro, 3-14 June 1992 (United Nations publication, Sales No. E.93.I.8 and corrigenda).

\section{Judgements}

Mox Plant Case (Ireland v UK) (Order) [2001] International Tribunal for the Law of the Sea $<$ http//:www.itlos.org $>$.

Request for an Examination of the Situation in Accordance with Paragraph 68 of the Courts judgement of 20 December 1974 in Nuclear Tests (New Zealand v France) (Order 22 IX 95) [1995] ICJ Rep 348, 412 [Nuclear Case].

The Southern Bluefin Tuna Cases (New Zealand \& Australia v Japan) (Order 27) [1999] International Tribunal for the Law of the Sea $<\mathrm{http} / /$ :www.itlos.org $>$.

\section{Resolutions}

Decision V/6 by the Conference of the Parties to the Convention on Biological Diversity at its fifth meeting, Nairobi, 15-26 May 2000, UNEP/COP/5/23.

Oceans and the law of the sea Report of the Secretary General GA Res 69(a) A/61/63, (2006).

Oceans and the law of the sea GA Res 71(a) A/Res/61/222, (2006).

Resolution LDC 44(14) on the Application of the Precautionary Approach to Environmental Protection within the Framework of the London Dumping Convention, Annex 2, Doc. LDC 14/16, December 301991

United Nations Environmental Planning Governing Council Decision on the Precautionary Approach to Marine Pollution, Including Waste-Dumping at Sea, Decision 15/27, UN GAOR $44^{\text {th }}$ sess, Supp No 25 UN Doc A/44/25 152 (25 May, 1989).

UN General Assembly Resolution 44/225 on Large-Scale Pelagic Driftnet Fishing and its impact on the Living Marine Resources of the World's Oceans and Sea's, March 15, 1990, (1990) 29 ILM 1555. 
United Nations General Assembly, Open-ended Informal Consultative Process on Oceans and the Law of the Sea (2006) at its $7^{\text {th }}$ Meeting in New York, U.N. Doc. A/61/156 17 July 2006) ICP Report-7

\section{Books and Chapters in Books}

Alan Boyle and David Freestone, International Law and Sustainable Development: Past Achievements and Future Challenges (Oxford University Press, Oxford, 1999).

Alan Boyle and David Freestone (eds) International Law and Sustainable Development: Past Achievements and Future Challenges (Oxford University Press, Oxford, 2001)

Alexandre Kiss and Dinah Shelton International Environmental Law (3ed, Transnational Publishers, New York, 2004).

A Hurrell and B Kingsbury (eds) The International Politics of Environment (Clarendon Press, Oxford, 1992)

Arie Trouwborst Evolution and Status of the Precautionary Principle in International Law (Kluwer Law International, The Hague, 2002)

Arie Trouwborst Precautionary Rights and Duties of States (Martinus Nijhoff Publishers, Leiden, 2006).

A Weale The new politics of pollution (Manchester University Press, London, 1992)

Benedicte Sage-Fuller The Precautionary Principle in Marine Environmental Law (Routledge, London, 2013). Bruce Pardy Environmental Law: A Guide to Concepts (Butterworths, Toronto, 1996)

Cagan Sekercioglu "Ecosystem functions and services" in Navjot Sodhi and Paul Ehtlich Conservation Biology for All" (Oxford University Press, Oxford, 2010)

Daniel Bodansky, Jutta Brunnee and Ellen Hey (eds) The Oxford Handbook of International Environmental Law (Oxford University Press, Oxford, 2007).

David Freestone (ed) Legal Aspects of Sustainable Management (Martinus Nijhoff, Boston, 2011).

David Freestone and Ellen Hey (eds) The Precautionary Principle and International Law: The Challenge of Implementation (Kluwer International, Hague, 1996). 
David D Cameron and Harry N Scheiber (eds) Bringing New Law to Ocean Waters (Martinus Nijhoff Publishers, Berkeley/Boston, 2004).

DM Lavigne (ed) Gaining Ground: In Pursuit of Ecological Sustainability (Guelph, Ontario, 2006).

Derek Nolan Environmental Law and Resource Management $\left(4^{\text {th }}\right.$ ed, Lexis Nexis, Wellington, 2011).

Donald R Rothwell and David L VanderZwagg "The sea change towards principled oceans governance" in Donald R Rothwell and David L VanderZwagg (ed) Towards Principled Oceans Governance: Australian and Canadian approaches and challenges (Routledge, London, 2006) 3.

Davor Vidas "Responsibility for the Seas" in Davor Vidas (ed) Law, Technology and Science for Oceans in Globalisation (Martinus Nijhoff, Boston, 2010).

DM Lavigne (ed) Gaining Ground: In Pursuit of Ecological Sustainability (Guelph, Ontario, 2006).

Durwood Zaelke, Donald Kaniaru and Eva Kruzikova (eds) Making Law Work: Environmental Compliance and Sustainable Development Volume 1 (Cameron May, London, 2005).

DA. Laffoley, E. Maltby, M. A. Vincent, L. Mee, E. Dunn, P Gilliland, J. P Hamer, D. Mortimer, and D. Pound, The ecosystem approach. Coherent actions for marine and coastal environments. A report to the UK Government (English Nature, Peterborough, 2004),

Ebbesson, J. Compatibility of international and national environmental law $\left(6^{\text {th }}\right.$ ed, Kluwer Law International, London, 1996).

Elizabeth Fisher, Judith Jones and Rene von Schomberg (eds) Implementing the Precautionary Principle: Perspectives and Prospects (Edward Elgar, Cheltenham, 2006)

G Likens An Ecosystem Approach: Its Use and Abuse (Ecology Institute, Oldendorf, 1992).

Gary E. Marchant and Kenneth Mossman Arbitrary and Capricious: The Precautionary Principle in the EU Courts (AEI Press, Washington, 2004)

Geoffrey Palmer Environment: The International Challenge (Victoria University Press, Wellington, 1995) 
Harald Hohmann Precautionary Legal Duties and Principles of Modern International Environmental Law (Martinus Nijhoff, London, 1994).

James Cameron "The precautionary principle: Core meaning, constitutional framework and procedures on implementation" in Ronnie Harding and Elizabeth Fisher Perspectives on the Precautionary Principle (The Federation Press, Sydney, 1999) 2.

Julian Morris Rethinking Risk and the Precautionary Principle (Butterworth-Heinemann, Oxford, 2000)

James E Hickey and Vern R Walker "Refining the Precautionary Principle in International Environmental Law" (1995) 14 Va. Envtl. L.J. 423.

Jacqueline Peel "The Precautionary Principle in Practice: Environmental decision-making and scientific uncertainty" (Federation Press, Melbourne, 2005)

Joe Tickner and Carolyn Raffensperger The Precautionary Principle in Action: A Handbook ( $1^{\text {st }}$ ed, Science and Environmental Health Network, Massachusetts, 1999) at 1.

Kerfoot WC, Sih A (eds) Predation: direct and indirect impacts on aquatic communities (University Press of New England, Hanover, 1987)

Klaus Bosselmann, David Grinlinton and Prue Taylor (eds) Environmental Law for a Sustainable Society (2 ${ }^{\text {nd }}$ ed, NZCEL, Auckland, 2002).

L King Medical Thinking: A Historical Preface (Princeton University Press, Princeton, 1982)

Marcus Haward and Joanna Vince, Oceans Governance in the Twenty-first Century: Managing the Blue Planet (Edward Elgar, Cheltenham, 2008).

Malgosia Fitzmaurice, David Ong and Panos Mekouris (eds) Research Handbook on International Environmental Law (Edward Elgar, Cheltenham, 2010).

Malcom Evans (ed) International Law ( $3^{\text {rd }}$ ed, Oxford University Press, Oxford, 2010) Morgan, GM \& Henrion, M Uncertainty. A guide to dealing with uncertainty in quantitative risk and policy analysis, (Cambridge University Press, Cambridge, 1990).

Nicolas de Sadeleer, Environmental Principles: From Political Slogans to Legal Rules (Oxford University Press, Oxford, 2002).

Patricia Birnie, Alan Boyle and Catherine Redgewell International Law and the Environment ( $3^{\text {rd }}$ ed, Oxford University Press, Oxford, 2008). 
Philippe Sands, Principles of International Environmental Law (2nd ed, Cambridge University Press, New York, 2003).

Rajendra Ramlogan, "Sustainable Development: Towards a Judicial Interpretation" in

Richard L. Revesz, Philippe Sands and Richard B. Stewart, Environmental Law, the Economy, and Sustainable Development (Cambridge University Press, Cambridge, 2000). Raffensberger, Carolyn and Joel Tickner (eds) Protecting Public Health and the Environment: Implementing the Precautionary Principle (Island Press, Washington DC, 1999)

Ronnie Harding and Elizabeth Fisher "Introducing the precautionary principle" in Ronnie Harding and Elizabeth Fisher Perspectives on the Precautionary Principle (The Federation Press, Sydney, 1999) 2.

Rosie Cooney \& Barney Dickson Biodiversity and the Precautionary Principle: Risks and Uncertainty in Conservation and Sustainable Use (Earthscan, London. 2005)

RL Smith and TM Smith Elements of Ecology ( $4^{\text {th }}$ ed, Pearson Publishing, Virginia, 2000) R.V. O'Neill et al A Hierarchical Concept of Ecosystems (Princeton University Press, New Jersey, 1986).

Sue Elworthy and Jane Holder Environmental Protction: Text and Materials (Cambridge University Press, Cambridge, 1997)

Sumudu Arapattu, Emerging Principles of International Law (Transnational Publishers, New York, 2006)

S Woodley, J Kay and G Francis (eds) Ecological Integrity and the Management of Ecosystems (University of Waterloo Press, Waterloo, 1993)

Tim O'Riordan, James Cameron and Andrew Jordan (eds) Reinterpreting the Precautionary Principle (Cameron May, London, 2001)

Simon Marr The Precautionary Principle in the Law of the Sea: Modern Decision Making in International Law (Martinus Nijhoff Publishers, New York, 2003) 


\section{E Journal Articles}

Adriana Fabra and Viginia Gascon "The Convention on the Conservation of Antarctic marine Living Resources (CCAMLR) and the Ecosystem Approach" (2008) 23 The International Journal of Marine and Coastal Law 567 at 577

BG Hatcher "Coral reef ecosystems: How much greater is the whole than the sum of the parts?” (1997) 16 Coral Reefs 77.

Charmain Barton "The Status of the Precautionary Principle in Australia: It's Emergence in Legislation and as Common Law Doctrine" (1998) 22 Harv. Envtl. L. Rev. 509.

Christopher Stone "Is there a Precautionary Principle?” (2001) 31 ELR 10790 at 10795.

Chris Tollefson and Jamie Thornback "Litigating the Precautionary Principle in Domestic Courts" (2008) 19 JELP 33

Daniel Pauly "Fishing Down Marine Food Webs" (1998) 279 Science 860 - 863 as cited in L. Juda, "Rio Plus Ten: The Evolution of International Marine Fisheries Governance" (2002) 33 Ocean Development and International Law 109

D Freestone and Z Makauch "The New International Environmental Law of Fisheries: The 1995 UN Straddling Stocks Convention” (1996) 7 E.I.E.L. 3 at 14

David Farrier and Linda Tucker "Access to Marine Bioresources: Hitching the Conservation Cart to the Bioprospecting Horse” (2001) 32 Ocean Dev. \& Int'l L. 213.

David Vanderzwaag “The Precautionary Principle and Marine Environmental Protection: Slippery Shores, Rough Seas, and Rising Normative Tides" (2002) 33 Ocean Development \& International Law 165.

David Vanderzwaag "The Precautionary Principle in Environmental Law and Policy: Elusive Rhetoric and First Embraces" (1999) 8 J Environ Law Pract 355.

David VanderZwaag "The Precautionary Approach and the International Control of Toxic Chemicals: Beacon of Hope, Sea of Confusion and Dilution" (2011) 33 Hous. J. Int'l L. No. 3, 605 .

Derek Nolan and Martin Williams "Electromagnetic Radiation Emissions and the 'precautionary principle"” (1996) 16 NZRMB 215

Donald K Anton “Law for the Sea’s Biodiversity” (1997) 36 Colum J Transnat'1 L 341. 
Donna R Christie "Implementing an Ecosystem Approach to Ocean Management: An Assessment of Current Regional Governance Models" (2005) 16 Duke Envtl. L. \& Pol'y F 117

D Gascuel "Towards the implementation of an intergrated ecosystem fleet-based management of European fisheries" (2012) 36 Marine Policy 1022 at 1022

Douglas Clyde Wilson The Paradoxes of Transparency: Science and the Ecosystem Approach to fisheries Management in Europe Amsterdam University Press, Amsterdam, 2009)

Ellen Hey "The Precautionary Concept in Environmental Policy and Law: Institutionalizing Caution" (1992) 4 Geo. Int'1 Envtl. L. Rev. 303.

Estes JA and Duggins DO "Sea otters and kelp forests in Alaska: generality and variation in a community ecological paradigm" (1995) 65 Ecol Monogr at 75

Ellen Hey "The Precautionary Concept in Environmental Policy and Law: Institutionalizing Caution" (1992) 4 Geo. Int'l Envtl. L. Rev. 303.

Farquharson LJ and Dmith J"The Status of the Precautionary principle in International Law: $R$ v. Secretary of State for Trade and Industry ex parte Duddridge and Others" (1995) 7(2) Journal of Environmental Law at 224

G Likens An Ecosystem Approach: Its Use and Abuse (Ecology Institute, Oldendorf 1992) at 10. R.V. O'Neill et al A Hierarchical Concept of Ecosystems (Princeton University Press, New Jersey, 1986).

Gary E. Marchant "From General Policy to Legal Rule: Aspirations and Limitations of the Precautionary Principle” (2003) 111 Environmental Health Perspectives No. 141799.

Greg Severinsen "Letting our Standards Slip? Precaution and the Standard of Proof under the Resource Management Act 1991” (2014) 18 NZJEL173.

Hanling Wang, "Ecosystem Management and Its Application to Large Marine Ecosystems: Science, Law, and Politics” (2004) 35 Ocean Dev. \& Int'l L 41.

G.M. Watters et al "Decision-making for ecosystem-based management: evaluating options for a krill fishery with an ecosystems dynamics model" (2013) 23(4) Ecological Applications 710

Graeme Parkes "Precautionary fisheries management; the CCMLR approach" (2000) 24 Marine Policy 83. 
Hector, A et al "Conservation implications of the link between biodiversity and ecosystem functioning" (2001) 129 Oecologia 624-628.

HL Rouse and N Norton "Managing Scientific Uncertainty for Resource Management Planning in New Zealand" (2010) 17 Australasian Journel of Environmental Management 66 at 66.

Hon Justice Cooke "The Concept of Environmental Law - The New Zealand Law - An Overview" [1975] NZLJ 631.

$\mathrm{H}$ Osterblom et al "Making the ecosystem approach operational - Can regime shifts in ecological and governance systems facilitate the transition?" (2010) 34 Marine Policy 1290.

Hooper, D. U et al "Effects of biodiversity on ecosystem functioning: a consensus of current knowledge" (2005) 75 Ecological Monographs 3.

James E Hickey "Refining the Precautionary Principle in International Environmental Law" (1995) 14 Va. Envtl. L.J. 423.

J.Brunée and S. Toope, "Environmental Security and Freshwater Resources: A Case for International Ecosystem Law," (1994) 5 Yearbook of International Environmental Law 41. James Cameron, Will Wade-Gery and Julie Abouchar "Precautionary Principle in Future Generations in Emmanuel Agius et al Future Generations in International Law (Routledge, London 1998) 93.

Joan Forret "Scientific Evidence and Environmental Litigation in New Zealand" (1998) 2 N.Z. J. ENVTL L. 39.

Joanna Mossop "Protecting Marine Biodiversity on the Continental Shelf Beyond 200 Nautical Miles" (2007) 38 Ocean Dev. \& Int'l L. 283.

John S Applegate "The Taming of the Precautionary Principle" 27 (2002) Wm. \& Mary Envtl. L. \& Pol'y Rev. 13.

Jon Day "The need and practice of monitoring, evaluating and adapting marine planning and management - lessons from the Great Barrier Reef" (2008) 32 Marine Policy 823.

John Lemons, Kristin Shrader-Frechette and Carl Cranor "The Precautionary Principle: Scientific Uncertainty and Type I and Type II Errors (1997) 2 Foundations of Science 207. John Paterson "Sustainable development, sustainable decisions and the precautionary principle" (2007) 42 Natural Hazards 515. 
J Steele "The ocean landscape" (1989) 3 landscape ecology 185.

James E Hickey and Vern R Walker "Refining the Precautionary Principle in International Environmental Law" (1995) 14 Va. Envtl. L.J. 423.

John Paterson "Sustainable development, sustainable decisions and the precautionary principle" (2007) 42 Natural Hazards 515.

J M Van Dyke "Applying the Precautionary Principle to Ocean Shipments of Radioactive Materials" (1996) 27 O.D.I.L. 379

James Cameron and Juli Abouchar "The Precautionary Principle: A Fundamental Principle of Law and Policy for the Protection of the Global Environment" (1991) 14 B. C. Int'l \& Comp. L. Rev. 1

Karl-Hermann Kock et al Fisheries in the Southern Ocean: An Ecosystem Approach" (2007) 362 PhiL Trans' R' Soc' B 2333.

Kriebel et al "The precautionary principle in environmental science" (2001) 109 Environmental Health Perspectives at 871 to 876.

Mark Geistfeld "Implementing the Precautionary Principle" (2001) 31 Envtl. L. Rep 11,326 at 11,326 citing Christopher Stone "Is There a Precautionary Principle?" (2001) 31 ELR 10790.

Matthee, M and Vermersch D "Are the Precautionary Principle and the International Trade of Genetically Modified Organisms Reconcilable?" (2000) 12 JAEE 59.

MH Mendelson "The Formation of Customary International Law" (1998) 272 RdC at 155 Michael M'Gonigle et al "Taking Uncertainty Seriously: From Permissive Regulation to Preventative Design in Environmental Decision Making" (1994) 32 Osgoode Hall L.J. 99 Lothar Gundling "The Status in International Law of the Precautionary Principle of Precautionary Action” (1990) 23, 24 Int'l J. of Estuarine \& Coastal L. 23.

Marguerite Quin "The Fisheries Act 1996: Context, Purpose, and Principles" (1999) 8 Auckland U. L. Rev. 503.

Michael Haezel "Scientific Uncertainty and the International Whaling Commission: an alternative perspective on the use of Science in Policy Making" (2004) 28 (5) Marine Policy 365 .

Noah M. Sachs "Rescuing The Strong Precautionary Principle From Its Critics" (2011) (4) University of Illinois Law Review 1285. 
Owen McIntyre and Terry Mosedale "The Precautionary Principle as a Norm of Customary International Law" (1997) 9 JEL 221.

Owen McIntyre "The Emergence of an 'Ecosystem Approach' to the Protection of International Watercourses under International Law" (2004) 13 (1) RECIEL 1 at 1.

P.A. Larkin "Concepts and issues in marine ecosystem management" (1996) 6 Reviews in Fish Biology and Fisheries 139.

Per Sandin "Dimensions of the Precautionary Principle" (1999) 5.5. Human and Ecological Risk Assessment: An International Journal 889.

P.E. Taylor "From Environmental to Ecological Human Rights: A New Dynamic in International Law?” (1998) 10 Geo Int'l Env. L. Rev 309.

Rakhyun Kim \& Donald Anton "The Application of the Precautionary and Adaptive Management Approaches in the Seabed Mining Context: Trans-Tasman Resources Ltd Marine Consent Decision under New Zealand's Exclusive Economic Zone and Continental Shelf (Environmental Effects) Act 2012" (2015) 30 IJRL 175.

RC Earll "Common Sense and the Precautionary Principle - An Environmentalists Perspective" (1992) 24(4) Marine Pollution Bulletin 182.

Randall Peterman and Michael M'Gonigle "Statistical Power Analysis and the Precautionary Principle (1992) 24, No 5 Marine Pollution Bulletin 231.

Richard Hildreth, Casey Jarman and Margaret Langlas "Roles for a Precautionary Approach in Marine Management" (2005) 19 Ocean Y.B. 33.

Rusong Wang et al "Understanding eco-complexity: Social-Economic-Natural Complex Ecosystem approach" (2011) 8 Ecological Complexity 15 at 17.

Scheffer M et al "Catastrophic shifts in ecosystems" (2001) 413 Nature at 591.

Scheffer, M. \& Carpenter, S. "Catastrophic regime shifts in ecosystems: linking theory to observation" (2003) 18 Trends Ecol. Evol. At 648.

Scott Lafranchi "Surveying the Precautionary Principle's Ongoing Global Development:

The Evolution of an Emergent Environmental Management Tool" (2005) 32 B.C. Envtl. Aff. L. Rev. 679.

Sonia Boutillon "The Precautionary Principle: Development of an International Standard" (2002) 23 Michigan Journal of International Law 429. 
Steve Maguire and Cynthia Hardy "The Emergence of New Global Institutions: A Discursive Perspective” (2006) 27(1) Organisational Studies 7.

Stephen Gardiner “A Core Precautionary Principle” (2006) 14, 1 J Polit Philos 33.

Terborgh J et al "Ecological meltdown in predator free forest fragments" (2001) 2, 94 Science 1923.

Thomas Elmqvist et al "Response diversity, ecosystem change, and resilience" (2003) 1, 9 Frontiers in Ecology and the Environment 488.

Vitousek PM and Walker LR. "Biological invasion by Myrica faya in Hawaii: plant demography, nitrogen fixation, ecosystem effects" (1989) 59 Ecol Mon at 247.

\section{F Government Publications}

Cabinet Minute of Decision "Proposal for Exclusive Economic Zone Environmental Effects Legislation” (16 May 2011) CAB Min (11) 19/7B.

Cabinet Minute of Decision "Transfer of Discharge and Dumping Functions in the Exclusive Economic Zone and Extended Continental Shelf to the Environmental Protection Authority" (28 September 2011) EGI Min (11) 21/7.

Cabinet Paper "Transfer of discharge and dumping functions in the exclusive economic zone and extended continental shelf to the Environmental Protection Authority" (15 September 2011).

Cabinet Paper "Proposal for Exclusive Economic Zone Environmental Effects Legislation" (4 May 2011).

Department of Conservation New Zealand Coastal Policy Statement (2010).

Department of Conservation "Monitoring the Effectiveness of the New Zealand Coastal Policy Statement: Views of Local Government Staff” 2003

Linda Cameron Environmental Risk Management in New Zealand - Is There Scope to Apply A More Generic Framework? (New Zealand Treasury, Policy Perspectives Paper 06/06, July 2006). 


\section{G Papers, Unpublished Papers and Reports \\ $1 \quad$ Papers}

Andreas Klinke and Ortwin Renn "Prometheus Unbound: Challenges of Risk evaluation, risk classification and risk management" (Working Paper No 153, Akademie für Technikfolgenabschätzung in Baden-Württemberg, Stuttgart, 1999).

Catherine J Iorns Magallanes "The Precautionary Principle in the New Zealand Fisheries Act: Challenges in the New Zealand Court of Appeal" (paper presented to Australasian Law Teachers Association, Melbourne, July 2006).

Derek Nolan "The Legal Standards of Proof to be Applied to Coastal Projects and Predictions of Coastal Behaviour, and the role of the Precautionary Principle" in Pacific Coasts and Ports '97: Proceedings of the 13th Australasian Coastal and Ocean Engineering Conference and the 6th Australasian Port and Harbour Conference; Volume 1. Christchurch, N.Z.: Centre for Advanced Engineering, University of Canterbury, 1997 James Cameron and Will Wade-Gery Addressing Uncertainty: Law, Policy and the Development of the Precautionary Principle (CSERG, Working Paper GEC 92-43, 1992). Joe Tickner and Carolyn Raffensperger The Precautionary Principle in Action: A Handbook ( $\left({ }^{\text {st }}\right.$ ed, Science and Environmental Health Network, Massachusetts, 1999)

SM. and Towns, D.R. "An ecosystem approach to maximise conservation of indigenous biological assets of New Zealand" (paper presented to the Department of Conservation, Auckland, 2001).

Marco Martuzzi \& Joel Tickner (eds) The precautionary principle: protecting public health, the environment and the future of our children (World Health Organisation Europe, ISBN 928901098 3, 2004).

R Schlaepfer Ecosystem-Based Management of Natural Resources: A Step towards Sustainable Development (IUFRO, Occasional Paper No. 6, 1997).

Rosie Cooney, The Precautionary Principle in Biodiversity Conservation and Natural Resource Management (IUCN Policy and Global Change Series No. 2) IUCN, 2004, 5-6 Secretariat of the Convention on Biological Diversity The Ecosystem Approach (CBD Guidelines, Montreal, 2004). 
Serge Garcia "The Precautionary Approach to Fisheries and its Implications for Fisheries Research, Technology and Management: An Updated Review" in FAO Fisheries Technical Papers 350/2 (FAO, 1993).

The Royal Society of Canada Elements of Precaution: Recommendations for the Regulation of Food Biotechnology in Canada (Health Canada, Canadian Food Inspection Agency and Environment Canada, Expert Panel Report, January 2001).

2 Unpublished Papers

A Kumar Duralappah et al Ecosystems and Human Wellbeing: Diversity Synthesis: A Millennium Ecosystem Assessment Report [Washington D.C. 2005].

Jude Antony "The Fisheries Act 1996 Amendment Bill 2007: A Missed Opportunity to Impliment the Precautionary Principle in New Zealand Fisheries Law" (LLB (HONS) Research Paper, Victoria University of Wellington, 2008).

Sandra Denise Herzog "The Precautionary Principle: Current Status and Implementation in International Maritime Law" (LLM, Paper, Victoria University of Wellington, 2005).

3 Reports

Ministry for the Environment Environment 2010 Strategy: A Statement of the Government's Strategy on the Environment (1995).

Commission of the European Communities "Communication from the Commission: on the precautionary principle" (COM 1, Brussels, February 2000).

Jamie Benidickson et al "Practicing Precaution and Adaptive Management: Legal, Institutional and Procedural Dimensions of Scientific Uncertainty" Final Report Submitted to SSHRC \& Law Commission of Canada (University of Ottowa, June 2005) at 20.

$\mathrm{K}$ von Moltke The Vorsorgeprinzip in West German Environmental Policy (Royal Commission on Environment and Pollution, Twelfth Report, UK, HMSO, CM 310, 1988) at 57 . 
Linda Cameron "Environmental Risk Management in New Zealand - Is There Scope to Apply A More Generic Framework?" (New Zealand Treasury Policy Perspectives Paper 06/06, July 2006).

A Kumar Duralappah et al Ecosystems and Human Wellbeing: Diversity Synthesis: A Millennium Ecosystem Assessment Report [Washington D.C. 2005] at 18

Ministry for the Environment Managing our Oceans - A discussion document on the regulations proposed under the Exclusive Economic Zone and Continental Shelf (Environmental Effects) Bill (Ministry for the Environment, a discussion document, May 2012).

The Royal Society of Canada Elements of Precaution: Recommendations for the Regulation of Food Biotechnology in Canada (Health Canada, Canadian Food Inspection Agency and Environment Canada, Expert Panel Report, January 2001). 